\title{
REPORT TO CONGRESS ON
}

THE FEASIBILITY OF ESTABLISHING A HEATING OIL COMPONENT TO THE STRATEGIC PETROLEUM RESERVE

\section{$\frac{\text { Volume I }}{A}$}

June 1998

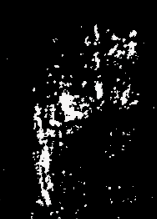

\section{Department of Energy}

Assistant Secretary, Fossil Energy

Deputy Assistant Secretary, Strategic Petroleum Reserve
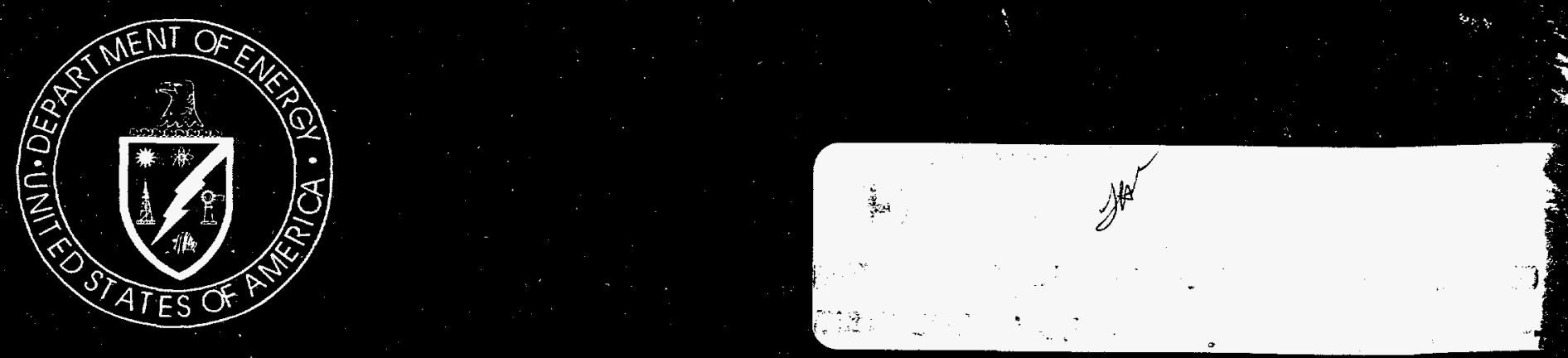


\section{DISCLAIMER}

This report was prepared as an account of work sponsored by an agency of the United States Government. Neither the United States Government nor any agency thereof, nor any of their employees, makes any warranty, express or implied, or assumes any legal liability or responsibility for the accuracy, completeness, or usefulness of any information, apparatus, product, or process disclosed, or represents that its use would not infringe privately owned rights. Reference herein to any specific commercial product, process, or service by trade name, trademark, manufacturer, or otherwise does not necessarily constitute or imply its endorsement, recommendation, or favoring by the United States Government or any agency thereof. The views and opinions of authors expressed herein do not necessarily state or reflect those of the United States Government or any agency thereof. 


\section{DISCLAIMER}

Portions of this document may be illegible electronic image products. Images are produced from the best available original document. 


\section{TABLE OF CONTENTS}

EXECUTIVE SUMMARY $\ldots \ldots \ldots \ldots \ldots \ldots \ldots \ldots \ldots \ldots \ldots \ldots \ldots \ldots \ldots \ldots \ldots$

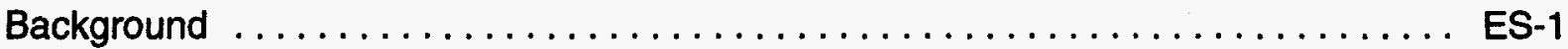

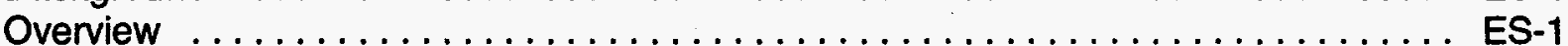

Additional Findings $\ldots \ldots \ldots \ldots \ldots \ldots \ldots \ldots \ldots \ldots \ldots \ldots \ldots \ldots$

CHAPTER I: INTRODUCTION $\ldots \ldots \ldots \ldots \ldots \ldots \ldots \ldots \ldots \ldots \ldots \ldots \ldots \ldots \ldots \ldots \ldots$

The Perceived Problem $\ldots \ldots \ldots \ldots \ldots \ldots \ldots \ldots \ldots \ldots \ldots \ldots \ldots \ldots \ldots \ldots$

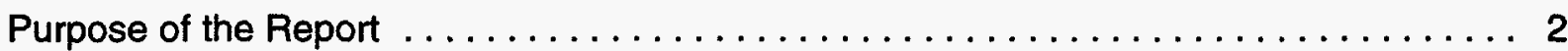

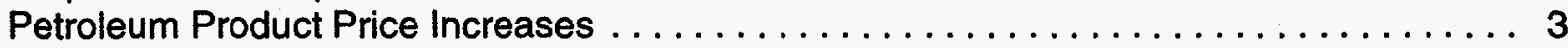

Effects of Events on World Prices for Crude Oil and Distillate ............... 5

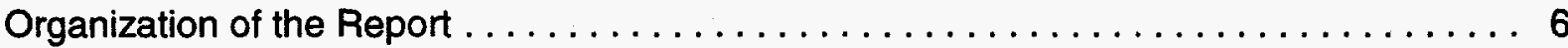

CHAPTER II: ANALYSIS OF NORTHEAST HEATING OIL MARKET $\ldots \ldots \ldots \ldots \ldots \ldots$

Description of the Northeast Heating Oil Market . . . . . . . . . . . . . . . . . . . 10

Production and Supply of Heating Oil $\ldots \ldots \ldots \ldots \ldots \ldots \ldots \ldots \ldots \ldots \ldots \ldots \ldots \ldots$

Evidence of a Petroleum Product Shortage in a Competitive Market . . . . . . . . . . 14

Heating Oil Supply Logistics in the Northeast . . . . . . . . . . . . . . . . . . . 16

Source of Concern About the Adequacy of Primary Stocks in the Northeast . . . . . . . 19

\section{CHAPTER III: ANALYSIS OF DISTILLATE PRIMARY STOCK MANAGEMENT IN THE}

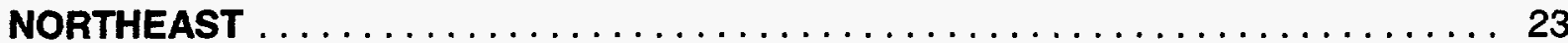

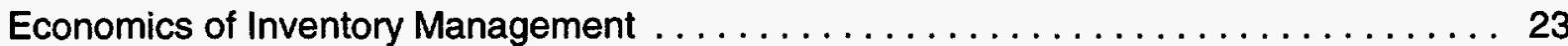

The Futures Market . . . . . . . . . . . . . . . . . . . . . . . . . . 25

Management of Primary Stocks of Distillate in the Northeast $\ldots \ldots \ldots \ldots \ldots \ldots \ldots$

Examination of the 1996 Distillate Market . . . . . . . . . . . . . . . . . . . . 29

Potential Risk from Low Stock Levels to Heating Oil Customers in the Northeast . . . . . . 30

Market Response to Cold Weather in December and January . . . . . . . . . . . . 31

Local Stocks and Prices During a World Supply Shortfall ............... 33

CHAPTER IV: THE BENEFITS OF A REGIONAL DISTILLATE RESERVE $\ldots \ldots \ldots \ldots \ldots \ldots$

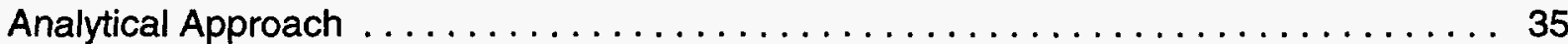

Size and Frequency of Severe Cold Spells $\ldots \ldots \ldots \ldots \ldots \ldots \ldots \ldots \ldots \ldots \ldots \ldots$

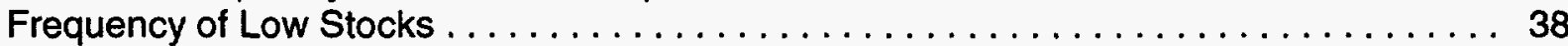

Regional Price Increases Caused by Heating Oil Supply Problems . . . . . . . . . . . 39

Appropriate Conditions to Trigger the Reserve's Use . . . . . . . . . . . . . . . . . 40

Potential Consumer Benefits of a Distillate Reserve . . . . . . . . . . . . . . . . 43

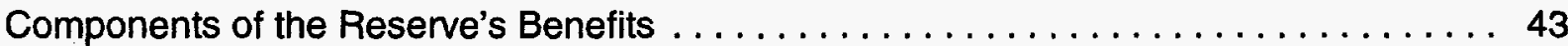

Benefits of the Reserve in 1989--An Example $\ldots \ldots \ldots \ldots \ldots \ldots \ldots \ldots \ldots \ldots \ldots 44$

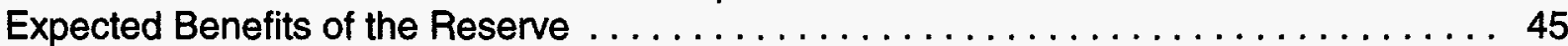

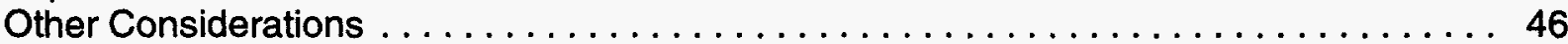

CHAPTER V: FEASIBILITY AND COSTS OF A DISTILLATE RESERVE FOR THE

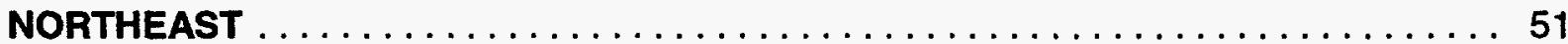

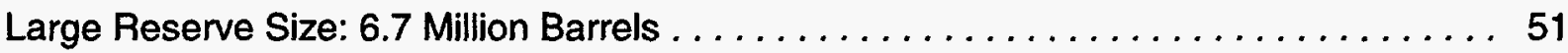

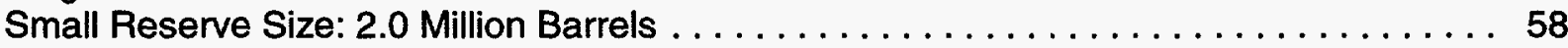

Other Concerns About the Federal Government Options $\ldots \ldots \ldots \ldots \ldots \ldots \ldots \ldots \ldots$

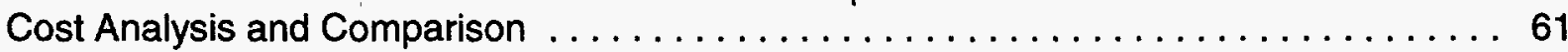


TABLE OF CONTENTS (cont'd)

CHAPTER VI: BENEFIT COST ANALYSIS

67

Methodology

67

Discussion of Results

68

Summary

72

CHAPTER VII: ALTERNATIVE POLICY OPTIONS

73

Privately-Owned Distillate Reserve

73

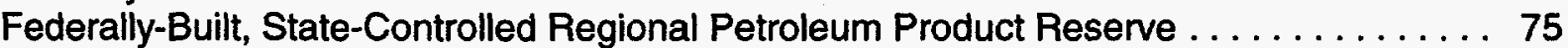

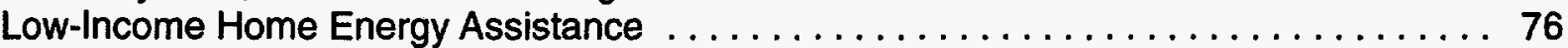

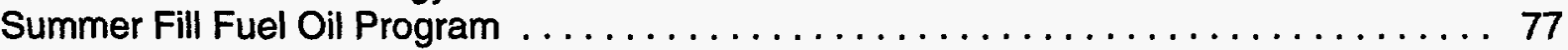

Fixed-Price or Levelized-Price Heating Oil Contracts

81

ii 


\section{LIST OF EXHIBITS}

Exhibit E-1

Life Cycle Costs for RPPR Options $\ldots \ldots \ldots \ldots \ldots \ldots \ldots \ldots \ldots \ldots \ldots \ldots$ ES-3

Exhibit E-2

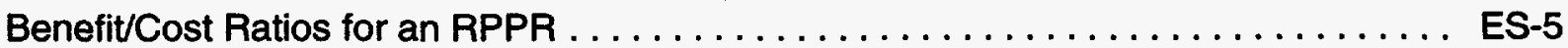

Exhibit l-1

Effects of Events on World Prices for Crude Oil and Distillate $\ldots \ldots \ldots \ldots \ldots \ldots \ldots$

Exhibit I-2

Illustrative Effect of a Regional Reserve During $1989-1990 \ldots \ldots \ldots \ldots \ldots \ldots$

Exhibit II-1

Northeast Region $\ldots \ldots \ldots \ldots \ldots \ldots \ldots \ldots \ldots \ldots \ldots \ldots \ldots \ldots \ldots$

Exhibit II-2

Northeast Households by Heating Fuel Type $(1993) \ldots \ldots \ldots \ldots \ldots \ldots \ldots \ldots$

Exhibit II-3

Annual Residential Consumption of Heating Fuels $\ldots \ldots \ldots \ldots \ldots \ldots \ldots \ldots \ldots$

Exhibit II-4

Prices of Fuel Oil and Natural Gas for Residential Space Heating in $1993 \ldots \ldots$. . . . 12

Exhibit II-5

Gas Utility Residential Customers Using Gas for Space Heating in the Northeast $\ldots \ldots 12$

Exhibit II-6

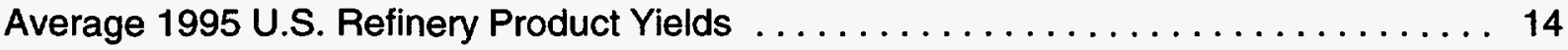

Exhibit II-7

1987-1996 Prices of Heating Oil, Jet Fuel, and Gasoline in New York Harbor . . . . . 15

Exhibit II-8

Northeast Seasonal Demand for No. 2 Fuel Oil and Diesel Fuel $\ldots \ldots \ldots \ldots \ldots \ldots$

Exhibit II-9

Monthly Yield of Distillate in PADD 1 Refineries $\ldots \ldots \ldots \ldots \ldots \ldots \ldots \ldots \ldots$

Exhibit II-10

Sources of Distillate Supplies to the Northeast Market $\ldots \ldots \ldots \ldots \ldots \ldots \ldots \ldots$

Exhibit II-11

Typical Delivery Times from Distillate Supply Sources to the Northeast $\ldots \ldots \ldots \ldots$

Exhibit II-12

1989-1996 Residential and New York Harbor Monthly Distillate Spot Prices . . . . . . . . 20

Exhibit II-13

1989-1996 Primary Stocks of Distillate in the Northeast . . . . . . . . . . . 21

Exhibit II-14

Monthly Primary Stocks of Distillate in the Northeast During 1989-90 and 1996-97 . . . 22

Exhibit III-1

Average Monthly Spot Price of Distillate in New York Harbor $(1987-1996)$. . . . . . . 25

Exhibit III-2

1988-1996 Distillate Stock Levels in the Northeast $\ldots \ldots \ldots \ldots \ldots \ldots \ldots \ldots$

Exhibit III-3

June Distillate Futures Price for December Minus the June Distillate Spot Price . . . . . . 27

Exhibit III-4

Additions to Primary Stocks of Distillate in June Versus Expected Distillate Price

Increases Between June and December $\ldots \ldots \ldots \ldots \ldots \ldots \ldots \ldots \ldots \ldots \ldots$

Exhibit III-5

Additions to Primary Stocks of Distillate in September Versus Expected Distillate

Price Increases Between September and December . . . . . . . . . . . . . . 28 


\section{LIST OF EXHIBITS (cont'd)}

Exhibit III-6

Northeast Primary Distillate Stock Levels During the Winters of 1989-90, 1993-94, and

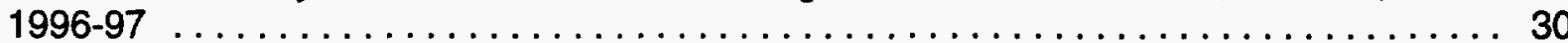

Exhibit III-7

Profile of a Heating Oil Crisis $\ldots \ldots \ldots \ldots \ldots \ldots \ldots \ldots \ldots \ldots \ldots \ldots \ldots \ldots \ldots \ldots \ldots \ldots$

Exhibit III-8

Northeast Primary Distillate Stock Levels During the Winter of $1990-91 \ldots \ldots \ldots$. . . . 33

Exhibit IV-1

Temperature Deviations From 102 Year Average by Month . . . . . . . . . . . 37

Exhibit IV-2

1988-1996 Primary Stocks on October 31 st $\ldots \ldots \ldots \ldots \ldots \ldots \ldots \ldots \ldots \ldots \ldots$

Exhibit IV-3

Components of the Increase in Consumer Distillate Costs in 1989-1990 . . . . . . 41

Exhibit IV-4

Benefits Estimates for a $6.7 \mathrm{mmb}$ Reserve $\ldots \ldots \ldots \ldots \ldots \ldots \ldots \ldots \ldots \ldots$

Exhibit IV-5

Effect of December 1989 Cold Spell on Typical Household Fuel Oil Bill

Exhibit $\mathrm{V}-1$

Ceiling Price Drawdown Strategy $\ldots \ldots \ldots \ldots \ldots \ldots \ldots \ldots \ldots \ldots \ldots \ldots \ldots$

Exhibit V-2

New England 1996-1997 Heating Oil Storage Capacity and Utilization . . . . . . . . . 52

Exhibit V-3

NAAQS Attainment Status for Proposed Heating Oil Storage Tanks Sites . . . . . . . 53

Exhibit V-4

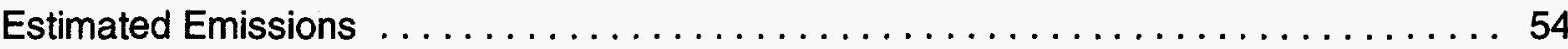

Exhibit V-5

New York/New Jersey 1996-1997 Commercial Storage Capacity . . . . . . . . . . . 55

Exhibit VI-1

Regional Product Reserve Cost Components .................... 64

Exhibit VI-2

Benefits and Costs of a 6.7 mmb Reserve Ceiling Price Drawdown Strategy . . . . . . . 69

Exhibit VI-3

Benefits and Costs of a 2.0 mmb Reserve Ceiling Price Drawdown Strategy . . . . . . 70

Exhibit VI-4

Benefits and Costs of a 6.7 mmb Reserve Trigger Price Drawdown Strategy . . . . . 71

Exhibit VII-1

Benefits and Costs of a 2 mmb Reserve Trigger Price Drawdown Strategy . . . . . . 71

Exhibit VII-2

Average Household Cost Savings of June Fuel Oil Tank Fill $\ldots \ldots \ldots \ldots \ldots \ldots$

Illustrative Effects of a Summer Fill Program on Northeast Residential

Distillate Consumption 


\section{BACKGROUND}

In the Autumn of 1996, consumers and Members of Congress from the Northeast expressed concern about high prices for heating oil and historically low levels of inventories. Some Members of Congress advocated building a Federal inventory of heating oil as part of the Strategic Petroleum Reserve (SPR). Regional reserves are authorized as part of the SPR for import dependent regions by the Energy Policy and Conservation Act. In response, the Department of Energy (DOE) proposed a series of studies related to heating fuels, including a study of the desirability, feasibility, and cost of creating a Federal reserve containing distillate fuel. This report documents that study.

\section{OVERVIEW}

This study started from the generally-accepted hypothesis that the U.S. refining industry cannot be profitably built to a size sufficient to supply seasonal demand for distillate and gasoline from current production. That being the case, the economics of the industry require stock building during off-peak seasons for drawdown during periods of heavy demand. When inventories fall below planned levels due to very heavy demand, prices rise, and incremental supply is provided either with imports or through increased production from domestic refiners. The study examined past instances of very heavy demand and found that, generally, inventories have been sufficient to meet demands above normal levels by the normal workings of the market. Looking at a recent winter event, the exceptionally cold December of 1989 , the study also concluded that suppliers are responsive to price signals and can import additional stocks of heating oil in four to seven weeks, albeit after an exceptional price rise in the case of December 1989. The benefit of a Regional Petroleum Product Reserve (RPPR) would be to protect the economy from the sudden price spikes that signal the demand for additional supplies.

The absence of documented failures of the supply system in the past led to the conclusion that the principal problem faced by Northeast heating oil consumers is economic in nature. That is, the unexpected shock of very high distillate prices causes some consumers to either buy fewer goods and services than they otherwise might, or forces them to reallocate funds from preferred expenditures. Heating oil markets in the Northeast are financially linked to other middle distillate products such as jet fuel, kerosene, and diesel fuel. Therefore, a heating oil price increase, even if it is weather-related, has a spill-over effect on consumers of other oil products in the northeastern States.

In this context, the study estimates the economic impact of the price-suppressing role an RPPR might play for northeastern State consumers if a weather-related heating oil price increase occurred. Although distillate price increases in the Northeast correlate with price increases elsewhere, calculations of the benefits for the petroleum product reserve only addressed the escalation of distillate prices in northeastern States. After appropriately weighting these estimates to reflect the likelihood of such events, the results are compared with life-cycle cost estimates for each of several RPPR configurations.

The analysis examines the costs, benefits, legal authorities, and other qualitative factors associated with establishing a Government-controlled RPPR holding No. 2 distillate. The report examines two potential sizes for the Reserve, 6.7 million barrels $(\mathrm{mmb})$ and $2 \mathrm{mmb}$, and several options for locating the Reserve in the Northeast, or in the Gulf Coast at SPR sites, or a combination of the two. Two methods of acquiring distillate fill, the largest single expense, are considered: outright purchase, and trading crude oil for most of the distillate fill and purchasing the rest. In the latter case, the volumetric size, and therefore the effectiveness of the SPR, remains constant. Since the study 
found that RPPR drawdown policy was a significant factor in assessing its benefits, and to a lesser extent its costs, both a conservative and an aggressive drawdown policy were analyzed in order to place bounds on the benefit/cost relationships.

\section{Summary of the Cost Benefit Analysis}

- The cost of a large $6.7 \mathrm{mmb}$ RPPR, sized to meet the worst weather contingencies, would exceed its benefits to northeastern States unless it is constructed entirely within the SPR sites in the Gulf. In this location, its responsiveness to an unexpected distillate shortage in the Northeast would be hampered by shipping times.

- A hybrid configuration with $2 \mathrm{mmb}$ of leased storage in the Northeast and a $4.7 \mathrm{mmb}$ in SPR caverns would solve the above responsiveness problem, and would be a significant improvement on the costs of leasing $6.7 \mathrm{mmb}$ of storage in the Northeast. However, its costs exceed its aggregate expected benefits unless the Government adopts an aggressive drawdown policy.

- The expected benefits of a smaller $2 \mathrm{mmb}$ RPPR located in leased terminals in the Northeast would approximate or exceed its costs, provided that those costs could be reduced by trading SPR crude oil for distillate fill. Basing the smaller RPPR in the SPR caverns in the Gulf Coast area would further improve its cost-benefit characteristics, but it would still be subject to the responsiveness considerations noted for the larger RPPR.

- Consumer cost savings, not included in the macroeconomic benefits calculations because they are generally viewed as transfers within the U.S. economy, would range between $\$ 24$ million and $\$ 99$ million (discounted \$1996), depending on the size of the reserve and its drawdown policy, over the 20-year lifetime of the RPPR.

\section{Cost Analysis}

The study evaluated two distillate RPPR sizes constructed under three design concepts: 1) Government owned and operated storage facilities in New England; 2) Government leased storage in the Northeast; and 3) storage in the SPR facilities on the Gulf Coast. Because oil stored entirely in the Gulf SPR sites would not be immediately available to consumers in the Northeast, the study also considered a hybrid option of $2 \mathrm{mmb}$ stored in leased facilities in the Northeast with $4.7 \mathrm{mmb}$ stored at Gulf Coast SPR sites.

Costs to the Government for each RPPR design would be influenced significantly by the manner in which the distillate fill was acquired and the drawdown policy the Government adopted. The study addressed the range of uncertainty in these two areas as follows:

- For each design concept, the study estimated costs for distillate to fill the Reserve in two ways: 1) the distillate fill is purchased outright, thereby adding to the overall size of the SPR, and; 2) an amount of crude oil equal to the RPPR fill is traded for an equal value of distillate, with the reminder of the RPPR fill being purchased outright.

- Profits to the Government from emergency RPPR sales partially offset costs, thereby reducing total net costs. For modeling purposes, two drawdown policies, discussed in greater detail in the next section, are evaluated in this study:

- A strategy wherein the Government would sell only enough RPPR distillate to ensure that prices did not rise past a pre-set "ceiling price." 
- A "trigger price" policy wherein the Government sells all the RPPR fill in each emergency. Here, Government profits would be higher and net life cycle costs lower than in the ceiling price drawdown strategy.

Both strategies assume that the reserve drawdown will begin when prices reach a given level. The same initiation price was used for all cases considered. These approaches should be viewed as bounding the range of costs (and benefits) for any option.

Exhibit E-1 shows that costs vary widely depending on design strategies and operational policy. Compared to the reference case using the ceiling price drawdown policy and purchased fill, exchanging crude oil for product or adopting a very aggressive drawdown approach tends to lower costs by fixed amounts regardless of where the RPPR is located. For that reason, choosing to trade crude for product fill, adopting an aggressive drawdown strategy and storing the product in the Gulf Coast area would be an option with relatively low net financial outlays.

Exhibit E-1

Life Cycle Costs for RPPR Options ${ }^{2}$

(Millions of \$1996)

\begin{tabular}{|c|c|c|c|c|c|c|}
\hline & \multicolumn{2}{|c|}{$\begin{array}{l}\text { New England } \\
\text { Construction }\end{array}$} & \multicolumn{2}{|c|}{ Lease in NY/NJ } & \multicolumn{2}{|c|}{$\begin{array}{c}\text { Gulf SPR Cavern } \\
\text { Storage }\end{array}$} \\
\hline & $\begin{array}{c}\text { Purchase } \\
\text { Fill }\end{array}$ & $\begin{array}{c}\text { Exchange } \\
\text { Crude }\end{array}$ & $\begin{array}{c}\text { Purchase } \\
\text { Fill }\end{array}$ & $\begin{array}{c}\text { Exchange } \\
\text { Crude }\end{array}$ & $\begin{array}{c}\text { Purchase } \\
\text { Fill }\end{array}$ & $\begin{array}{c}\text { Exchange } \\
\text { Crude }\end{array}$ \\
\hline \multicolumn{7}{|l|}{$6.7 \mathrm{mmb}$ RPPR } \\
\hline $\begin{array}{c}\text { Ceiling Price } \\
\text { Drawdown }\end{array}$ & 395 & 333 & 186 & 124 & 93 & 28 \\
\hline $\begin{array}{c}\text { Trigger Price } \\
\text { Drawdown }\end{array}$ & 393 & 332 & 184 & 122 & 91 & 27 \\
\hline \multicolumn{7}{|l|}{$2.0 \mathrm{mmb}$ RPPR } \\
\hline $\begin{array}{l}\text { Ceiling Price } \\
\text { Drawdown }\end{array}$ & 82 & 64 & 53 & 35 & 27 & 8 \\
\hline $\begin{array}{c}\text { Trigger Price } \\
\text { Drawdown }\end{array}$ & 80 & 61 & 51 & 33 & 24 & 5 \\
\hline
\end{tabular}

a For a 20-year life time with annual costs discounted at 7 percent per year.

A logistical analysis performed in the study suggests that release of product from an RPPR based entirely in the U.S. Gulf, however, would take 7-10 days to reach consumers in the Northeast. Thus, the low SPR storage costs may not lead to creation of an RPPR that is as effective as modeled in this study. The hybrid $6.7 \mathrm{mmb}$ RPPR described above solves the responsiveness problem, but at a higher cost. If the RPPR fill for this option is purchased outright, its net life cycle cost ranges between $\$ 120$ and $\$ 122$ million, depending on drawdown policy; if crude oil is traded for product, the range of net life cycle cost is $\$ 57$ to $\$ 59$ million ( $\$ 1996)$.

\section{Benefit/Cost Relationships}

Drawdown policy affects benefits calculations much more than it does costs. The two strategies modeled to bound the range of the benefit calculations are: 
- Ceiling Price Strategy -- This option releases product stocks only when prices exceed a predefined ceiling price, terminating release when prices fall below the ceiling price. The study used a wholesale price of $\$ 0.80$ per gallon and a crude oil distillate price spread of $\$ 0.30$ per gallon for all its calculations.

- Trigger Price Drawdown Strategy -- An alternative strategy is to release the entire reserve once a predefined trigger price is reached. This approach would yield much higher benefits to consumers for a given release price than does the ceiling price strategy. Depending on the size of the reserve and the length and degree of the cold spell, heating oil prices could be driven below normal price levels. ${ }^{1}$ The study also used a wholesale price of $\$ 0.80$ per gallon and a spread of $\$ 0.30$ per gallon to trigger the drawdown analyses.

This study's 6.7 million barrel reference case assumes that an RPPR would be designed to substantially reduce the economic damage resulting from one of the most severe winter cold snaps in history and its attendant escalation of middle distillate (heating oil, diesel and jet fuel) prices. While a large RPPR would minimize economic damage in the most severe--and rare--conditions, it would be larger than needed in the more frequent, less severe situations where it might be employed. The smaller reserve case has costs that are proportionately less than the larger reserve resulting in a superior ratio of benefits to costs. Those savings come at the expense of potentially running out of oil prior to the resolution of the worst weather events.

The study estimated that, over its 20 -year lifetime, a product reserve would produce the following benefits: ${ }^{2}$

- For a $6.7 \mathrm{mmb}$ RPPR, economic benefits would total $\$ 40$ million under assumptions of the ceiling price drawdown policy and $\$ 136$ million $(\$ 1996)$ if the more aggressive drawdown strategy were employed.

- The economic value of a $2 \mathrm{mmb}$ RPPR would range between $\$ 34$ and $\$ 53$ million under the above two drawdown assumptions, respectively.

These results show the extent to which the $6.7 \mathrm{mmb}$ RPPR is oversized if the more conservative drawdown strategy is employed. This stems from the observation that, under the ceiling price drawdown policy, on average, only 1.3 million barrels would be used in a drawdown. While the larger reserve would be able to address the severe but rare event, in most cases a $2 \mathrm{mmb}$ reserve would be just as effective as the larger reserve. With a more aggressive, and market intrusive, drawdown policy, the larger RPPR would have increased capability to lower market prices, thereby raising its "benefit" as calculated in the study.

The study also estimated consumer cost savings separately from the macroeconomic benefits described above because they are viewed by economists as financial transfers within the economy from consumers to the oil industry. For a $6.7 \mathrm{mmb}$ RPPR, these would range between $\$ 28$ and $\$ 99$ million. For the smaller $2 \mathrm{mmb}$ RPPR, the range is $\$ 24$ to $\$ 38$ million $(\$ 1996)$. In both cases, the higher figures are for the more aggressive drawdown strategy.

1 That situation did not occur in the cases modeled in this study.

2 Benefits are estimated as the reduction in the nation's import bill (called "terms of trade" benefits) and the avoidance of reductions in the gross domestic product (GDP) related to petroleum product price increases. 
Exhibit E-2 combines the cost and macroeconomic benefits estimates to display ratios of the two. It shows that, in some cases, benefits exceed the costs the Government would incur for the RPPR. The costs of a large $6.7 \mathrm{mmb}$ RPPR, sized to meet the worst of expected weather contingencies, would conclusively exceed its expected benefits if it is constructed entirely in New England. Under certain conditions, leasing storage in New York/New Jersey shows positive benefits.

Exhibit E-2

Benefit/Cost Ratios for an RPPR

\begin{tabular}{|c|c|c|c|c|}
\hline \multirow{2}{*}{} & \multicolumn{3}{|c|}{ Ceiling Price Drawdown Policy } & \multicolumn{2}{c|}{ Trigger Price Drawdown Policy } \\
\cline { 2 - 5 } & Purchase Fill & Exchange Crude & Purchase Fill & Exchange Crude \\
\hline 6.7 mmb RPPR & 0.10 & 0.12 & 0.35 & 0.41 \\
\hline $\begin{array}{c}\text { New England } \\
\text { Construction }\end{array}$ & 0.21 & 0.32 & 0.74 & 1.11 \\
\hline NY/NJ Lease & $N^{\mathrm{a}}$ & $\mathrm{NC}^{\mathrm{a}}$ & $\mathrm{NC}^{\mathrm{a}}$ & $\mathrm{NC}^{\mathrm{a}}$ \\
\hline $\begin{array}{c}\text { Gulf SPR } \\
\text { Cavern Storage }\end{array}$ & 0.41 & 0.53 & 0.66 & 0.86 \\
\hline 2 mmb RPPR & 0.64 & 0.98 & 1.04 & 1.63 \\
\hline $\begin{array}{c}\text { New England } \\
\text { Construction }\end{array}$ & $\mathrm{NC}^{\mathrm{a}}$ & $\mathrm{NC}$ & $\mathrm{NC}^{\mathrm{a}}$ & $\mathrm{NC}^{\mathrm{a}}$ \\
\hline \begin{tabular}{c} 
NY/NJ Lease \\
\hline $\begin{array}{c}\text { Gulf SPR } \\
\text { Cavern Storage }\end{array}$
\end{tabular} & & & & \\
\hline
\end{tabular}

aNot computed.

The benefits of a smaller $2 \mathrm{mmb}$ RPPR located in leased terminals in the Northeast would approximate or exceed its costs, provided that its costs could be reduced by trading SPR crude oil for distillate fill.

The benefit/cost ratios of the hybrid RPPR discussed above range from 0.33 to 0.68 under the ceiling price drawdown policy, depending on whether distillate fill is purchased or obtained through a crude oil trade, respectively. For the more aggressive drawdown policy, the range for the benefit/cost ratio is 1.31 to 2.41 .

The above results should be viewed with caution, however, because of several important caveats:

- Economic literature does not adequately address the extent to which a short-term petroleum product price increase affects GDP. Therefore, while the results are useful for comparative purposes, the absolute values are highly dependent on debatable assumptions.

- Macroeconomic benefits are not the same as Government revenue receipts. For this reason, none of these proposals is revenue-neutral, particularly in the nearby budget years, and appropriations would be required to create an RPPR. 
- The Federal Government provides funds for the states to distribute to its poorer residents for heating subsidies. This program is described in Chapter VII. The reduction in expected Government outlays for the Low Income Energy Assistance Program (LIHEAP) are not included in the benefit or cost calculations. If a regional reserve prevented sharp increases in heating fuel costs in the Northeast, emergency fund outlays would be reduced. In the winter of 1996-97, States in the Northeast, despite relatively warm weather, received $\$ 60$ million in contingency funds to cover the spike in fuel costs.

- The higher-return aggressive drawdown strategy would be viewed by many people as very marketintrusive. Even if an RPPR were created on the assumption of its use, the actual benefits would depend on the willingness of policy makers to trigger full draws.

While storing distillate in Gulf SPR sites is the least costly option, the methodology does not adequately account for the delay involved in moving the product to northeastern markets. This infers that the benefits may be overstated for this RPPR design, so the cost benefit ratio was not computed. The hybrid design is aimed at overcoming the responsiveness problem.

\section{ADDITIONAL FINDINGS}

\section{Crude Oil versus Distillate Reserves}

Over time there are instances when both crude oil and distillate prices rise sharply (the most recent major event of this type was during the Iraqi war in 1991). This study distinguished between those types of events affecting the world petroleum market generally and a price spike related to an imbalance in the supply and demand for distillate alone. Chapters III and IV and Appendix D conclude that whenever prices of all products and crude oil increase dramatically, the underlying market is short of crude oil and not specific products. In those instances if the prices are so high as to pose a threat to the U.S. economy, the proper policy response is to use the crude oil in the SPR to reduce prices. A refined product or regional reserve could also be used in conjunction with the crude oil reserve to mitigate such situations.

\section{Regional Reserve Authorization}

The review found that authorization for regional reserves in the Energy Policy and Conservation Act based upon dependence on imports is anachronistic. Situations that would cause the Northeast to experience price anomalies are unlikely to be related to product import disruptions, but will most likely be related to low preseason inventories of heating fuels and weather conditions outside of normal. The current authorization within EPCA for regional reserves is based upon import dependence of 20 percent or higher, but availability of imported products, separable from crude oil availability, is unlikely to be an issue in the foreseeable future. Therefore, the authorization within the Energy Policy and Conservation Act would require review if any future policy decision should be made to proceed with regional reserves.

\section{The Future Impacts of International Refining and Natural Gas Competition on Distillate}

The Department understands that over time the availability of distillate to the Northeast is highly dependent on production from the world's refineries and competition from other fuels, especially natural gas. Studies conducted for the Department and included as Appendices $C$ and $G$ to the report indicate that the state of refining throughout the world is in flux, and that the world in general will find a relative tightness in the supply of distillates between now and the year 2000 , but at the same time refineries in Europe will operate at very low profit margins and there will be pressures to rationalize the industry by closures. Within the United States, the projections are for very modest increases in refinery 
throughput capacity, with downstream capacity additions being oriented to the production of gasoline but with some distillate additions.

Growing supplies of natural gas, however, will help to relieve pressure on distillate demand in the Northeast as new pipeline capacity is added. Projections are that growth in residential and commercial demand will be satisfied by products other than distillate, and that distillate consumption in these sectors will fall, on average, by about one percent per year. This implies that while the absolute importance of distillate will continue in the Northeast for the foreseeable future, its relative importance will diminish.

\section{Weather and Low Inventories Both Required for a Price Spike}

The worst cold weather month in the Northeast in the last 102 years was December 1989 . Cold weather sat over the entire eastern half of the country for over 30 days, and beginning in the middle of December, the price of heating oil for delivery in New York Harbor began to rise sharply. However, even in that severe event, weather alone did not account for the price escalation. Very low inventories of distillate going into the heating season compounded supply problems. Thus, abnormally cold weather, in conjunction with low commercial inventories, is likely to be the necessary condition for a drawdown of a distillate reserve.

\section{Inventory Trends and Anomalies}

The study concluded that the statistical likelihood that low inventories will occur is approximately 1 out of 3 years. The study used the history of heating degree days combined with the probabilities of low inventories and created a statistical model for evaluating the use of a Distillate Reserve if it were created. Futures markets price patterns of price backwardation were used to identify periods of low stocks. In the jargon of the futures market, "backwardation" occurs when the future price of distillate is lower than the current price. In 1989, prices were backwardated, inventories of distillate were low, and when the weather event occurred, prices for distillate spiked. Appendix D describes the outcomes of these statistical analyses, and concludes that while winter events such as December 1989 would generate very great benefits from the release of a distillate reserve, the probability of repeating the events of that month is extremely low. 

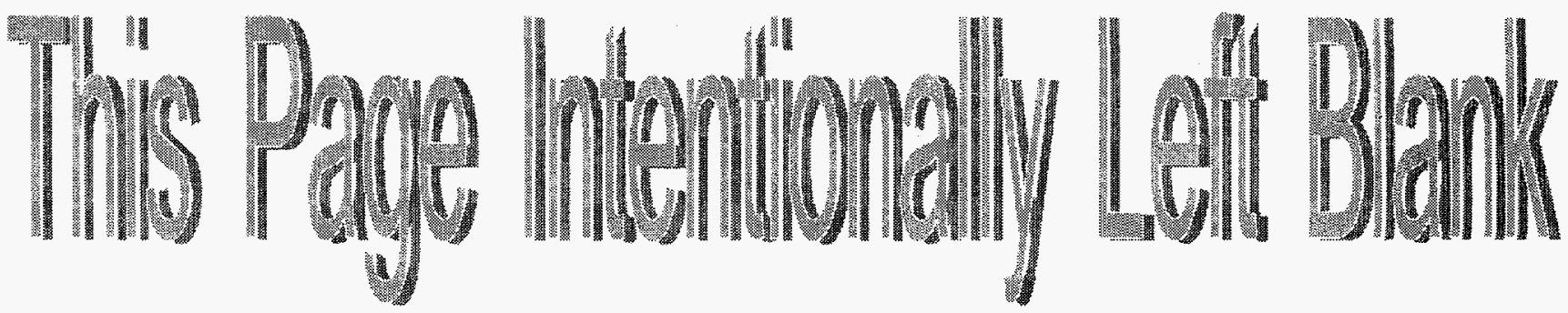
In 1996, there was widespread consumer, and ultimately Congressional, concern over the rising costs of petroleum products, particularly gasoline and heating oil. This concern over prices was heightened by public awareness that product stocks were the lowest they had been in the last decade.

During 1996, a confluence of events, both domestic and foreign, subjected consumers in the United States to two price surges: a gasoline price increase in the spring and a middle distillate (heating oil, diesel, jet fuel) price increase in the fall/winter. The increases in prices were a result of the interaction of a combination of events: the undue length of the 1995-1996 winter and its disruption of the normal seasonal switch between maximum distillate and maximum gasoline production; increased demand for petroleum both in the United States and abroad; market uncertainties over the future role of Iraq; and uncertainties over the Organization of Petroleum Exporting Countries' (OPEC's) production levels. Inventories of refined products dropped below their historically observed lows. When seasonal demand picked up, prices rose to relatively high levels. As a result consumers became uneasy, first at the absolute prices, and second, at the prospect that spot shortages might occur, resulting in exorbitant prices.

Particular concern has been expressed over the situation in the Northeast regarding heating oil. The New England portion of the Northeast is vulnerable to any form of heating oil supply constraints during the winter season. New England has no refineries, so that all heating oil must be brought in from outside the region, making the reliability of refiners and logistics essential. A high percentage of movements both into and around the region are marine, putting movement of heating oil at risk during very severe winters when rivers, and in some cases harbors, freeze. In addition, the region, having relatively high-cost natural gas, has the highest reliance on heating oil for space heating compared to other regions of the country and is, therefore disproportionately affected by heating oil price increases. All of this, plus the experience of an unusually long cold winter in 1993-1994 and the coldest December in 100 years in 1989, has made consumers especially aware of inventory levels, and very price conscious.

Since deregulation of the oil markets in 1981, there has been a consensus that free markets allocate petroleum much better than Government regulations. That consensus was fortified by the oil price collapse in 1985-6 and was further confirmed when the world weathered the Iraqi war in 1991 without any apparent shortages of supply and an immediate retreat of prices to pre-war levels shortly after the success of the initial bombing raids on Iraq. That confidence in free markets continued through 1995. However, beginning with the spring of 1996, when gasoline prices surged without any clearly identifiable specific event triggering a shortage, and again in the autumn of 1996 when heating oil inventories fell to all-time lows, the issue of whether markets were operating efficiently was raised again.

\section{The Perceived Problem}

The major problem, from the consumers' point of view, is the surge in petroleum product prices. Coupled with this is the concern over the observed low level of stocks. The common assumption is that the petroleum industry has moved, as have other industries, to "just-in-time" inventory management. The general public unease grows from the realization that if this change in stock management is permanent, industry will have a much lower margin of safety for responding to random events that may require large stock withdrawal. In other words, that price spikes and possibly real physical shortages will result during a cold winter and that, in general, price volatility will increase. 
This unease has translated itself into specific concerns about the Northeast, which is seen as being particularly vulnerable because of its high reliance on heating oil and its lack of self- sufficiency in production. Proposals have been made for mandated stock levels, regional government reserves, export controls, and other Government interventions, all aimed at increasing stock availability or modifying prices.

\section{Purpose of the Report}

Based upon the events of 1996, the Department of Energy (DOE) decided, with the urging of concerned members of Congress, to conduct a study to determine whether or not Government intervention in the petroleum markets could be beneficial through the creation of a Regional Petroleum Product Reserve (RPPR) as part of the Strategic Petroleum Reserve (SPR).

The SPR was authorized in 1975 by the Energy Policy and Conservation Act (EPCA). ${ }^{3}$ Its creation was a reaction to the rising oligopoly power of OPEC and especially to the 1973-4 targeted embargo of the United States by the Arab Organization of Petroleum Exporting Countries. Before the Reserve could be effectively constructed and filled with oil, the world experienced another major disruption during the Iranian revolution of 1979-80. That event reinforced the concept that the SPR's mission is to protect the United States from distinct recognizable disruptions in petroleum supply, especially of imports.

EPCA focused on the growing petroleum import dependency of the United States and the vulnerability to future supply disruptions which, at that time, were expected to continue to occur frequently. Although the main focus of the legislation was on crude oil supply disruptions, consideration was also given to import dependency on residual fuel oil and other major refined products. ${ }^{4}$ EPCA Sec.157. (a)(1) states that, "The Strategic Petroleum Reserve Plan shall provide for the establishment and maintenance of a Regional Petroleum Reserve in, or readily accessible to, each Federal Energy Administration Region, ..., in which imports of residual fuel oil or any refined petroleum product, during the 24-month period preceding the date of computation, equal more than 20 percent of demand for such oil or product in such regions during such period, as determined by the Secretary. Such volume shall be computed annually."

The creation of regional reserves was required under EPCA only for those regions qualifying as import dependent on products. Thus, under EPCA the approach to potential product supply shortages is similar to crude oil supply shortages and assumed to originate in the same fashion, i.e. import cut offs or vulnerabilities. Any consideration of regional problems related to prices does not exist in EPCA.

Furthermore, EPCA provides for the substitution of crude oil for the qualifying products, and Congress accepted the initial SPR Plan developed by the DOE calling for a centralized crude oil reserve in the U.S. Gulf Coast region rather than dispersed product reserves. To date, it has been DOE policy that a crude oil Reserve in the U.S. Gulf Coast was the optimal, most cost effective way of protecting the United States against the shock of a supply disruption. This location is accessible to most refining centers in the country.

3 P.L. 94-163, December 22, 1975, as last amended by P.L. 102-486, October 24, 1992.

4 Residual fuel oil was singled out from other products since, at that time, it was the main product import. 
However, changes in oil markets since the enactment of EPCA, especially elimination of price and allocation regulations and amendments to EPCA itself, imply that events other than import disruptions may be important in determining the value of a regional reserve.

In addition, it is not clear that treating crude oil and products in a similar fashion is appropriate. Certainly crude oil shortages can translate into product shortages. In the absence of a crude supply shortage, product shortages in the United States appear to be largely regional and unrelated to import dependency. The obvious example is the potential for heating oil shortages in the Northeast. These shortages, if and when they occur, will be driven by extremes of weather, probably not by import dependency.

Concerns over a shortage of heating oil in the Northeast persistently turn up. This does appear to be a region where there is relatively more risk of supply problems than any of the other regions that traditionally qualify under the EPCA guidelines. Chapters II and III show that the heating oil market in the Northeast is a complex situation that cannot be explained simply by the fact that the region is import dependent.

\section{Petroleum Product Price Increases}

The history of the world oil market leads to the conclusion that price increases in the petroleum product markets can arise, in large part, from two quite different market situations, one local or regional, and one worldwide:

- A regional constraint. A very short-term constraint on a specific product, such as tightness in heating oil supply in the Northeast, driven by a regional event such as unusually severe weather. Prices of products and crude do not move in tandem even in the region and the price of the constrained product surges for a limited period in the regional market. Examples of this are the short-run price spike for heating oil in the Northeast market during the severe cold periods in the winters of 1983-1984, 1989-1990, and 1993-1994, the late winter weather of 1996, and the gasoline price increase after the Valdez oil spill briefly interrupted crude oil supplies on the West Coast. Exhibit 1-1 shows that in 1989 the spot prices in New York, Rotterdam, and the Gulf all rose sharply, but by different amounts. Those for Singapore and crude oil prices did not move. Note that 1989 severe regional events moved market prices in Europe and the U.S. Gulf - an effect carried over to consumers outside the Northeast. The spot price increase for 1994 was contained in the Northeast, as shown in the lower part of the exhibit.

- A worldwide constraint. A general shortage (or anticipation that one might develop) of petroleum in the world market. Prices for crude oil and products rise everywhere in tandem. Worldwide constraints can be short-term or medium-term. An example of a recent worldwide short-term event can be seen during the Iraqi invasion of Kuwait. A more long-term constraint may be one of the underlying causes of price increases in early 1996. On the right-hand side of Exhibit I-1, prices of distillates worldwide rise in tandem with prices of crude oil - a possible indication that market tightness extends to the underlying supply of crude oil. A worldwide constraint that has not been seen but theoretically is possible is a medium-term shortage of specific products because of refinery constraints, again resulting in an imbalance between supply and demand. This latter possibility is examined in Appendix $G$. 


\section{Exhibit 1-1}

Effects of Events on World Prices for Crude Oil and Distillate

(actual prices)
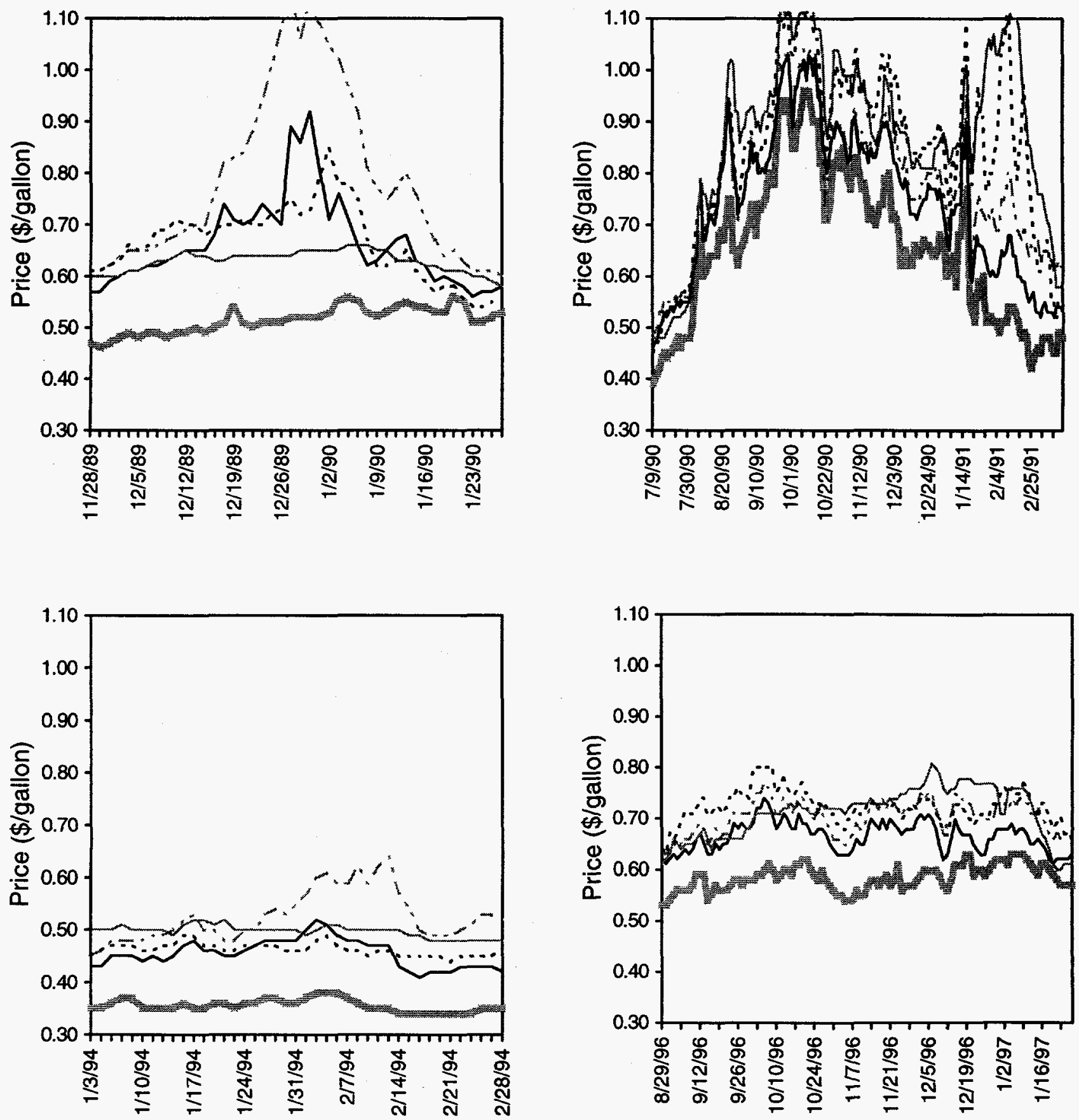

Sources:

Rotterdam prices - Reuters database

Other prices - Wall Street Joumal 


\section{Effects of Events on World Prices for Crude Oil and Distillate}

Since the United States is part of the world petroleum market any or all of the above market situations may apply. Prices for products may increase in two different time periods for totally different reasons. Therefore one type of Government intervention that might be appropriate and effective in one situation may not be appropriate or have any effect in another.

Assuming the existence of a Regional Reserve, if a rapid and large regional product price run up occurred, then the Reserve, if drawn down, would mitigate the price surge. A Regional Reserve successfully implemented in 1989 could have mitigated substantial price increases. Exhibit I-2 illustrates the process. Assume that a ceiling price strategy is in effect, with the ceiling price being $\$ 0.80 /$ gallon and the conditioned price spread between crude and distillate rising above $\$ 0.30 /$ gallon. Then the Reserve would have released its stocks beginning in mid-December. Successful use of this Reserve would have capped New York prices at \$0.80/gallon, resulting in significant price suppression in favor of Northeast consumers of heating oil, a reduction of imports, and maintenance of economic growth.

The petroleum market is an integrated worldwide market and price movements always have a spillover effect. This price cap in New York would have had smaller spillover effects on Gulf and Rotterdam prices. The relative size of consumer cost savings generated by a Reserve can be seen by the shaded regions of Exhibit I-2. While some effect is seen in the Gulf Coast and Rotterdam, the great majority of heating oil savings accrues in the Northeast.

\section{Exhibit 1-2 \\ Illustrative Effect of a Regional Reserve During 1989-1990 (actual prices)}

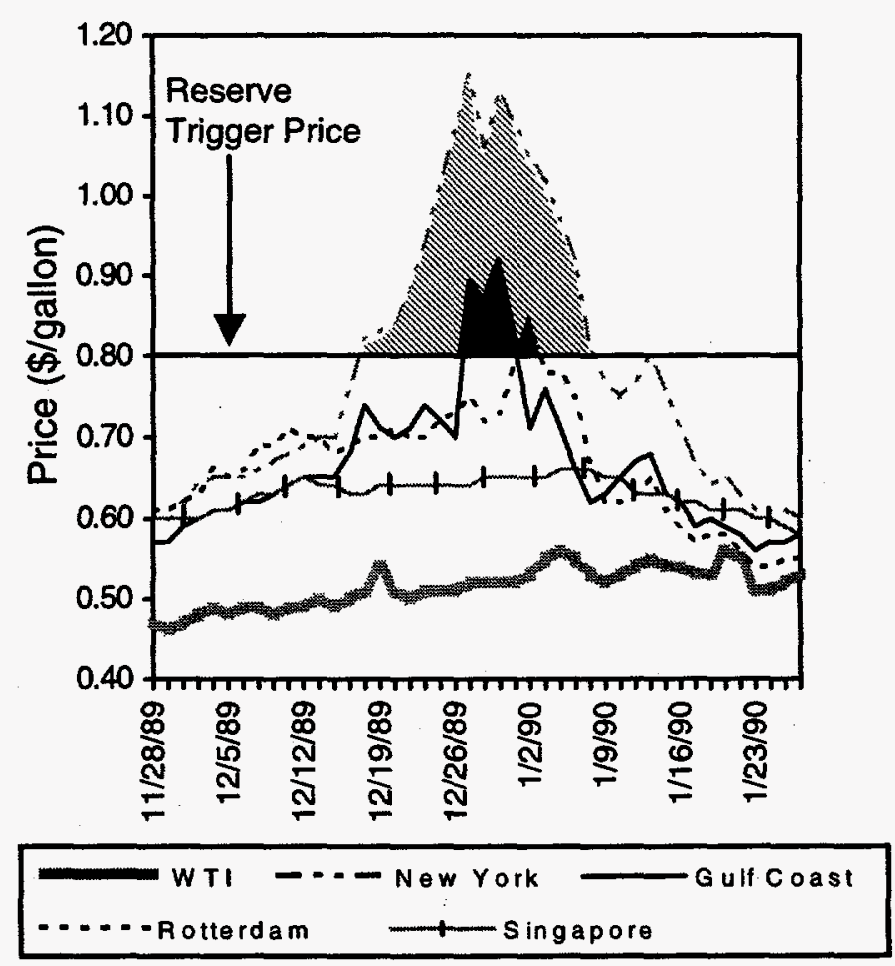

Sources:

Rotterdam prices - Reuters database

Other prices - Wall Street Joumal 
Examination of Exhibit 1-2, which illustrates the price responses during the coldest December in 102 years, also shows the rapidity with which product prices rise and fall during a crisis driven by weather. The speed at which a heating oil crisis passes in the Northeast is reinforced by examining the January-February 1994 portion of Exhibit I-1. Once a "spike" in the very volatile spot market prices occurs, it translates to increased consumer costs.

If the rise in product prices is being driven by a worldwide shortage of petroleum, then drawdown of the crude oil Reserve in the U.S. Gulf is the appropriate Government response. At the Government's option, the regional reserve could be drawn down as well.

\section{ORGANIZATION OF THE REPORT}

This study is structured around three facets of the Northeast heating oil market. First, it identifies the nature of the problems that beset the Northeast and attempts to determine the difference between a regional problem versus a national problem with regional implications. Second, the study examines when a problem is likely to be sufficiently large to warrant Government action. Third, the study considers what the Government could do if it were determined that Government actions were appropriate. Estimates are then made of the costs and benefits of various actions and an assessment of the Government's statutory authorities to intervene in the market. as follows:

Volume I of the report consists of seven chapters and Volume II consists of eight appendices

\section{Volume I}

Chapter l: Introduction.

Chapter II: Analysis of the Northeast Heating Oil Market. This chapter examines the history of the heating oil market in the Northeast and the relationship of imports, domestic production, and inventories to supply.

Chapter III: Analysis of Distillate Primary Stock Management in the Northeast. This chapter examines the reliability and efficiency of the markets and examines the main determinants of inventory levels. The report examines how the industry is responding to the behavior of the futures markets and whether or not there are structural changes in these markets. The year 1996 is examined in detail, as are the cold spells of December 1989 and 1993-94.

Chapter IV: The Benefits of a Regional Distillate Reserve. This chapter examines the magnitude of the regional heating oil problem. The frequency and the duration of winter cold spells are examined and the price effects on the regional and national economies are examined. Estimates are also made of the future likelihood of such events and the potential benefits of a distillate reserve.

Chapter V: Feasibility and Costs of a Distillate Reserve. This chapter examines the various options open to the Federal Government to create a distillate reserve either in the Northeast or at an existing Strategic Petroleum Reserve site. The costs of all the options are developed.

Chapter VI: Benefit Cost Analysis. This chapter combines the results of chapters IV and V and compares costs and benefits of creating a distillate reserve. 
Chapter VII: Alternative Policy Options. This chapter examines policy options for addressing heating oil market problems that are alternatives to the creation of Government-owned distillate reserve.

\section{Volume II}

Appendix A: Northeastern U.S. Distillate Supply Systems. This appendix examines how distillate gets to the Northeast and the time it takes to supply the system.

Appendix B: New England Fuel Oil Storage Capacities and Inventories. This appendix examines the availability of existing capacity that might be used by the Federal Government to create a distillate reserve in the Northeast.

Appendix C: Characteristics of the Northeast Natural Gas Market. The future of distillate demand in the Northeast is closely related to the demand for natural gas. This appendix shows the current status and outlook for the Northeast natural gas market.

Appendix D: Documentation of the Statistical Models. The estimated benefits of building a distillate reserve are very sensitive to assumptions about what constitutes a benefit, the frequency of use, and the reaction of the economy to a price spike in distillate prices. This appendix provides detailed information about the models for the study and the output of those models.

Appendix E: Conceptual Engineering Design and Costs. This appendix lays out conceptual designs and costs for building storage tanks in New England and converting a Strategic Petroleum Reserve crude oil cavern to distillate storage.

Appendix F: Other Countries Experience with Refined Product Storage. Many of the International Energy Agency member countries have satisfied their obligations for strategic petroleum storage with refined products. This appendix describes their programs.

Appendix G: Global Refinery Supply and Demand Appraisal. The availability of distillate over the next few years is dependent on both the availability of crude oil and the ability of refineries to produce the refined product. This appendix examines the state of the world's refining capacity and the outlook through 2000.

Appendix $\mathrm{H}$ : Summary of Federal Authorities Relevant to the Establishment of Petroleum Product Reserves. While the Energy Policy and Conservation Act authorizes the creation of regional product reserves, a distillate reserve would be part of the Strategic Petroleum Reserve and bound by the Energy Policy and Conservation Act and other pertinent laws. This appendix examines the applicable laws.

Appendix I: Product Stability and Turnover Requirements. Refined petroleum products must meet certain specifications to be useable. Oil in storage can degrade over time, and the speed of degradation is sensitive to the composition of the product and the conditions under which it is stored. This appendix examines product stability and the associated question of the frequency of turnover. 

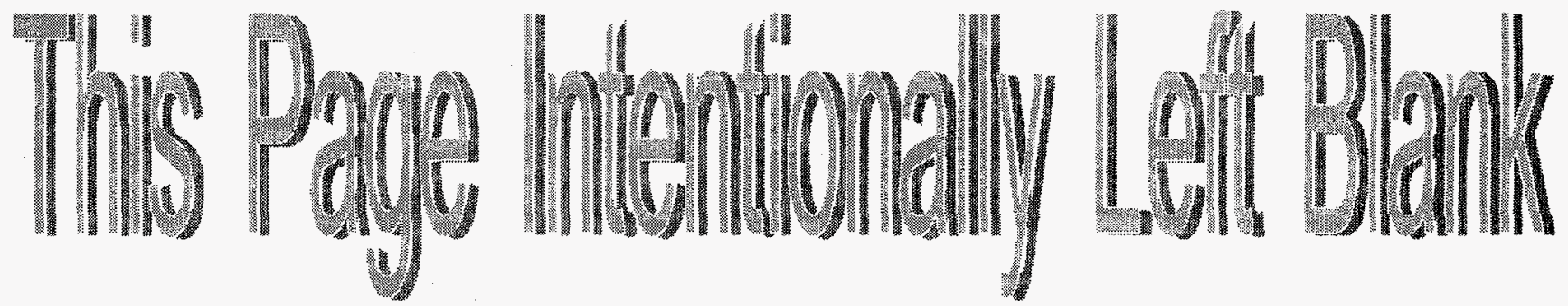
This section of the Report describes in detail the operation of the heating oil market in the Northeast region of the United States and addresses directly whether there is a significant risk that there could be a shortage of heating oil supplies in this region--which would manifest itself either as a physical inability of consumers to obtain heating oil for a period of time or as an increase in the heating oil price that is so large that some consumers could no longer afford to buy heating oil.

The Northeast market is composed of two subregions, New England and the Middle Atlantic region. Although these two subregions have their own distinguishing characteristics, they are part of one market. Distances between the two markets are small, and both regions receive imported supplies from similar locations. Consequently, except in extremely unusual circumstances, any physical shortage in the region would affect both subregions and prices tend to be similar in both subregions.

Statistics for the Northeast can be problematic in that this region is defined differently in the data sets of the Energy Information Administration (EIA) and the U.S. Bureau of the Census, the two main sources of data. Exhibit II-1 shows the region, including the difference between the Middle Atlantic Census Region and the Middle Atlantic DOE region. The Middle Atlantic DOE region includes Maryland, D.C. and Delaware, while the Census region does not.

Exhibit II-1

Northeast Region

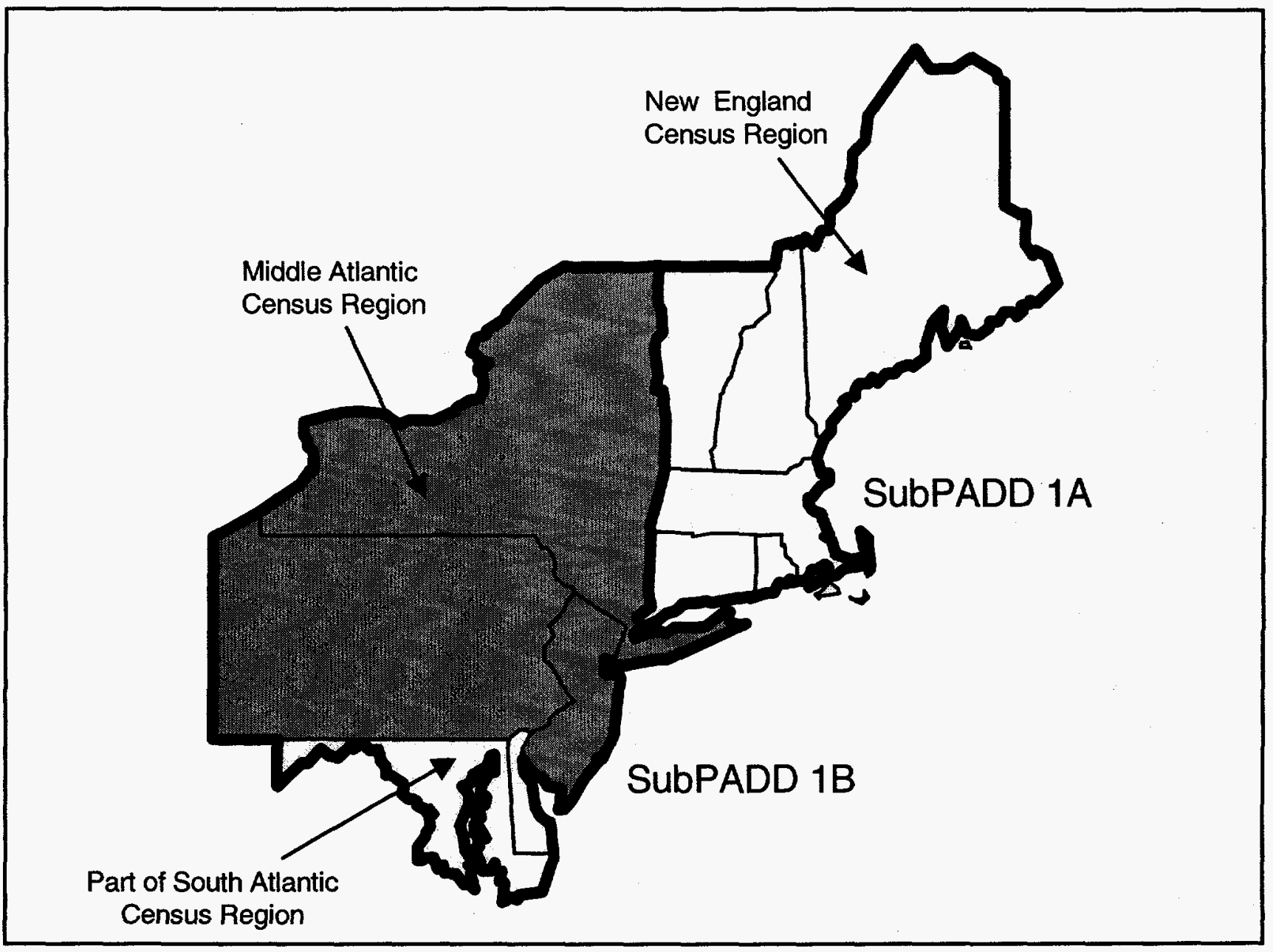




\section{Description of the Northeast Heating Oil Market ${ }^{5}$}

The Northeast is atypical of the nation in its dependence on heating oil (No. 2 fuel oil) for residential space heating. In 1993, the most recent year for which DOE/EIA survey data are available, 10.8 million households in the U.S. (out of 96.6 million), or 11 percent, relied on fuel oil as their main heating fuel. Most of these households (69 percent) were located in the Northeast Census region.

Exhibit II-2 shows the number of households in the Northeast census region that used various energy sources as their main space heating fuel. In the overall region 38 percent of all households relied on fuel oil as their main heating fuel. Outside the Northeast, in contrast, only 4 percent of all U.S. households relied on fuel oil as their main fuel. This makes heating oil supply security very much a regional issue.

Exhibit II-2

Northeast Households by Heating Fuel Type (1993)

\begin{tabular}{|l|c|c|c|c|c|c|}
\hline \multirow{2}{*}{ Energy Type } & \multicolumn{2}{|c|}{ New England } & \multicolumn{2}{c|}{ Middle Atlantic* } & \multicolumn{2}{c|}{ Total Northeast } \\
\cline { 2 - 7 } & $\begin{array}{c}\text { Households } \\
\text { (millions) }\end{array}$ & $\begin{array}{c}\text { Percent } \\
\text { of total }\end{array}$ & $\begin{array}{c}\text { Households } \\
\text { (Millions) }\end{array}$ & $\begin{array}{c}\text { Percent } \\
\text { of total }\end{array}$ & $\begin{array}{c}\text { Households } \\
\text { (Millions) }\end{array}$ & $\begin{array}{c}\text { Percent } \\
\text { of total }\end{array}$ \\
\hline Fuel Oil & 2.6 & 54 & 4.7 & 32 & 7.4 & 38 \\
\hline Natural Gas & 1.6 & 33 & 7.9 & 57 & 9.4 & 51 \\
\hline Propane & 0.1 & 2 & 0.1 & 1 & 0.2 & 1 \\
\hline Electricity & 0.5 & 10 & 1.4 & 10 & 1.9 & 10 \\
\hline Total & 4.8 & 100 & 13.9 & 100 & 18.5 & 100 \\
\hline *Census region: New York, Pennsylvania, New Jersey & & & \\
\hline
\end{tabular}

Source: Department of Energy/Energy Information Administration, Household Energy Consumption and Expenditures 1993

The data in Exhibit II-2 further indicate that the heating oil issue is focused on the New England region. In New England 54 percent of all households relied on fuel oil as their main heating fuel in 1993, while only 32 percent relied on fuel oil in the Middle Atlantic states.

The Northeast's reliance on heating oil as a main space heating fuel is based on the economics of energy supply in the region. The rest of the nation generally relies on either natural gas or electricity as its principal space heating fuel. Electricity is advantageous in regions with more moderate temperatures because annual space conditioning needs can be met with electric heat pumps. Natural gas is used in colder regions. Given the large supplies of natural gas in the West, the Mid-continent, and the U.S. Gulf, all of the northern regions except the Northeast have low-cost access to natural gas.

The relative shares of heating oil, natural gas, propane, and electricity can be seen by examining consumption of these fuels converted to their BTU content. Exhibit II-3 shows that the relative important of fuel oil for space heating is much greater in the Northeast than it is on the national level.

5 Details of the Northeast heating oil market can be found in Appendix A. 
Exhibit II-3

Annual Residential Consumption of Heating Fuels

\begin{tabular}{|l|c|c|c|c|}
\hline & \multicolumn{2}{|c|}{ Northeast Census Region } & \multicolumn{2}{c|}{ Total US } \\
\hline & Quadrillion BTU & Percent of Total & Quadrillion BTU & Percent of Total \\
\hline Heating Oil & 0.76 & 32 & 1.02 & 10 \\
\hline Natural Gas & 1.11 & 46 & 5.27 & 53 \\
\hline LPG & 0.03 & 1 & 0.38 & 4 \\
\hline Electricity & 0.47 & 20 & 3.28 & 33 \\
\hline Kerosene & 0.02 & 1 & 0.05 & $<1$ \\
\hline
\end{tabular}

Source: Department of Energy/Energy Information Administration, Household Energy Consumption and Expenditures 1993

In recent years more gas transmission capacity has been added into the Northeast, making it more feasible to heat with gas in the region than in the past. ${ }^{6}$ Nevertheless, given the transport distances, gas is relatively expensive, and many households have chosen to continue their use of heating oil for space heat even after connecting to the gas delivery system.

Exhibit II-4 presents the estimated cost (\$/MMBtu) of natural gas and fuel oil for space heating in New England, the Middle Atlantic, and East North Central regions of the U.S. in 1993. In New England natural gas was 24 percent more expensive than fuel oil. In the Middle Atlantic region natural gas was 13 percent more expensive than fuel oil. In the Mid West region gas was 14 percent less expensive than fuel oil. ${ }^{7}$ The higher cost of gas in the Northeast partially explains why households have continued using fuel oil for space heating.

Exhibit II-5 shows gas utility residential customers in the Northeast and the proportion of those customers that use gas for space heating. These data include only utility customers, so the number of customers/households is smaller than shown in Exhibit II-2. These data show that the total number of gas utility customers has increased over the 1975-93 period and that the proportion of these customers heating with gas has continued to rise. Many customers, however, have continued to use oil when they could have easily switched to gas.

6 For details on the Northeast natural gas market see Appendix C.

7 The Census East North Central region. 
Exhibit II-4

Prices of Fuel Oil and Natural Gas for

Residential Space Heating in 1993

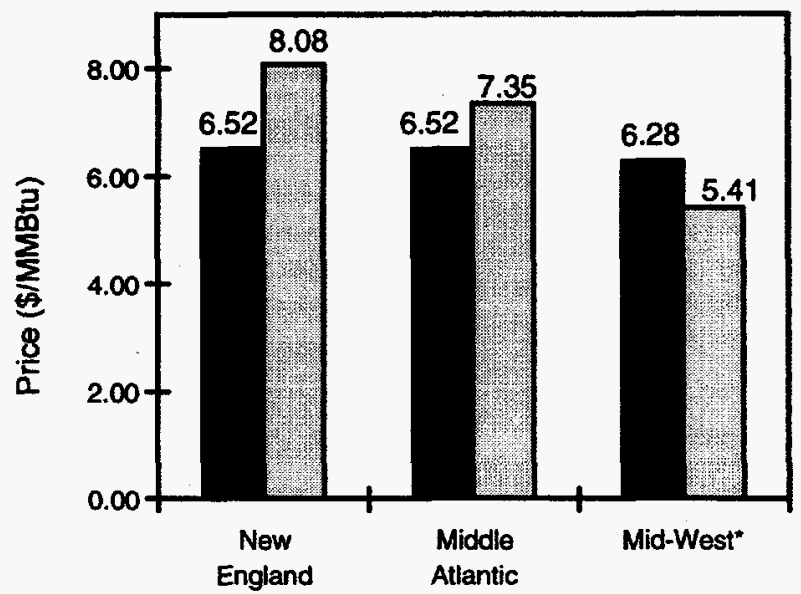

Guel Oil DGas

*East North Central Census Region

Source:

Department of Energy/Energy Information Administration, Household Energy Consumption and Expenditures 1993, October 1995, pp. 77 and 80

Exhibit II-5

Gas Utility Residential Customers Using Gas for Space Heating in the Northeast (Thousands)

\begin{tabular}{|l|c|c|c|c|c|c|}
\hline & \multicolumn{3}{|c|}{ New England } & \multicolumn{3}{c|}{ Middle Atlantic (Census Region) } \\
\cline { 2 - 7 } Year & $\begin{array}{c}\text { Residential } \\
\text { Customers }\end{array}$ & $\begin{array}{c}\text { Heating } \\
\text { with Gas }\end{array}$ & $\begin{array}{c}\text { Saturation } \\
\text { (Percent) }\end{array}$ & $\begin{array}{c}\text { Residential } \\
\text { Customers }\end{array}$ & $\begin{array}{c}\text { Heating } \\
\text { with Gas }\end{array}$ & $\begin{array}{c}\text { Saturation } \\
\text { (Percent) }\end{array}$ \\
\hline 1975 & 1,564 & 857 & 54.8 & 7,630 & 4,128 & 54.1 \\
\hline 1980 & 1,601 & 1,010 & 63.1 & 7,537 & 4,522 & 60.0 \\
\hline 1985 & 1,683 & 1,138 & 67.6 & 7,733 & 5,011 & 64.8 \\
\hline 1990 & 1,850 & 1,319 & 71.3 & 8,184 & 5,426 & 66.3 \\
\hline 1993 & 1,865 & 1,434 & 76.9 & 8,383 & 6,891 & 82.2 \\
& & & $9,422^{*}$ & $7,760^{*}$ & $82.4^{*}$ \\
\hline
\end{tabular}

*Includes Maryland, D.C., and Delaware 
The statistics in Exhibit II-5 can be employed to make inferences about the extent to which fuel switching has taken place between oil and gas. In 1993 Exhibit II-5 shows that about 19 percent or 1.9 million gas utility customers in the Northeast had not switched to natural gas for space heating.

The data in Exhibit II-5 also indicates that consumers that have the capability to switch to natural gas heating have shown a sensitivity to oil prices over the years shown. In most of the 5-year periods shown, the growth in customers heating with gas exceeds the overall growth in gas utility customers.

Subtracting the growth in gas customers from the growth in gas space heating customers gives a measure of the minimum conversion rate from other fuels to gas for space heating. Taking the two parts of the Northeast together, the minimum conversion rate seems to have averaged 102,000 households per year during 1975-80. Preceding that period, oil prices had risen sharply (during 197475), and rose again at the end of the period (1979-81). Oil prices peaked in early 1981 and started slowly downward through 1985 . During $1980-85$, minimum conversions fell to an average of 68,000 households per year. Prices turned sharply downward in 1986 and stayed relatively low until the severe winter of 1989-90. In the 1985-90 period, conversions were about 3,000 per year on average. The double price shock of the winter of 1989-90 and the 1990-91 Iraqi war seems to have had a dramatic effect on the growth of space heating conversions. Over 1990-93, the estimate of minimum conversions jumped to 455,000 per year.

Undoubtly, there are other factors affecting consumers heating preference in the Northeast. Nevertheless, it seems that a large number of the households demonstrated a high degree of price sensitivity. The 1993 data in Exhibits II-2 and II-5 together suggest, however, that a sizeable fraction of households in the Northeast are not connected to a natural gas source, and would require construction of a distribution line and its associated cost to use natural gas.

\section{Production and Supply of Heating Oil}

Heating oil or No. 2 fuel oil is a middle distillate of crude oil that is used in a variety of applications. It is used in homes and small buildings for space and hot water heating and in gas turbines to generate electricity, and in these applications it competes directly with natural gas and propane. It is also very similar to and may be indistinguishable from diesel fuel used to power diesel engines. In recent years diesel fuel increasingly has been subject to more stringent specifications than heating oil to improve its combustion characteristics and to reduce its level of pollutants, particularly in the U.S., and increasingly in many parts of the world.

In addition, kerosene and jet/kero are similar, but slightly less viscous products than heating oil. They are sufficiently similar that refineries can increase yields of heating oil/diesel fuel by reducing yields of kerosene and jet/kero and vice versa.

Since both diesel fuel and jet/kero are subject to more stringent product specifications than heating oil, a heating oil shortage can occur only if a diesel fuel and jet/kero shortage also occurs, while a shortage of diesel fuel or jet/kero could occur even if a shortage of heating oil did not occur. For example, diesel fuel can be used as a substitute for heating oil, and jet/kero can be blended into poor quality heating oil to bring it up to U.S. specifications. As a result, prices of all the middle distillates tend to move in concert. Consequently, a heating oil shortage must be understood as a middle distillate shortage.

Exhibit II- 6 shows the average refinery yield of middle distillates from a barrel of crude oil in the United States. It can be seen that about 22 percent of the yield is typically heating oil/diesel fuel, while 10 percent is typically kerosene or jet/kero. There is some ability to increase the yield of middle distillates by altering the operation of a refinery and yields are normally increased somewhat in the 
winter, but absent investment in additional processing equipment, this flexibility is limited. Consequently, a middle distillate shortage can arise due to a shortage of oil products in general or due to the limitation on the maximum yield of middle distillates relative to other products.

\section{Exhibit II-6 \\ Average 1995 U.S. Refinery Product Yields}

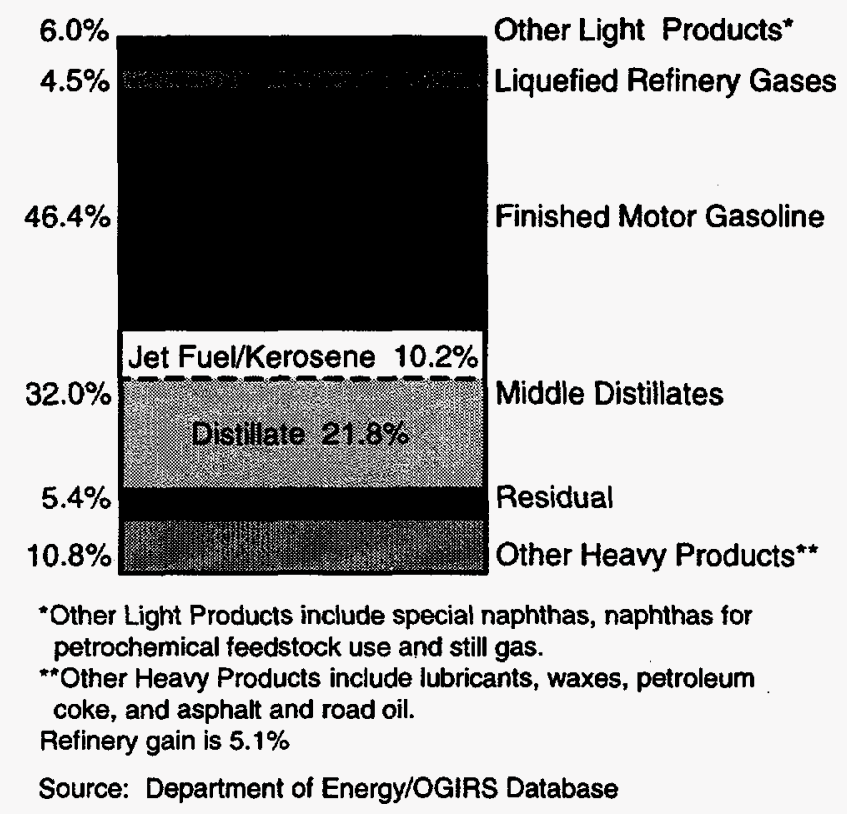

Petroleum products are freely traded throughout the world. As a result, a shortage of some or all petroleum products usually means a world shortage, although a targeted shortage caused by political action is possible. Nevertheless, given the flexibility to reroute petroleum from one location to another, it is difficult to confine a shortage to one region for very long. When a shortage occurs, prices rise, and products are rapidly transported from other areas where prices are lower. In this manner the market moves available products to the highest bidder.

Local shortages generally will be ameliorated through the transport of oil from other parts of the world, although a shortage due to an unexpected event in one region of the world could lead to a temporary price spike, if local stocks are insufficient to respond to this event while world supplies are in transit to the region.

\section{Evidence of a Petroleum Product Shortage in a Competitive Market}

In a competitive market, traditional economics suggest that physical shortages of a petroleum product are converted into high prices as the price of limited supplies is bid up. As prices rise, some consumers decide to limit their consumption, some additional supplies may become available, and at some price the demand falls to the level consistent with the available supply. In this scenario, product may always be available to the highest bidder, and in that sense there is no physical shortage except for those that cannot pay the market price. However, most people would still believe that there is a shortage if they cannot afford the full volume of product they wish to purchase or are unwilling to pay the higher prices. 
Exhibit II-7 shows spot prices of heating oil, jet fuel, and gasoline in New York Harbor for the 198796 period. Spot prices are prices of single cargoes of a product which are not purchased in conjunction with a longer-term contract. While it is never obvious exactly what increase in prices constitutes a "shortage," it is possible to identify periods when oil products were more scarce relative to demand than at other times.

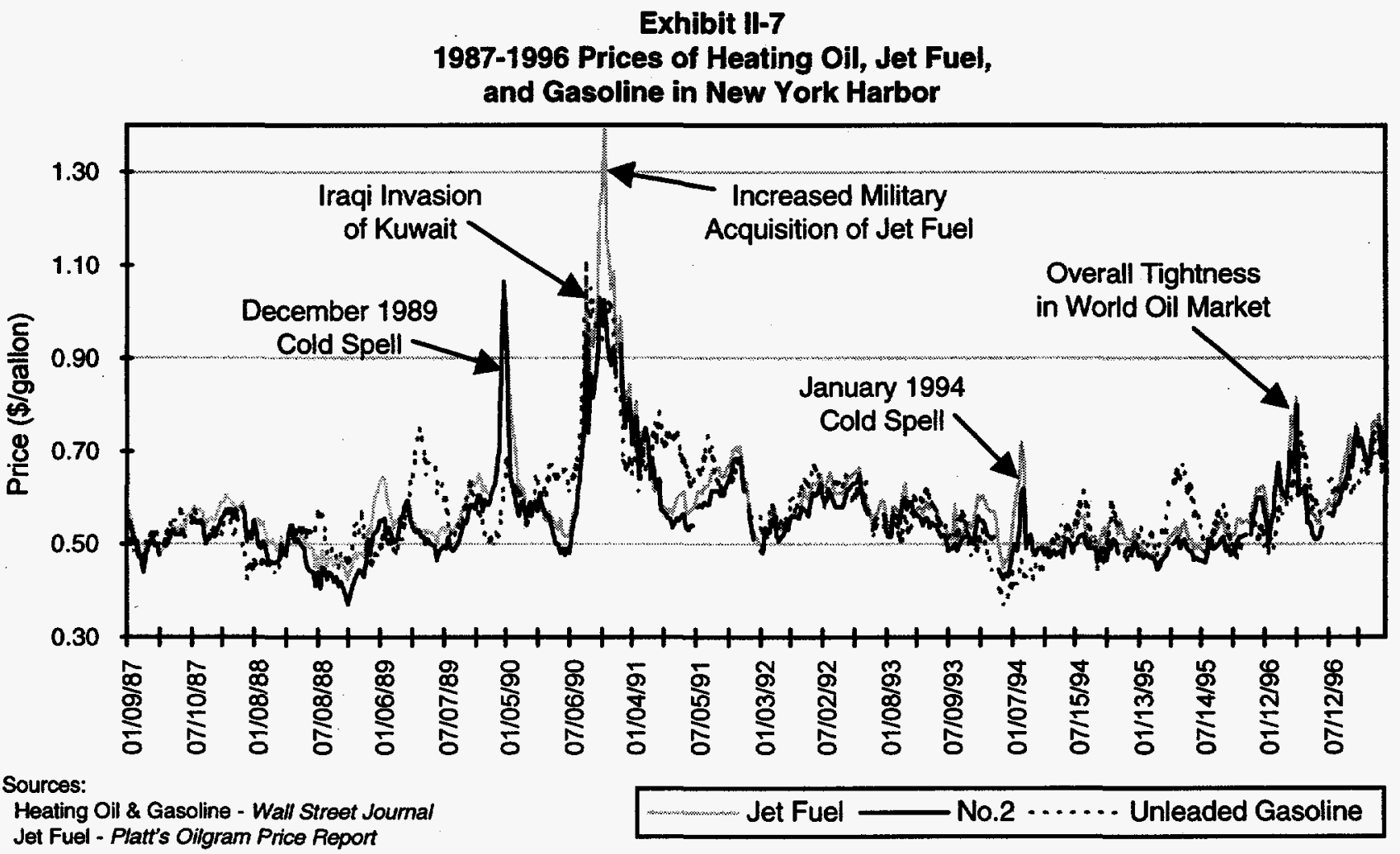

- The first such period shown in the exhibit is the winter of 1989-90 when very cold weather led to an increase in demand for heating oil and the New York Harbor spot price more than doubled for a short time. Jet fuel costs also rose, but gasoline prices were relatively unaffected by the heating oil shortage.

- The second period is the fall and winter of 1990-91 when Iraq invaded Kuwait and the West responded with operations "Desert Shield" and "Desert Storm." During this period jet fuel became particularly scarce due to high military use combined with the loss of Iraqi and Kuwaiti refineries.

- The third period is the winter of 1993-94 when severe cold weather led to a price spike in heating oil. During this event the severe weather did not affect the U.S. Gulf refineries as did the 1989 winter weather, and because this event happened in late winter, prices in the U.S. Gulf did not rise significantly.

- The fourth period is the winter of 1995-96 when late cold weather again led to an increase in demand for heating oil, stocks were low and the price rose by about 50 percent. The increase in the heating oil price was followed by an increase in the gasoline price as world refiners found themselves unable to meet world demand for both products. After heating oil and gasoline prices declined in the summer of 1996, they both rose again in the fall, reflecting a concern about the adequacy of stocks in the winter. This shortage abated by March 1997, and crude oil and product prices returned to the levels of the previous summer. 
These four events are indicative of the situations that potentially can lead to a shortage of heating oil in the Northeast. To examine the dynamics of a potential shortage situation, it is important to first review how heating oil is supplied to consumers in the Northeast.

\section{Heating Oil Supply Logistics in the Northeast}

The demand for No 2. fuel (heating) oil is extremely seasonal, which complicates the supply process. Exhibit II-8 shows the normal seasonal pattern of demand for No. 2 fuel oil and diesel fuel. Both fuels are shown because they are very similar from a refinery perspective and are supplied from similar sources. A review of the exhibit reveals that while diesel fuel demand is very stable, the demand for heating oil is three times greater in January than it is in June.

\section{Exhibit ll-8}

\section{Northeast Seasonal Demand for No. 2 Fuel Oil and Diesel Fuel} (Average for 1986-1995)

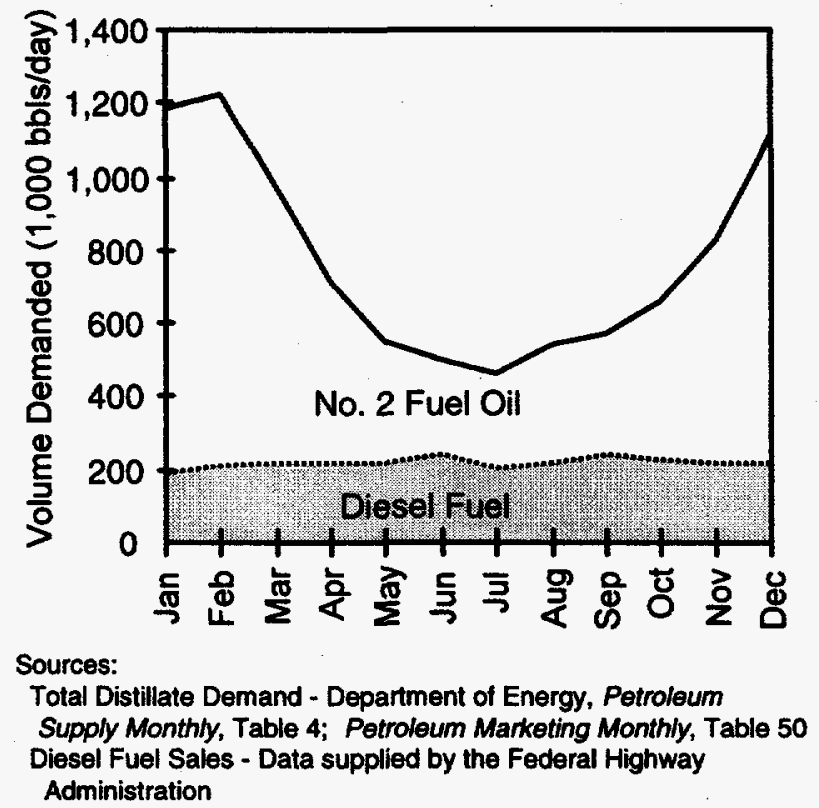

Some electric utilities and industries that normally use natural gas may switch to distillate when natural gas supplies are interrupted or very expensive. These users normally maintain their own supplies of distillate for this purpose, so their switching does not necessarily lead to an immediate increase in distillate demand. Nevertheless, during particularly cold winters, their need for distillate will be above normal and they are likely to enter the market for incremental supplies. Although this incremental demand for distillate is not that large, it can lead to further price increases during very cold weather.

Meeting the seasonal level of demand variation for middle distillates out of current refinery production is difficult. Refineries can adjust their yields of gasoline and distillate to provide more of one by reducing the other, but their flexibility is limited, and marginal production costs rise for the production of either of these products as these limits are reached.

Refineries do normally produce more distillate in the winter than in the summer, but this variation in yield is normally small. As shown in Exhibit II-9, on average PADD I (Middle Atlantic) refineries only vary their monthly yield of distillate from 22 to 25 percent over the course of a year. As a result, in a 
year of stable crude prices, the lowest-cost manner to supply the seasonal demand swings in the Northeast heating oil market is to build up considerable stocks over the May-to- November period and draw them down over the December-to-April period.

\section{Exhibit II-9}

Monthly Yield of Distillate in PADD 1 Refineries

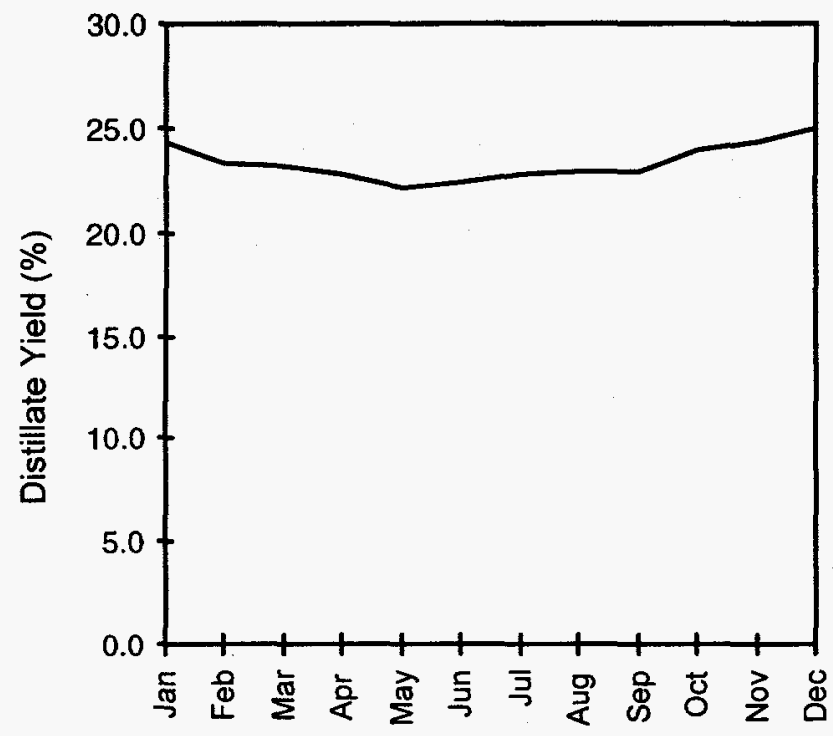

Source: Department of Energy/OGIRS database

Despite this general conclusion, changing refinery product slates is a critical aspect of industry's ability to react to market conditions and price signals. This was demonstrated during the fall and early winter of 1996, when, after prices had risen sharply, refinery distillate yields went above 26 percent and total distillate production reached record levels, demonstrating the flexibility of the sophisticated processing equipment in most U.S. refineries.

Exhibit II-10 shows the typical levels of distillate supplies by source to the Northeast in January and July. A review of the exhibit reveals that in a typical winter month (January) most of distillate supplied to the Northeast comes from local refinery production in that month, stock drawdown, and Colonial Pipeline shipments from PADD-III refineries. Marine movements from the U.S. Gulf are minimal, reflecting the high cost of U.S. vessels. Of imports, 25 percent is produced in the U.S. Virgin Islands; 22 percent is produced in Canada; and 53 percent is supplied by refineries located all over the world. 


\section{Exhibit II-10 \\ Sources of Distillate Supplies to the Northeast Market \\ (1991-1995)}

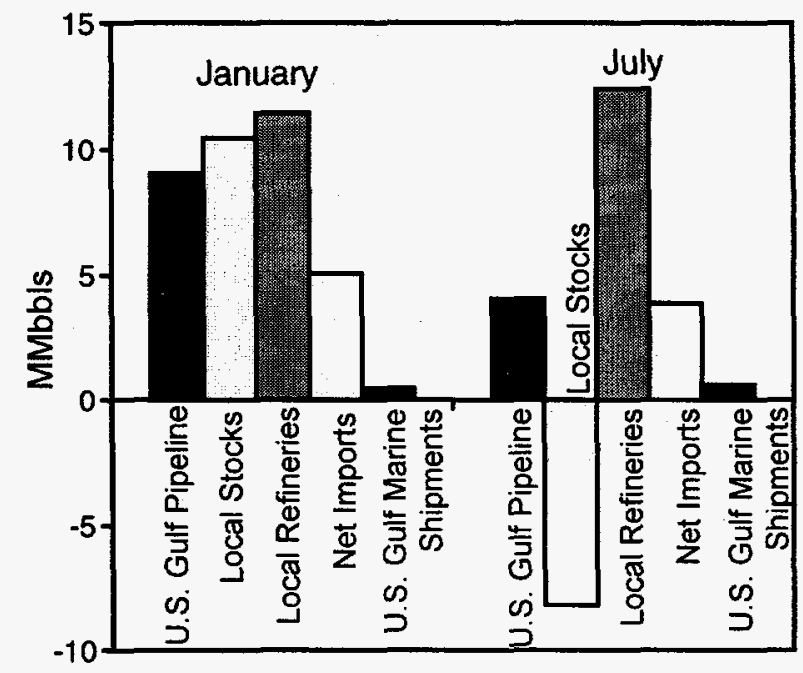

\footnotetext{
Sources:

Refinery Production - Department of Energy, Petroleum Supply

Annual 1994, Volume 2

Pipeline Supplies - Data supplied by Colonial Pipeline Company

Stocks - Department of Energy/OGIRS database

Net Imports - Data supplied by Department of Energy

Marine Shipments - Department of Energy, Petroleum

Supply Monthly
}

In July the normal supply pattern is somewhat different. Much less distillate is sent from the Gulf Coast refiners and imports are also lower. A substantial part of the supplies is added to local stocks in preparation for winter.

In unusually cold winter months the pattern of supply sources is somewhat different. Since an unusually cold month is by definition unexpected and Middle Atlantic and Eastern Canadian refineries may be already producing maximum yields, additional supplies must come from further afield. In December distributors in the Northeast must rely on imports as refineries in the Gulf are also at maximum so incremental supplies are unavailable from them. In January and February Gulf refineries are not at maximum and incremental domestic supplies start showing up in the Northeast by the third week of the cold spell. However, because these refineries are usually undergoing maintenance in preparation for the coming gasoline season, such a shift can jeopardize gasoline supplies later in the year.

Additional imports from Europe are relatively difficult to obtain unless Europe is experiencing a mild winter, so the source of increased imports is likely to be the Caribbean, South America, or the Middle East. Delivery times from the U.S. Gulf and these foreign regions to the Northeast vary from 6 to 28 days, as shown in Exhibit II-11. 
Exhibit II-11

Typical Delivery Times from Distillate Supply Sources to the Northeast

\begin{tabular}{|c|c|}
\hline Supply Source & Minimum Shipping Time to New York \\
\hline U.S. Virgin Islarids & 6 days \\
\hline U.S. Gulf of Mexico & 10 days \\
\hline Rotterdam & 14 days \\
\hline Mediterranean & 15 days \\
\hline Brazil & 18 days \\
\hline Middle East & 28 days \\
\hline Singapore & 40 days \\
\hline
\end{tabular}

The logistics of supplying residential customers within the Northeast include several steps, from refining to final delivery to the customer. Appendix A lays out the details of the players and the distribution logistics in the Northeast. Appendix B has details on bulk storage (primary) storage facilities in the Northeast.

Wholesale distributors normally hold sufficient stocks to maintain adequate deliveries to the retail distributors while they await their deliveries from the producers. ${ }^{8}$ Their stocks are normally sufficient to deal with short periods of very cold weather. As a consequence, any regional shortage that would occur, absent conditions in which transport of distillate becomes impossible, would be due to insufficient distillate supplies at bulk terminals. For this reason the focus of the analysis in this Report is on the dynamics of the supply process at the bulk terminals.

\section{Source of Concern About the Adequacy of Primary Stocks in the Northeast}

Spot price increases shown in Exhibit $11-7$ are passed along to retail distributors and then to residential consumers over a relatively short period. Exhibit II-12 shows how these prices relate to each other. In early winter 1996 residential consumers noticed that their fuel costs had risen over 1995.

8 Wholesale in this report refers to the bulk or primary level of storage; retail, to the secondary level. 
Exhibit II-12

1989-1996 Residential and New York Harbor

Monthly Distillate Spot Prices

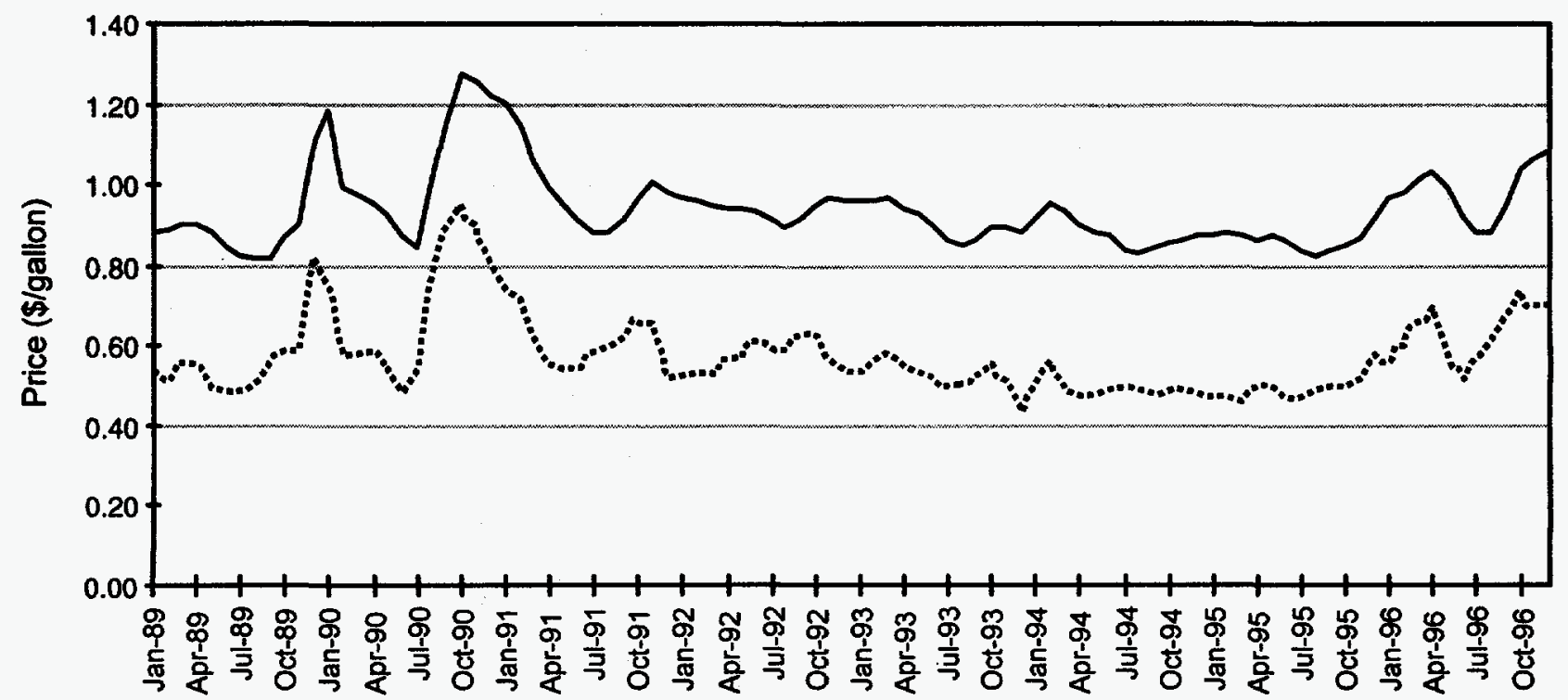

Monthly averages, not directly comparable with Exhibit II-6

Sources:

Spot Prices - Wall Street Joumal

Residential Prices - Department of Energy,

Petroleum Marketing Monthly, Table 39

The focus of the 1996 concerns was the uniquely low level of primary stocks of distillate that were widely reported in the press. Primary stocks of distillate at bulk terminals in the Northeast in April 1996 were the lowest on record, and this subnormal level of stocks continued through December 1996. Consumers understandably might fear that the 1996-97 primary stock situation put them at risk for significant physical shortages in the event that a serious cold snap occurred.

Exhibit II-13 shows primary stock behavior over the 1988 to 1996 time period. The normal winter inventory storage and drawdown pattern is clearly visible in the graph, but the graph also shows two years that depart significantly from normal, notably the winter of 1989-90 and the 1996-97 period. The 1989-90 winter was characterized by lower than normal stocks in October 1989 and then a severe depletion of these stocks in December 1989, which was associated with the huge price run-up in the New York spot market due to the extremely cold weather mentioned earlier. Subsequent to this event, the petroleum industry achieved relatively high levels of distillate in storage every fall until 1995, when a downward trend emerged. 


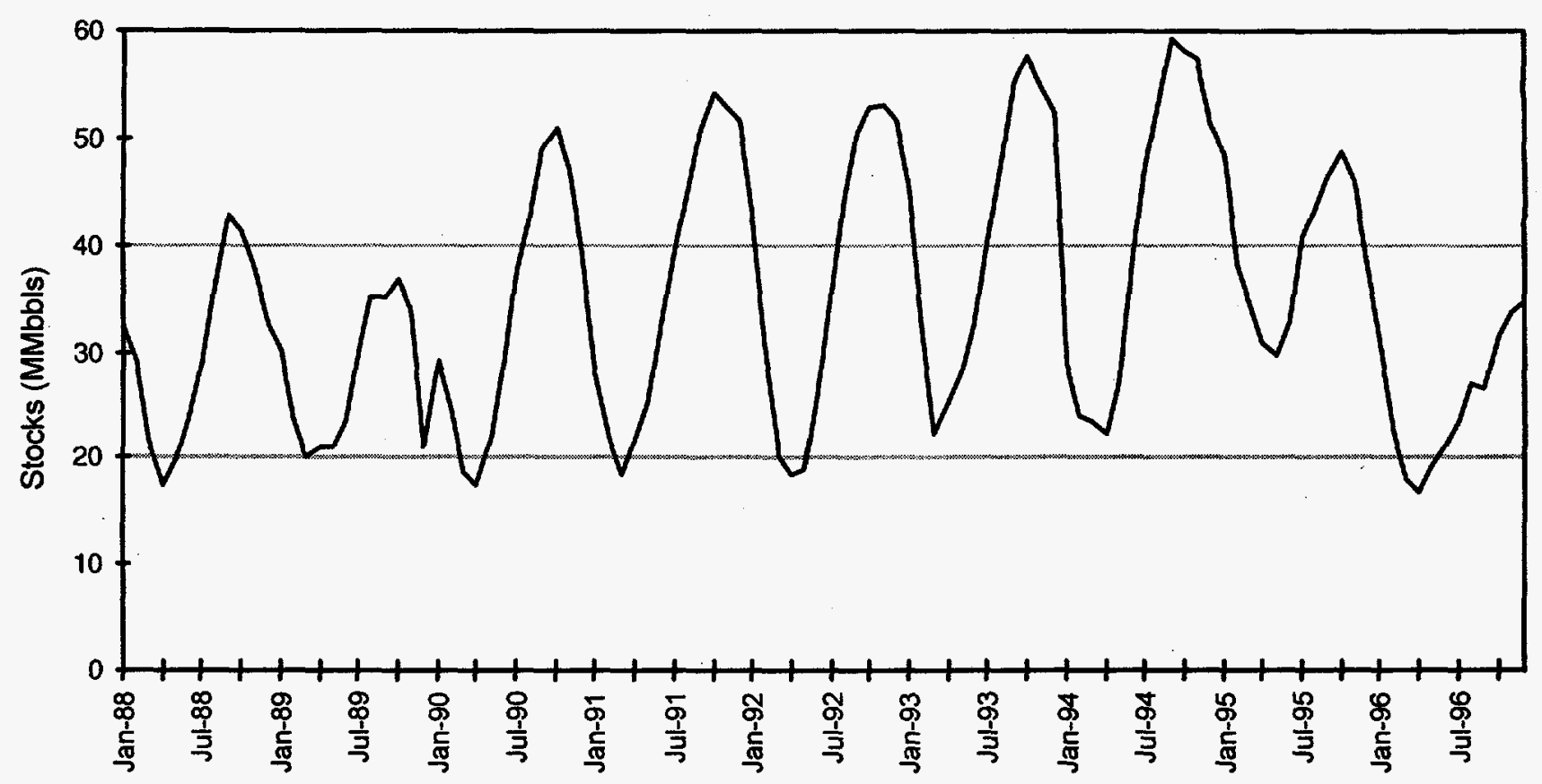

Source: Department of Energy/OGIRS database

Exhibit II-14 provides a monthly comparison of stock levels for the average year of the 1988-96 period, and the two winters 1989-90 and 1996-97. A review of the exhibit indicates that 1996-97 has been similar to 1989-90 in that fall stocks were below normal (even lower prior to the end of November), but different in that the very significant December 1989 drawdown of stocks did not occur. In 1996 stocks continued to rise through December, at which point they were at approximately the apparent target level for stocks in 1989. Although a Northeast cold spell did not occur in 1996, the press and broadcast media had some basis to raise fears about whether a cold spell might lead to a rapid heating oil price increase, given the similarities between stock levels in 1989 and 1996. 
Exhibit II-14

Monthly Primary Stocks of Distillate in the Northeast During 1989-90 and 1996-97

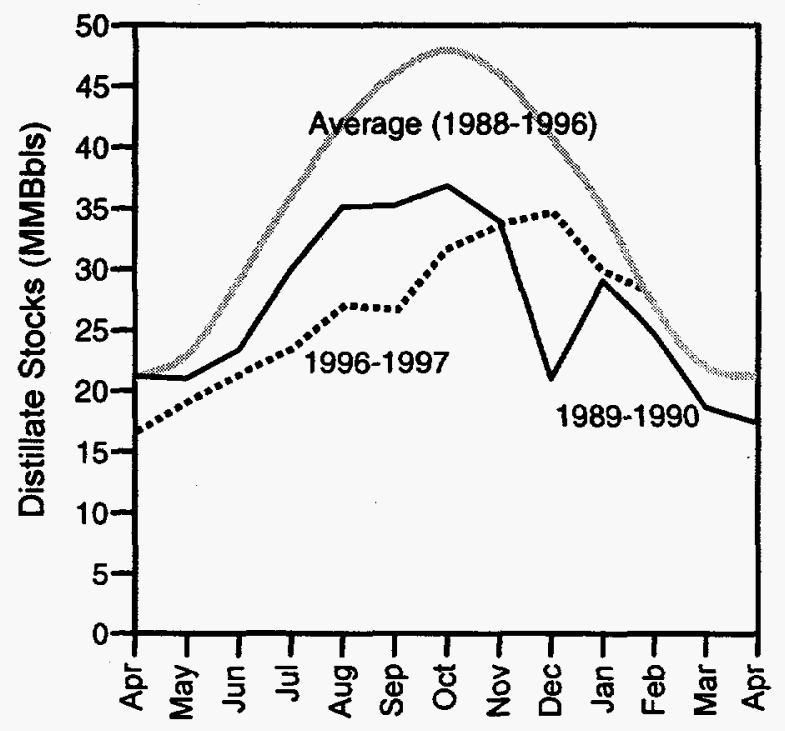

Source: Department of Energy/OGIRS database 


\section{CHAPTER III: ANALYSIS OF DISTILLATE PRIMARY STOCK MANAGEMENT IN THE NORTHEAST}

At the beginning of the 1996-1997 heating season, distillate stocks in the U.S. were at 112 million barrels. This marks the lowest level at this point of the year in EIA's monthly data series, which extends back some 40 years to a time when distillate demand in the U.S. was about half what it is today. In terms of more recent history, distillate stocks at the end of September 1996 were 17 million barrels, or 13 percent, below the levels of 1995 and 30 million barrels below 1994 .

The "normal" winter build-up of heating oil stocks in the Northeast is not a hedge against unusually cold weather. Rather, the normal build-up is the lowest-cost strategy that provides distillate supplies through the winter. The East Coast, including the Northeast, represents the heating fuel capital of the United States. It accounts for most of the winter heating oil consumption in the U.S., and nearly all of the seasonal build and drawdown in distillate stocks. At the end of September 1996, total distillate stocks in the U.S. were 24 million barrels below the 3-year average September levels, and this shortfall was entirely in the East Coast. Thus, the region of the country that relies most heavily upon stock withdrawals to meet its winter distillate demand was the region with the shortfall.

Had there been a severe winter in 1996-1997, there would have been a substantial increase in heating oil prices. This chapter of the report analyzes the dynamics of industry stock holding behavior and reviews the 1996 distillate market to explain the occurrence of high prices and low stocks going into the 1996-1997 heating season.

\section{Economics of Inventory Management}

Inventories are a fundamental component of the manufacture and distribution of goods. Since shipments are never instantaneous, there must always be goods in transit. If demand can be anticipated reliably, then the flow of goods through the distribution system can be controlled so that its output just equals the needs of the customer or user. Since this can never be accomplished perfectly, it is normal to have inventories of raw materials, semi-finished goods, and finished goods at various stages along the supply chain.

In manufacturing industries, inventories are to some degree a measure of the inefficiency of the supply chain. If the timing of deliveries of materials and goods is uncertain or unequal, larger inventories must be held to avoid a supply disruption, and supply disruptions must be avoided because they are expensive. At the manufacturing end of the business a shortage of raw materials will shut down operations. Since fixed operating costs will continue, the plant will lose money. At the product end of the business a shortage of products will likely cause a loss of sales, as consumers seek to obtain products elsewhere. As a result, inventory management is a constant effort to minimize inventories while maintaining continuous operations and available supplies.

Under certain conditions inventory building can be economically advantageous. One of these conditions is the existence of a significant seasonal demand for goods. Another condition is the significant likelihood of a supply disruption. Under both conditions the cost of holding additional inventories may be less than not holding them. 
When faced with a regular seasonal demand pattern, suppliers have several options to ensure regular supplies:

- Suppliers may size production capacity to meet maximum seasonal demand. This option is not cost-effective because some of the capacity will not be utilized much of the time and implicitly will be expensive per unit of output. Surplus capacity may be used to make products for export, but the returns on these sales may be low. ${ }^{9}$

- Suppliers may augment output with imports from other regions or countries during periods of peak demand. While more expensive than their own production, this option may offer higher profitability than expanding capacity to levels that will be rarely used. This option may be particularly advantageous if suppliers in other countries have a different seasonal demand pattern and themselves have surplus capacity when demand in this country is at its peak.

- Suppliers may size production capacity to meet average demand and stockpile surplus product offseason to meet demand peaks during each year.

- Suppliers may invest in flexible production capacity that may be convertible to make other products during parts of the year when demand for one product is lower.

- Suppliers may depend on high prices during peak periods to reduce demand to the lower level of supplies available.

The U.S. oil industry traditionally has used a combination of these methods to provide adequate supplies to meet the seasonal demand for heating oil. In the United States (east of the Rockies), distillate and gasoline seasons are phased so that in meeting demand for one product, the other is usually over produced. Inventories for the off-season product build and help lower production capacity requirements for the following high-demand season.

Historically, investment in enough capacity to meet the seasonal peak in heating oil demand entirely out of U.S. refinery production is not cost-effective. Under normal oil market conditions heating oil prices follow a seasonal cycle. Exhibit III-1 shows the average spot price of heating oil in New York Harbor over the 1987-96 period. On average, prices have peaked in October at a price about five cents/gallon above the low point in June. This price increase provides the additional revenues that offset the costs of holding seasonal inventories until demand rises in the fall.

The problem with storing large supplies of heating oil in bulk terminals for six months is that it potentially puts the owner of the supplies at risk that heating oil prices may decline during the storage period, leaving the owner with a large financial loss. Clearly if this risk is large, the owner will tend to store less heating oil and rely more on other supply methods to meet demand. Of course, there is also the possibility that prices will rise, leaving the owner with a large financial gain. Over time the losses and gains will tend to offset each other, so that the owners have been willing to bear the price risk, and more recently, hedge on the futures market.

9 For example, California diesel fuel consumption during the summer approximates what refineries normally produce during that period. In the winter, diesel demand falls disproportionately. Since there is not much demand for heating oil, refineries export distillate to Asian markets to prevent a build up in inventories. 
Exhibit III-1

Average Monthly Spot Price of Distillate in

New York Harbor (1987-1996)

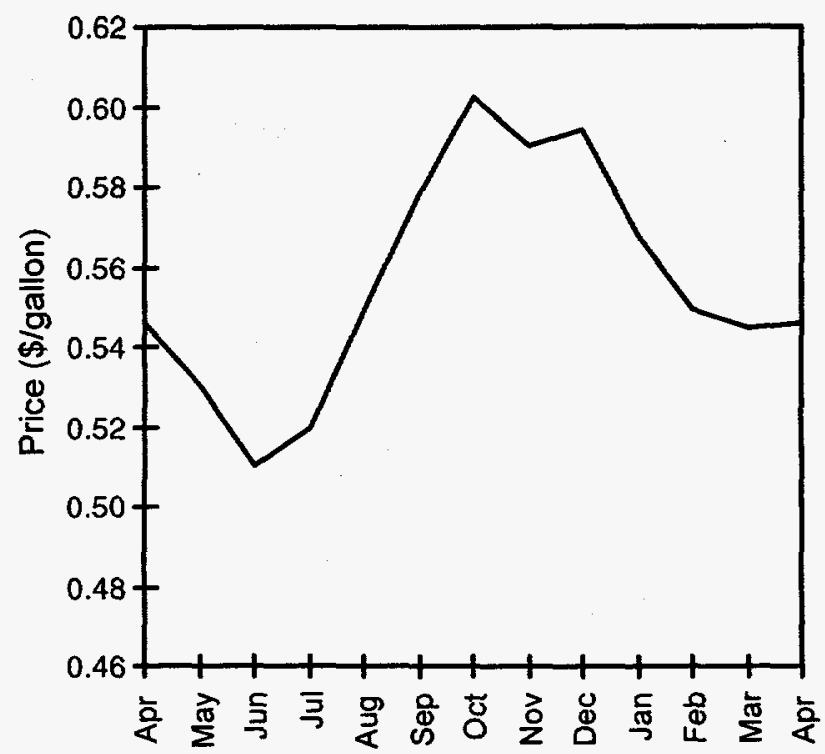

Source: Wall Street Joumal

\section{The Futures Market}

Futures markets were created to provide buyers and sellers of commodities a means to buy or sell them in the present for future delivery. Using futures contracts, buyers and sellers may lock in prices and eliminate the uncertainty about how much they will pay or receive for a good in the future.

The New York Mercantile Exchange (NYMEX) is the most active petroleum futures market, trading contracts for gasoline, heating oil, and crude oil. NYMEX contracts can be purchased on any given day for deliveries from one to several years in the future, although most of the volume is for deliveries within the next year. The results of these transactions provide an up-to-the-minute public indicator of prices for the major petroleum products.

The forward price curve is a plot of one month futures contracts prices at any particular time. When the nearby contract prices are higher than the contracts that mature at a future point, the forward curve is said to be "backward." The reverse situation is called "contango." Seasonal products such as gasoline and No. 2 heating oil shift between contango and backwardation. At mid-June 1997, for example, the July 1997 heating oil contract was priced at 51.6 cents per gallon, and the December 1997 and July 1998 contracts brought 55.7 cents and 53.0 cents respectively. In this case, the JulyDecember 1997 forward curve was in contango, while the December 1997 to July 1998 curve was in backwardation.

When a forward curve changes shape, or is abnormally shaped, analysis of the changes almost always show that the change was the product of a large movement in the nearby contracts. Thus, a backward curve would usually develop when current supply conditions are very tight and nearby futures contracts are bid upward compared to the ones that are farther in the future. This was the case in the Spring of 1996, when low stocks and an extended winter drove up spot prices for heating oil to 
the point that the forward curve was heavily backward. This situation repeated itself to a lesser degree in the fall as demand from heating oil dealers picked up and stocks were again low.

\section{Management of Primary Stocks of Distillate in the Northeast}

The normal build-up is the lowest-cost strategy to provide distillate supplies through the winter. Exhibit III-2 shows the range of primary stock levels for distillate held by month in the Northeast over the 1988-96 period. While even the minimum level of stocks held shows the anticipated seasonal build-up, the range of October inventories has been from 30 to 60 million barrels.

\section{Exhibit III-2 \\ 1988-1996 Distillate Stock Levels in the Northeast}

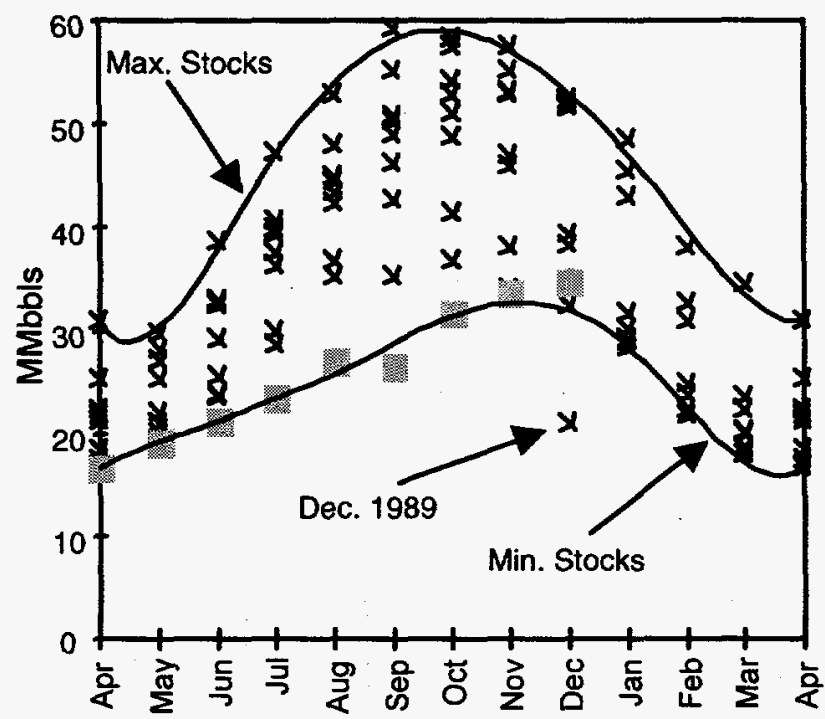

Squares indicate 1996-97 stock levels.

$X$ Marks indicate stock levels from other years.

Source: Department of Energy/OGIRS database

April is the normal low point for primary stocks of heating oil in the Northeast. By April the winter is past, and refineries can easily meet demand for distillate out of monthly production plus add to inventories for the following winter demand period. Consequently, at this time primary stock participants must begin to decide whether to buy distillate and increase stocks held in bulk terminals. During most years, prices are comparable with stock building beginning in May, and the industry normally adds stocks monthly until there is a peak in primary stocks in October or November. During this May-to-October/November period it is normal that futures prices for distillate for the winter months (when these stocks will be sold) will be slightly higher than current prices.

December is the first winter month in which distillate demand is almost certain to be greater than normal refinery production and primary stocks are likely to be drawn down. As a consequence traders are concerned about the likely prices in December when they make their decisions to buy and store distillate through the summer and fall months.

Exhibit III-3 shows that the forward price curve in 1996 was distorted enough by the late winter that, even as late as June, the June-December spread was lower than all previous years but 1989. Futures market theory often examines the economics of the 'storage hedge' depicted in the figure. If storage 
costs averaged about 0.5 cents per gallon per month, and a six-month price spread is less than 3 cents per gallon, then there seems to be no potential profit for a company that would normally stock up in the summer for winter sales.

\section{Exhibit III-3 \\ June Distillate Futures Price for December Minus the June Distillate Spot Price}

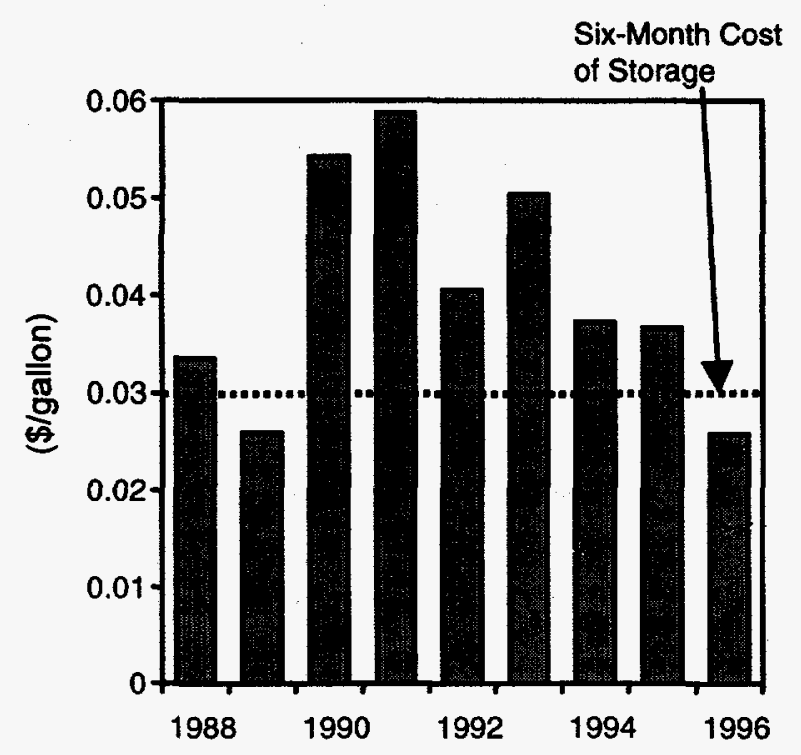

Source: Wall Street Joumal

Exhibits II-4 and III-5 show the statistical correlation of inventory building to future price differentials in the months of June and September over an eight year period. If we accept the assumption that producers are influenced to accumulate inventories to profit from storage hedges, than the low levels of inventory creation in June and September 1996 to a large extent are explainable by the lack of incentive as signaled by the low differentials between prices in those months and forward prices for the coming winter. 
Exhibit III-4

Additions to Primary Stocks of Distillate in June Versus Expected Distillate Price Increases Between June and December

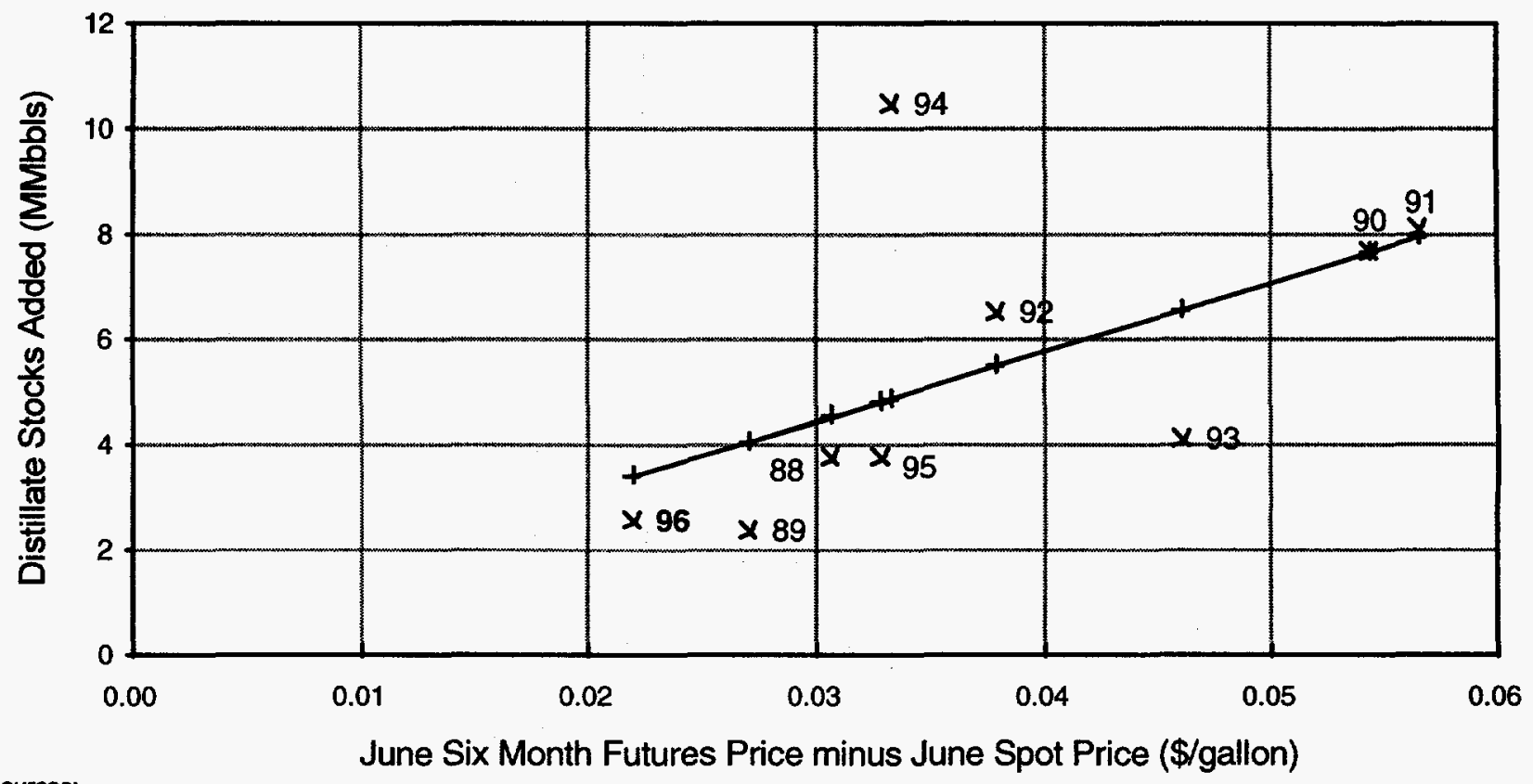

Sources:

Stocks - Department of Energy/OGIRS database

Prices - Wall Street Joumal

Exhibit III-5

Additions to Primary Stocks of Distillate in September Versus Expected Distillate Price Increases Between September and December

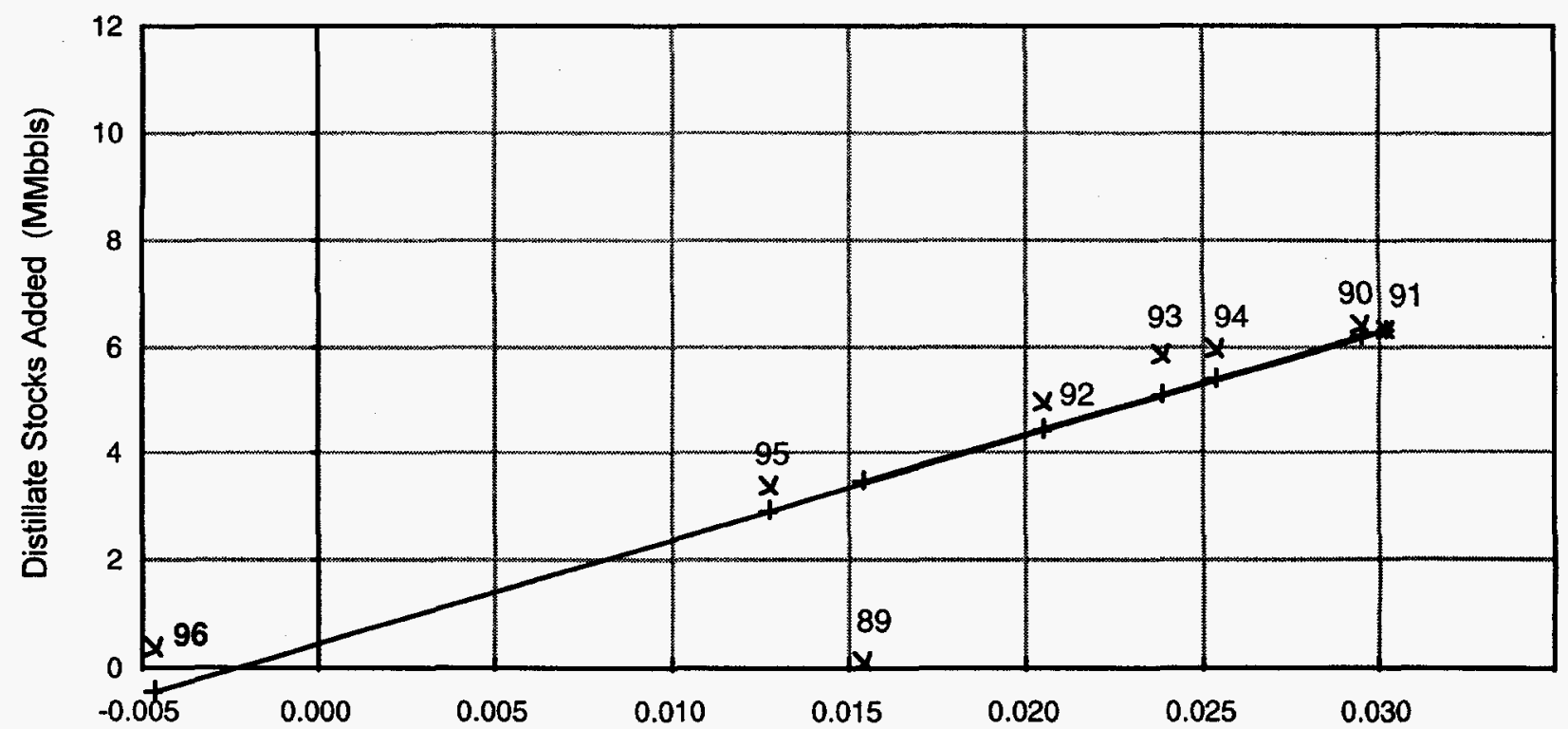

September Three Month Futures Price minus September Spot Price (\$/gallon) 


\section{Examination of the 1996 Distillate Market}

In 1996, unusually low distillate stocks created a tighter-than-normal supply situation and higher heating oil prices. An analysis of longer term historical trends in distillate shows that peak distillate stocks were on a generally declining path in the 1980's, reaching a low point in the winter of 1989. That trend reversed abruptly in 1990, and stock levels were generally rising through 1994. Three factors are cited as possible causes of the turnaround: (1) stocks were depressed by a series of colder than normal winters in the late 1980's; (2) the Persian Gulf War in 1990-91 may have contributed to precautionary inventory building; and (3) environmental regulations imposed by the Clean Air Act Amendments of 1990 reduced the fungibility of diesel fuel and heating oil inventories. In contrast to the shift in trend in distillate stocks, gasoline and crude oil inventories have gradually declined throughout the 1980's and the 1990's.

The winter of 1995-96 should have ended with seasonably low levels of inventories. However, winter weather lasted longer into the spring than was normal, severely depleting distillate stocks and creating sharp backwardation in distillate prices. The result was that distillate stocks at the end of the 1995-96 heating season were 89.7 million barrels, the lowest end-of-month level since March 1967, when distillate fuel demand in the U.S. was about 70 percent of the current level.

Unusually strong demand in the spring and summer of 1996, attributable in part to increasing diesel fuel consumption, spurred by robust economic growth, slowed the normal seasonal rebuilding of distillate stocks. This was the time of year when gasoline production should have been rising and distillate production declining. The late-season focus on distillate became a concern to the markets because gasoline stocks were running lower than normal. When gasoline production was affected briefly by the need to produce additional distillate to meet demand, gasoline prices rose by about 25 cents per gallon nationwide.

Diesel-driven demand for distillate fuel was unusually high in the summer of 1996 when distillate stock building is typically at its highest level of the year. In large part due to increased diesel fuel consumption, distillate demand in 1996 exceeded that of 1995 by 5 percent. Distillate production and imports were both strong in 1996, but not strong enough to rebuild stocks to more normal levels.

Distillate production in 1996 was 5.4 percent higher than in 1995. Net imports in 1996 were more than 100 percent higher than in 1995, but still they account for only a small proportion (less than 2 percent) of total product supplied. In addition, price differentials favored exports to Europe in September and October, a period when inventories would normally be building.

From the record low stock levels at the end of winter 1995-1996, the distillate stock builds that occurred in May and June of 1996 were typical of the builds seen in recent years. The lack of storage replenishment in July, historically the biggest build month of the year, began to raise concerns. Over the past 3 years, the average July build has been 12 million barrels, but in July 1996 it was less than 5 million barrels. The replenishment in August and September was also smaller than normal. The average third-quarter stock build over the past three years has been 23 million barrels compared to only 10 million barrels in 1996.

In summary, there are several factors that have contributed to the current low level of distillate stocks: (1) the cold snap in the spring of 1996; (2) strong diesel fuel demand; (3) exports; and (4) the low return from selling futures. 


\section{Potential Risk from Low Stock Levels to Heating Oil Customers in the Northeast}

Although the petroleum industry is likely to return to more normal levels of primary distillate stocks in the Northeast once futures markets return to normal, historical experience indicates that primary stock levels do affect distillate market behavior in the Northeast during a cold spell. When stocks are low, a cold spell can cause price spikes that would not occur if stocks are higher.

Exhibit III- 6 shows the range of primary distillate stock levels in the Northeast with the experience of 1989-90, 1993-94, and 1996 highlighted.

- In 1989 primary stocks were low going into the winter and the December cold spell caused these stocks to fall close to minimum operating levels. Prices jumped from $\$ 0.70 /$ gallon to $\$ 1.15 / g a l l o n$ (64 percent) over a two-week period.

\section{Exhibit III-6}

Northeast Primary Distillate Stock Levels During the Winters of 1989-90, 1993-94, and 1996-97

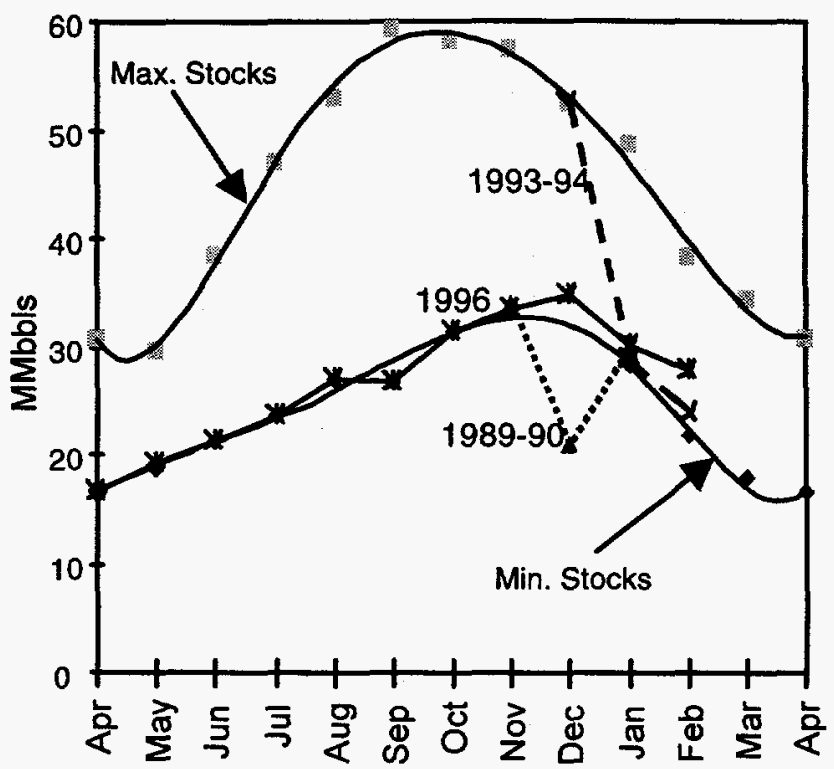

Source: Department of Energy/OGIRS database

- In 1993 primary stocks were high going into the winter. Although the January cold spell caused these stocks to fall precipitously, they did not reach even normal minimum levels for January, and there was no significant price run-up. Even though the one-month decline in stocks in 1994 was much greater than in 1989 , prices only increased from $\$ 0.45 /$ gallon to $\$ 0.64 /$ gallon (42 percent).

- In 1996 primary stocks were at all-time lows going into the winter. No cold spell occurred and primary stocks slowly rose to more normal levels by the end of February. While spot prices rose almost 20 cents per gallon in the fall, they peaked in December and declined thereafter.

These events suggest that while lower-than-normal primary stock levels may not lead to physical shortages, they do lead to greater risk of short-term price increases in the event that an unusual cold spell occurs. 
Given enough time, heating oil supplies respond to higher prices and can be delivered to the Northeast from elsewhere. Consequently, the danger posed by low levels of local stocks is that they run out before additional supplies arrive. A detailed review of the market response to the cold spells in December 1989 and December 1993 to February 1994 indicates how much time elapses before incremental supplies begin arriving during the coldest winter months.

\section{Market Response to Cold Weather in December and January}

Exhibit III-7 shows that in the 1989 episode, temperatures dropped below normal levels at the end of November and remained below normal until December 31. In the aggregate over this one month period, total heating degree days (HDD) exceeded normal by 372. Although primary stocks declined steadily over this period, prices did not begin increasing until December 15th, when stocks dropped below the normal December minimum level. Prices then rose steadily until December 27th, when the end of the cold spell could be forecast. Significant incremental supplies began arriving in the region on January 15th from the U.S. Gulf, four weeks after the original significant spot price increase. By January 22nd imports had risen significantly.

In the 1993-1994 episode, temperatures dropped below normal levels on December 27, 1993 and remained below normal until February 17 th. In the aggregate over this eight-week period total heating degree days exceeded normal by 331. Stocks were so high before the cold spell that they did not decline to worrisome levels until the end of January. Prices in New York Harbor and the margin between prices in New York and in other major world markets began to increase to a level sufficient to attract supplies from elsewhere on January 16 th. $^{10}$ Incremental supplies from the U.S. Gulf began arriving about February 15th, 30 days after the original spot price increase. Over the next three weeks about two million barrels per week above normal were received from the U.S. Gulf. Incremental imports did not appear until March 8th, seven weeks after the original spot price increase. Both of these episodes can be seen in Exhibit III-7.

The review of these two episodes suggest that additional supplies can be delivered to the region in response to cold spells within four to seven weeks of the onset of significant price increases due to an unanticipated cold spell, although supplies from Gulf Coast refiners might be slightly more responsive. Therefore, the most worrisome weather from a distillate supply security standpoint is a very cold one-month period. If such a period were to commence precisely when stocks were at the minimum end of the normal stock range in December, the region would have to survive on its existing primary stocks for the following month. Since previously scheduled supplies arriving from elsewhere would be based on normal weather requirements, local stocks would have to make up the difference between normal requirements and the need during the abnormally cold weather spell during the entire next month.

The experience in early 1996 is the only example of late winter cold weather in recent years, and it shows that the Northeast's vulnerability to a distillate price spike extends to these months.

10 New York spot heating oil prices first increased sharply around January 13-16, although they had been rising steadily for several weeks. Petroleum analysts usually examine the spread between the New York and Rotterdam spot barge markets as an indicator of the viability of Cross-Atlantic shipments. The spot 30,000 metric ton clean tanker rate usually runs about 4 cents per gallon (Platt's Oilgram Price Report (Port Utilities), December 14,1993, p. 4). The spread broke this differential at mid-month January, temporarily fell back, then marched upward to more than 15 cents by the second week in February. 


\section{Exhibit III-7}

Profile of a Heating Crisis
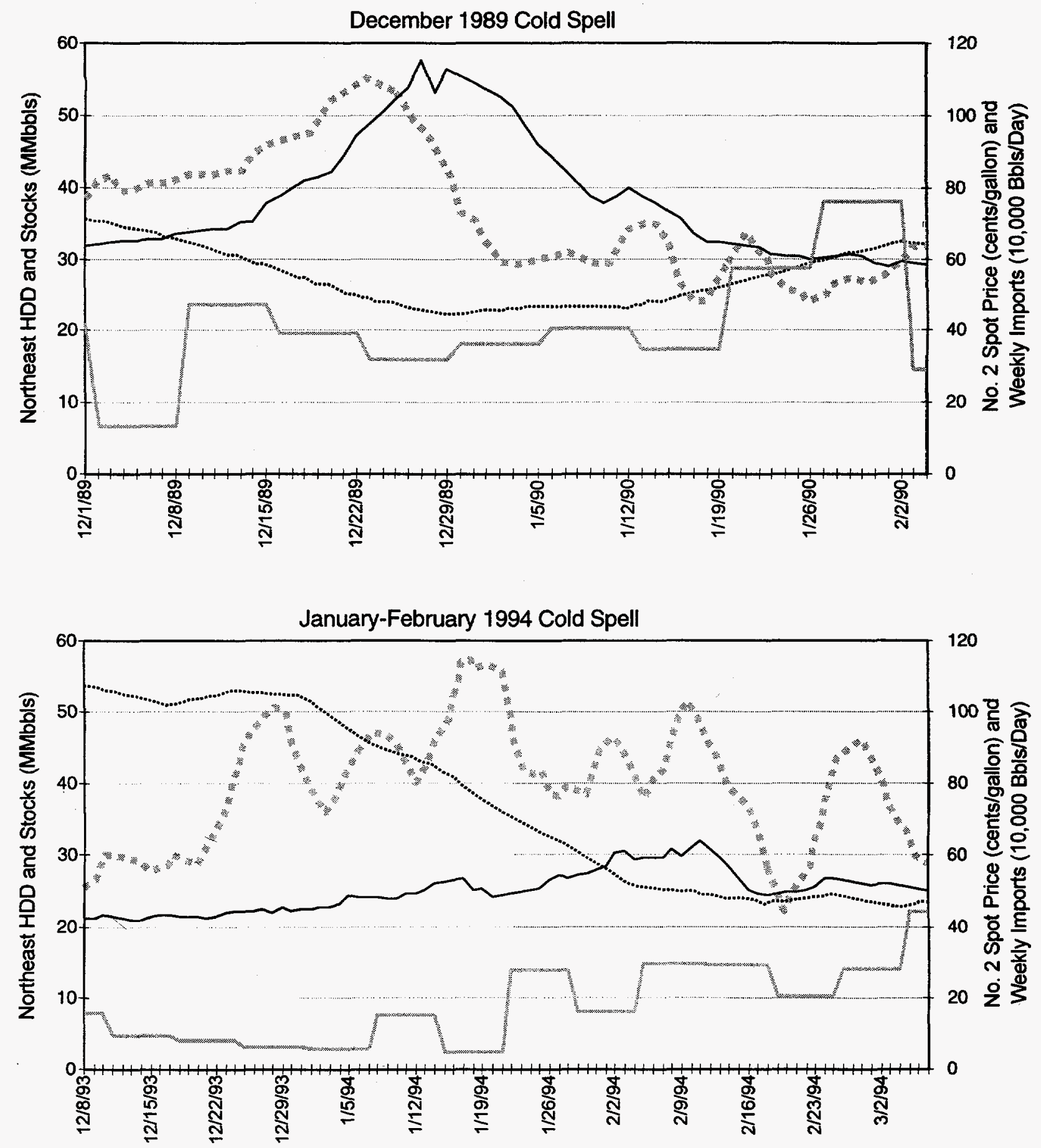

Normal Northeast HDD are 33 for December, 37 for January, and 36 for February.

Sources:

Stocks - Department of Energy /OGIRS database Price - Wall Street Joumal

Imports - Data supplied by API. Normalized to Department of Energy import data.

Heating Degree Days - National Oceanic and Atmospheric Administration 
By January distillate production has normally declined by 150,000 barrels/day relative to December, or by 4.5 million barrels/month. By February normal distillate production has declined by 200,000 barrels/day or 6.0 million barrels/month. In January 1994 the PADD-III refineries took advantage of this pattern in spare capacity and continued to produce distillate at their December level in response to the cold weather in the North.

If shipping capacity is available, incremental distillate production from the U.S. Gulf refineries can be delivered to the Northeast within two weeks. Even if U.S.-flag (Jones Act) vessels are not available, with a Department of Transportation waiver, foreign-flag vessels could be used in an emergency. Transportation on the Colonial Pipeline from Houston to Linden, New Jersey takes 14 days plus any time required to await the next distillate shipping period (0-20 days). As a result, even though the level of primary stocks in the Northeast normally falls after December, the risk of supply shortages is mitigated by the availability of spare U.S. Gulf refinery capability during the January-to-March period.

\section{Local Stocks and Prices During a World Supply Shortfall}

Two of the three periods of distillate price increases examined in Chapter II were due to overall tightness in the world petroleum market. Variations in local stocks would not affect the world price of distillate in a significant way; this is confirmed by examining stock data and prices in the Northeast. Exhibit III-8 shows Northeast stock levels during the 1990-91 period of the Iraqi invasion of Kuwait. At that time primary distillate stocks were at relatively high levels in the Northeast, and this did not prevent prices from increasing in the region in response to a world oil supply/demand imbalance. It is clear that when distillate price increases are related to world oil market price increases, a substantial drawdown of SPR crude oil would be required to significantly affect the world price of oil.

\section{Exhibit III-8}

Northeast Primary Distillate Stock Levels During the Winter of 1990-1991

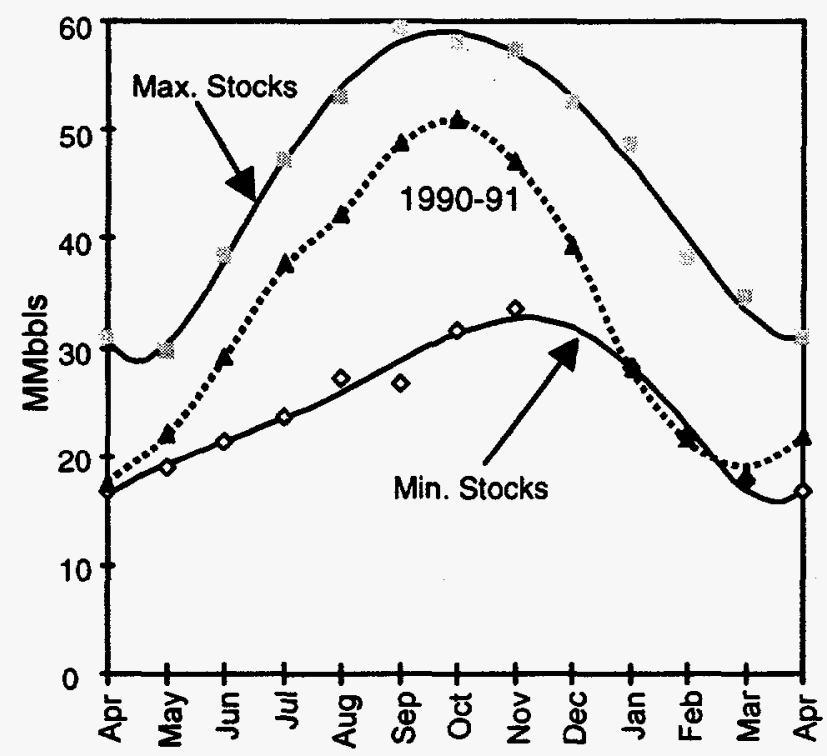

Source: Department of Energy/OGIRS database 

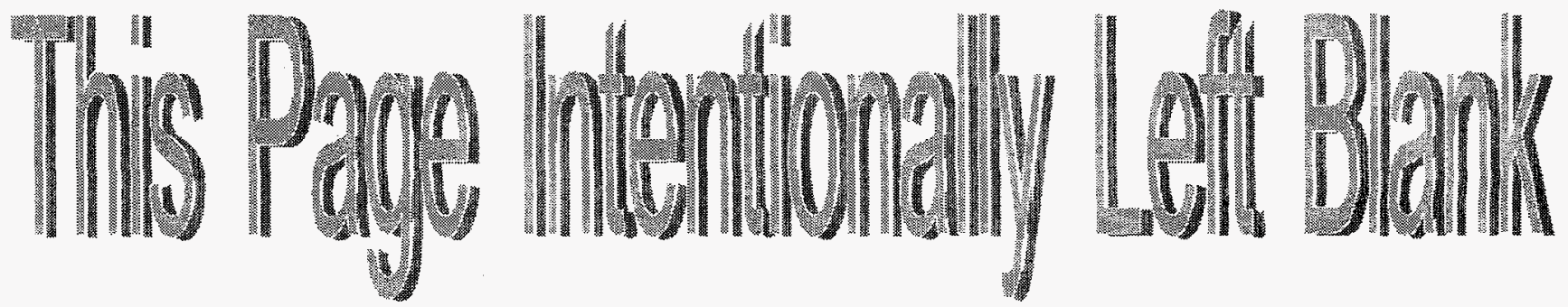
The creation of a Government-owned Regional Reserve of distillate (or heating oil) has been proposed as a solution to the costly but infrequent regional distillate supply problem that has occurred in the Northeast. This chapter examines the frequency and size of this potential supply problem and provides an estimate of the benefits of a Distillate Reserve to the Northeast and to the nation.

\section{ANALYTICAL APPROACH}

\section{Regional Reserve Options}

The report examines two potential sizes for the Reserve, 6.7 million barrels $(\mathrm{mmb})$ and $2 \mathrm{mmb}$. The larger size was based on the estimated incremental demand associated with the severe December 1989 weather. For each, three alternative sites and strategies were considered:

- Constructing Government owned and operated above-ground storage in New England--This was the highest cost option, because there is little available commercial storage in New England. It was assumed that this option would not be available until the year 2005 due to purchase, permitting and environmental regulatory delays.

- Leasing commercial storage in New York/New Jersey area--It is likely that $2 \mathrm{mmb}$ of available storage could be found readily, and $6.7 \mathrm{mmb}$ with somewhat more effort.

- Adapting available underground Strategic Petroleum Reserve (SPR) caverns to store distillate-This is the cheapest option overall, but front-end fixed costs are incurred that are independent of the size of the product reserve.

A release of supplies from a Gulf Coast product reserve probably would lower spot prices just as rumors of shipments from Europe lower prices long before they arrive. But it is less clear whether consumer prices would fall significantly until supplies physically enter northeast markets. For this reason, the study also considered a hybrid option of a $2 \mathrm{mmb}$ inventory stored in leased facilities in the Northeast with $4.7 \mathrm{mmb}$ stored at Gulf Coast SPR sites. The in-place $2 \mathrm{mmb}$ part of the reserve is roughly sized to accommodate the needs of the Northeast States while follow-on supplies take the 710 day trip by water from the Gulf SPR storage site.

Finally, because the study found that RPPR drawdown policy was a significant factor in assessing its benefits, and to a lesser extent its costs, two drawdown policies were analyzed in order to place bounds on the benefit/cost relationships. The first was one that would limit reserve drawdown volumes to cap prices at a pre-determined level somewhat higher than normal, while the other would drawdown all the oil in the reserve.

The U.S. Department of Energy has examined the nature of the Northeast distillate supply problem and concluded that it is likely to be almost entirely a weather-related problem in which a surge in regional demand leads to a supply shortfall. It is unlikely to be a petroleum-import-supply problem.

Historically world petroleum supply problems have been primarily crude oil supply problems, not distillate or heating oil supply problems. World crude oil price increases do lead to an increase in the distillate price in the Northeast, but such distillate price increases could not be reduced through the use of a Regional Distillate Reserve except to augment the existing Strategic Petroleum Reserve. Crude 
oil-related supply or price problems are best addressed through drawdown of the existing Strategic Crude Oil Reserve in the U.S. Gulf.

Aside from potentially augmenting an SPR drawdown, the Department has concluded that a Distillate Reserve's largest benefits would be generated during the simultaneous occurrence of two relatively infrequent events: a very severe one-month cold spell and low inventories accompanied by price backwardation in the world petroleum market. As a consequence, the benefits of a Distillate Reserve can be estimated by calculating:

- The expected size and frequency of winter cold spells;

- The expected frequency of price backwardation in the world crude oil market, (standing in as an indicator of low inventories);

- The effect of simultaneous events, occurrence of a cold spell and low inventories, on prices of distillate in the Northeast;

- The volume of oil released from Government reserves;

- The estimated reduction in the prices of distillate in the Northeast from the drawdown of a Government-owned Distillate Reserve using a ceiling price or a trigger price release strategy; and

- The benefits to the Northeast and to the nation associated with this distillate price reduction.

\section{Size and Frequency of Severe Cold Spells}

The study examined 102 years (1895-1996) of monthly Heating Degree Day (HDD) data and thirteen years (1984-96) of daily HDD data for the Northeast to characterize the historic severity and frequency of one-month cold spells occurring during the November-to-March winter period. The analysis performed in Chapter III concluded that a Northeast regional heating oil supply problem could develop over the period between the onset of very cold weather and the delivery of sufficient incremental supplies of heating oil to meet the incremental demand. Once significant incremental supplies of heating oil begin to arrive, the supply "emergency" is over.

The review of the 1989-90 and 1993-94 heating oil markets in the previous chapter indicated that the length of time before incremental supplies arrive in the Northeast depends on the month in which the cold spell occurs. When the cold spell of December 1989 occurred, additional supplies began to arrive four weeks after prices first increased. When the cold spell of January 1994 occurred, however, some additional supplies began arriving 2.5 weeks after prices surged and continued arriving in aboveaverage amounts for over a month. These events suggest that one month is a reasonable time period to use for an examination of potential supply problems.

Heating oil supply problems develop in the Northeast when the weather is much colder than normal for an extended period. Consequently, the Department's approach for analyzing cold spells was to estimate the mean or normal HDD/day for December through March and to then look at the distribution of the actual minus the mean or normal HDD/day for each of the December, January, February, and March calendar months during the 102-year period. This calculation is actually the same as the deviation in daily temperature relative to normal for each month. Periods much colder than normal then show up as the key periods potentially causing distillate supply problems. Exhibit IV-1 shows the results of this analysis. 
Exhibit IV-1

Temperature Deviations From 102 Year Average by Month

(Negative Numbers indicate colder months)

December

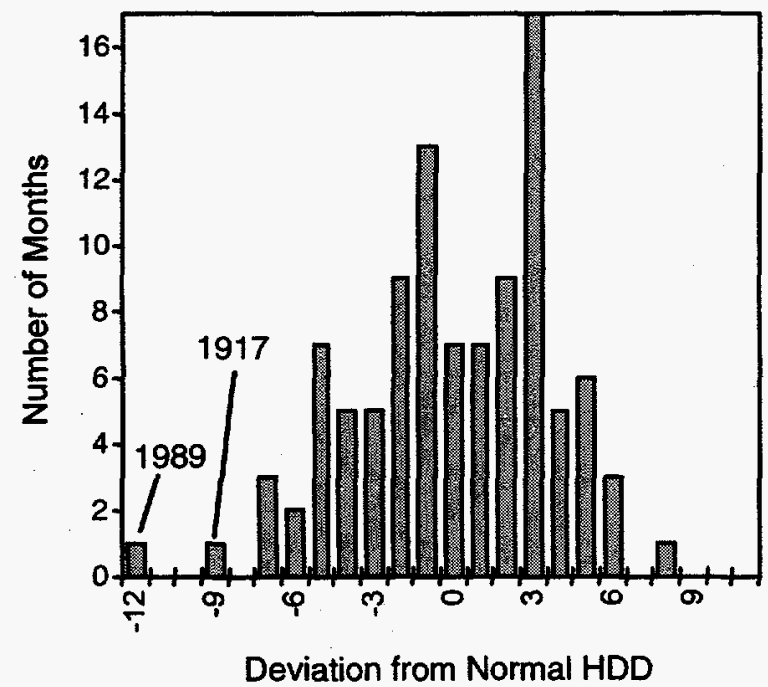

February

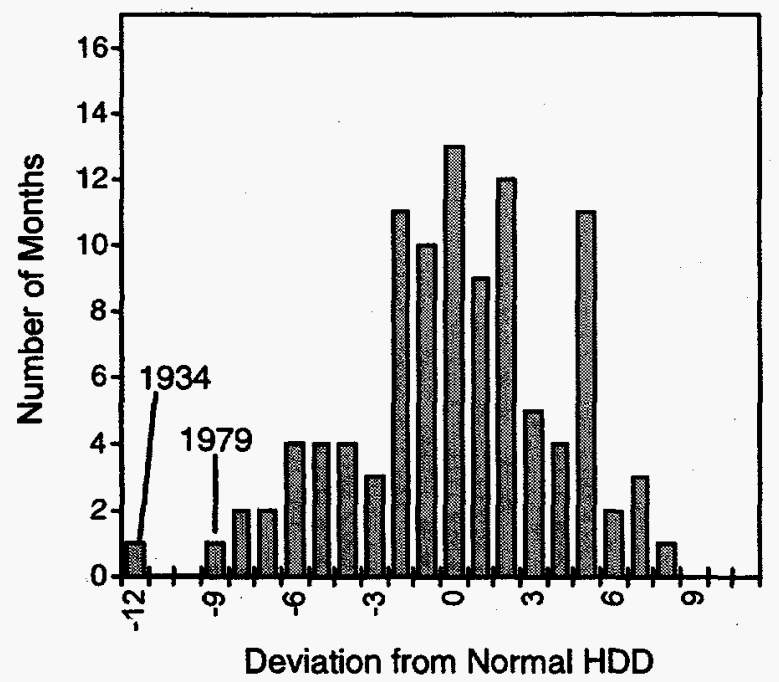

January

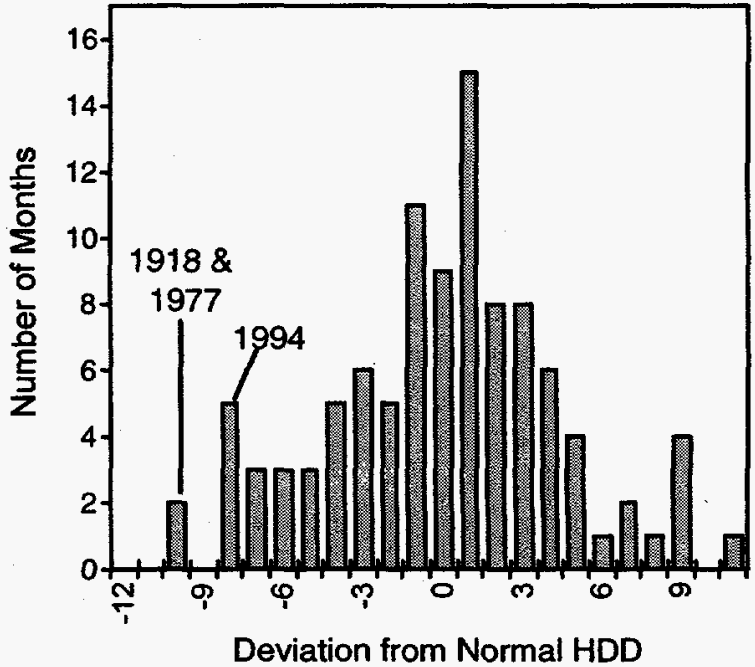

March

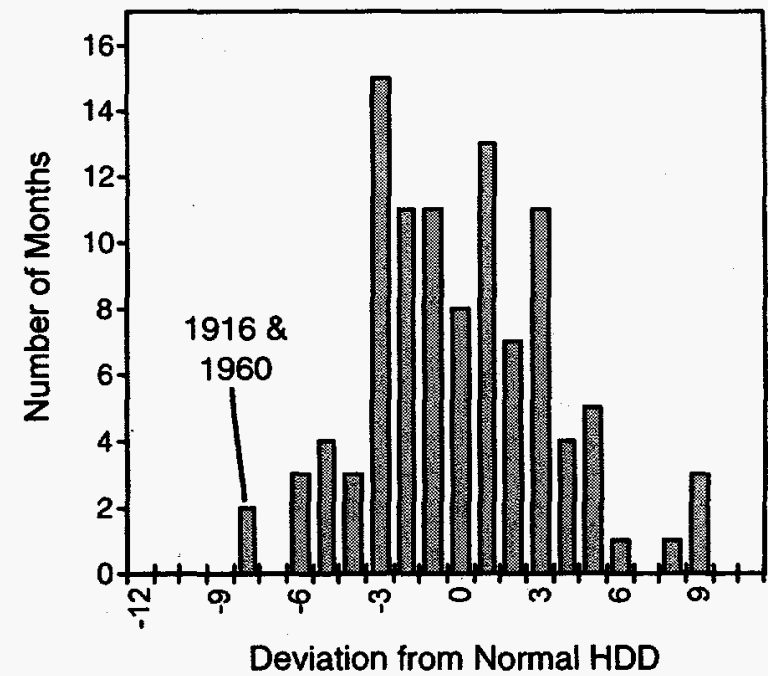

Heating Degree Day (HDD) deviations are obtained by subtracting a month's average daily HDD from the 102 year average daily HDD for that month.

HDD deviations are rounded to the nearest whole number for graphing purposes.

Source: National Oceanic and Atmospheric Administration 
The results indicate that December 1989 was the coldest December of the 102-year period and also the coldest one-month period relative to normal in any winter month. During December 1989 the average temperature was 12 degrees Fahrenheit below normal. There was one other equallyabnormal event in February 1934, but it was no colder relative to normal for February than the December 1989 event.

These statistics suggest that December 1989 and February 1934 were "worst case" events from a weather standpoint. Based on the 1989 event, it is very likely that any regional heating oil supply problem that does occur will be an economic problem caused by heating oil price increases, not a problem of actual physical shortage.

Although the distribution of cold spells in each month, as shown in Exhibit IV-1, is indicative of how cold a one-month event might be, the total number of such events during December, January, February, and March during the last 102 years is an underestimate of the frequency of such events over the entire winter. Additional cold spells occurred across months (e.g., in December-January) that do not look particularly severe within either month. The daily HDD data for the last 13 years were used to create a better statistical estimate of the total number and frequency of 31-day events occurring during an entire winter on an expected value basis. The results of this analysis were compared with the 102 years of data to confirm statistically that no measurable trends have occurred to indicate that deviations from normal are becoming more or less likely.

This analysis provides a distribution of cold spells that looks similar to the distribution shown in each month in Exhibit IV-1. The range of temperature deviation is the same, but the number of cold spells overall per winter is somewhat higher. The results of this analysis are shown in Appendix D. Overall, after taking into account the drawdown strategy discussed below, winter weather is only expected to be severe enough to employ the Reserve about one year in every 10 on average.

\section{Frequency of Low Stocks}

Since formal petroleum price futures markets have existed for only a relatively short time, historic data on distillate market price expectations are much more limited than historic data on weather variations. The analysis in Chapter III focused on petroleum market price behavior over the nine-year, 1988-96 period and showed that low stocks and forward price backwardation tended to occur at the same time.

A review of these data indicates that price backwardation has occurred several times, but only twice (1989-90 and 1996-97) during the period of the year (June-October) associated with normal distillate stock build-up in the Northeast. Additionally, prices showed some tendency toward backwardation during certain months in 1988.

Although price backwardation normally accompanies low primary stocks in the Northeast, it is the low stock levels that are the actual determinant of the potential need for a Governmentowned Reserve. Exhibit IV-2 illustrates the level of primary stocks on October 31st of each year over the 1988-96 period. These data indicate that while 1989 and 1996 were the years with the lowest level of primary stocks, 1988 also had relatively low stock levels. 


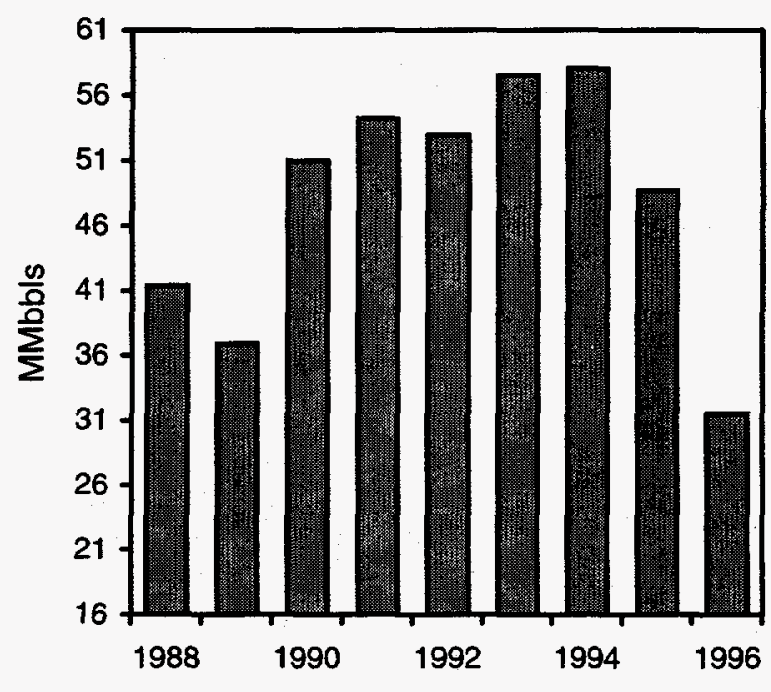

Source: Department of Energy/OGIRS database

The Department has used this information to conclude that the likelihood of low primary stock levels accompanied by price backwardation during the Northeast's normal stock build-up period is three times in nine years or 0.33 in any one year.

\section{Regional Price Increases Caused by Heating Oil Supply Problems}

The study used a weekly model of the dynamics of the winter distillate market in the Northeast. This model permits an analysis of the effect of changes in weather and primary stock levels in the region on wholesale and retail distillate prices. Documentation for this model is provided in Appendix D.

In this model, increases in Heating Degree Days (due to the onset of colder than normal weather) cause a direct increase in the demand for heating oil. In the short-term no additional supplies reach the region, so higher-than-normal demand causes a decline in the region's level of primary stocks. This decline has little effect on regional distillate prices until the level of primary stocks declines to levels significantly below the normal level for each month. Subsequently, as stock levels continue to decline, prices increase very rapidly until additional supplies arrive from outside the region. An increase in the regional price also leads to a reduction in the demand for distillate, but the Department's statistical analysis indicates that this effect is small. ${ }^{11}$

During December additional supplies do not arrive in the Northeast for over four weeks. In the later months, some supplies arrive from the U.S. Gulf after 2.5 weeks, consistent with the level of spare refinery capacity normally available in the U.S. Gulf beginning in January of each winter.

11 The estimated price elasticity of demand on a monthly basis is -0.07 . 
Since the model is calibrated to the market price run-up that occurred in 1989-90, a similar cold spell combined with petroleum market price backwardation will provide a similar price run-up over a period similar to 1989-90. A less severe cold spell will cause a smaller and shorter distillate price increase.

The creation of a Government-owned regional distillate reserve would increase the total amount of primary stocks in the Northeast region, as long as the petroleum industry does not reduce the level of primary stocks it holds by an equivalent amount. Subsequently, when these incremental Governmentowned stocks are made available to the market during a severe cold spell, they would limit the distillate price increase that would otherwise occur.

Exhibit IV-3 illustrates the distillate market dynamics during the severe cold spell that occurred in the Northeast over the November 1989 to January 1990 period. Although this cold spell was unusually severe, the market dynamics during any severe cold spell would be similar.

- The first graph in the exhibit shows the increased consumption of distillate (excluding jet fuel) caused by the abnormally cold weather. The additional consumption increases the cost of heating oil to consumers even if there are no product price increases. This chart does not reflect, however, the additional amount of heating oil consumers would have used had product prices remained unchanged.

- The second graph shows the price behavior for distillate in the New York spot market. The graph shows the normal price, the higher price that typically accompanies low stock years, and the even higher price due to the cold weather and low level of commercial stocks. The dark shaded area in the graph shows the portion of the price increase that could be reduced by the operation of a government-owned reserve set to a particular price ceiling. Also evident is the light shaded area in the graph that indicates the portion of the price increase that would not be reduced by use of the Reserve under that release strategy.

- The third graph shows the weekly consumer bill for distillate, including the portions of the total bill related to the various components of the distillate cost increase occurring due to the cold spell. These components include the cost due to higher consumption of heating oil, the price increase not affected by the Reserve under a ceiling price strategy, and the price increase that could be affected by the Reserve using ceiling price release. With a ceiling price strategy, only the increment of the total increase in the consumer's bill would be limited by the creation of a Reserve. The chart does not include additional costs that would be borne by consumers of jet and diesel fuel as the costs of those products rose with heating oil prices.

The amount of the total consumer bill that could be reduced by a Government-owned Reserve would depend on the characteristics of the particular winter event, the conditions set for the use of the Reserve, and the size of the Reserve. The conditions set for use of the Reserve are a key element in its analysis because they are crucial in determining both what the benefits would be over time and consequently how large the Reserve should be.

\section{Appropriate Conditions to Trigger the Reserve's Use}

The oil industry already maintains commercial stocks as part of a cost-efficient strategy of supplying Northeast distillate customers during a normal winter. The purpose of a Government-owned Reserve would not be to replace commercial stocks in the region. Nevertheless, if the Reserve had rules of operation that indicated it would be used frequently, it might lower the oil industry's estimates of the winter requirements for its distillate (and the likely price received for sales of its distillate), which would lead to a reduced level of commercial stocks in the region. 
Exhibit IV-3

Components of the Increase in Consumer Distillate Costs

in 1989-1990

No.2 Distillate Consumption

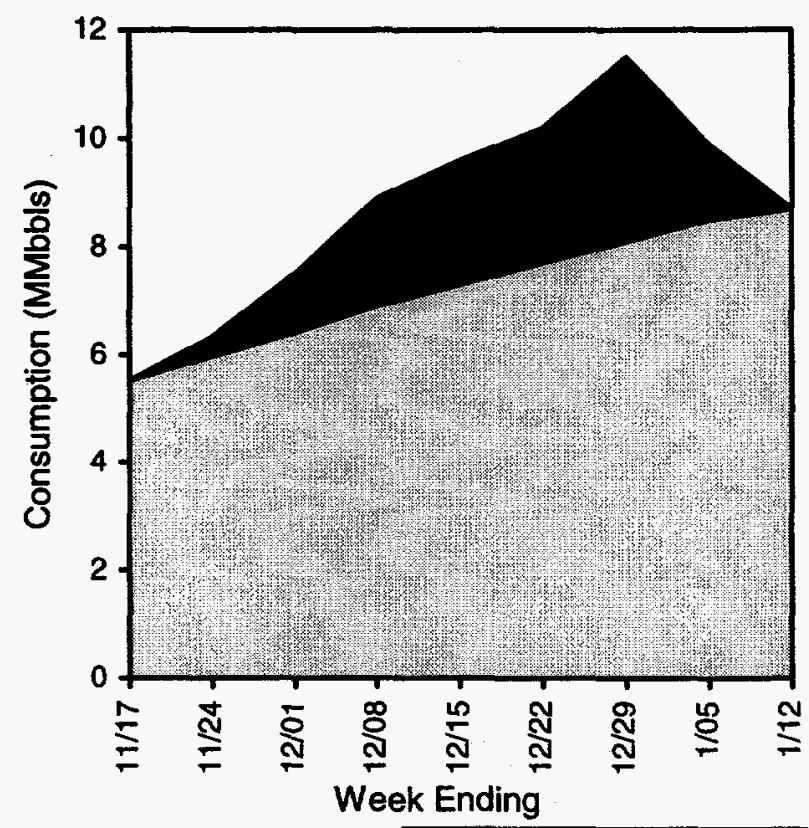

Wholesale Fuel Oil Prices

(1996\$)

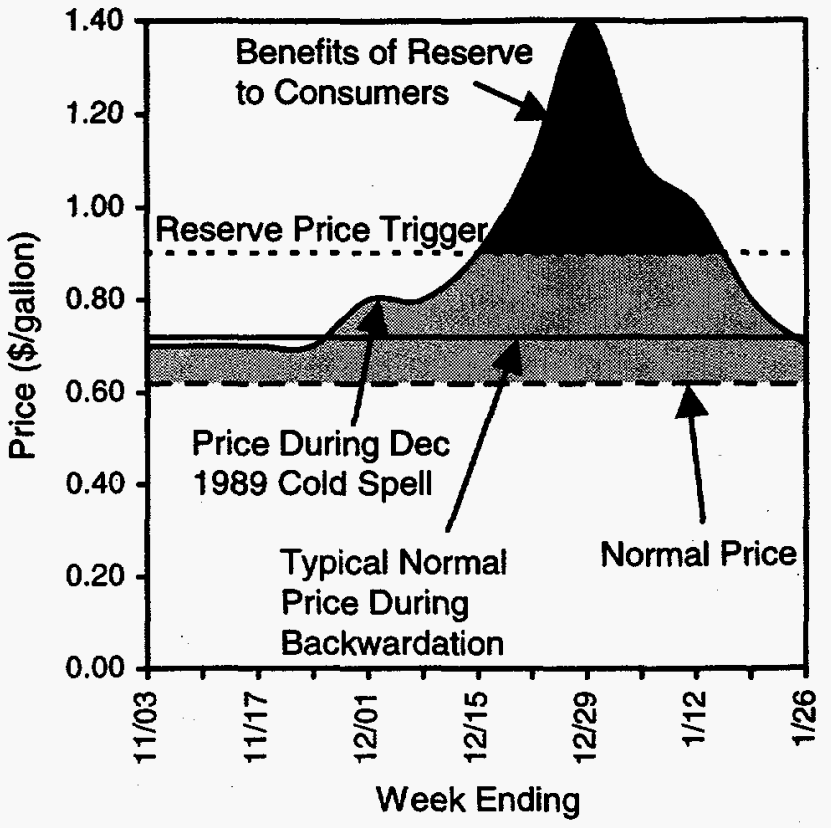

Normal Due to Cold

No.2 Distillate Expenditures

(1996\$)

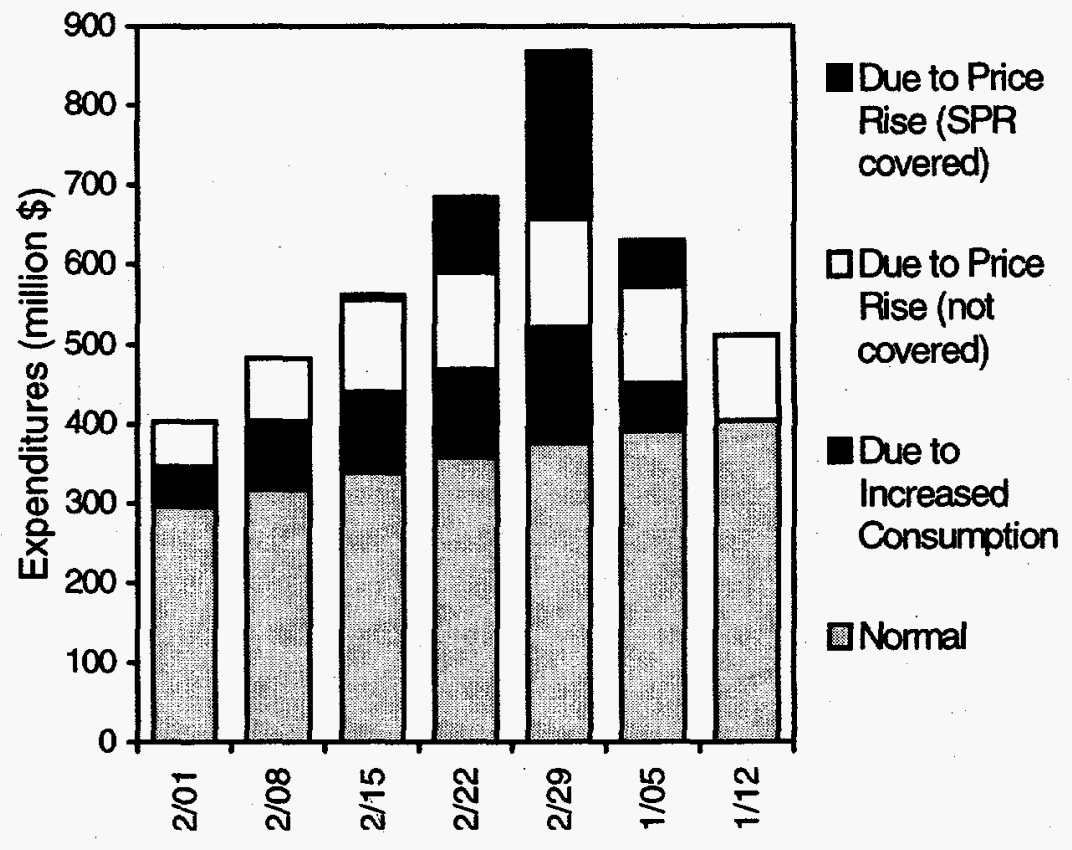


It is not the intent of the U.S. Department of Energy to create Government stockpiles of petroleum to compete with the commercial sector for sales under normal conditions. For this reason, the conditions specified for use of the Distillate Reserve would be formulated to ensure it would be used only during supply emergencies. To meet its objective of preventing significant price increases, the Distillate Reserve would have to be established with a drawdown trigger mechanism designed to meet the following criteria:

- The Reserve would be used only during a regional fuel oil shortage.

- The Reserve would be used to limit heating oil price increases due to extreme periods of winter weather.

- The release of the Reserve could not be triggered by heating oil price escalation caused by a world crude oil price problem. This would not rule out, however, a coordinated release with the SPR during a national or worldwide energy emergency.

In addition, to meet its objectives the Reserve would have to be viewed by the public as a dependable supply source during an emergency. Price speculation could be prevented only if the public had confidence that the Government's Reserve would be made available and that supplies would enter the Northeast distribution system in time to prevent any potential shortages. For this reason, it would be desirable for the conditions for use of the Reserve to be pre-specified and made public. To evaluate the economic effects of a potential Reserve in this report, the following assumptions about the publiclyannounced conditions for its use have been made:

- First, given that a normal winter price for distillate is $\$ 0.55-0.60 /$ gallon, the minimum price trigger was assumed to be $\$ 0.80 /$ gallon. Although this is a crucial parameter, $\$ 0.80 /$ gallon is an arbitrary choice, and, in the interest of limiting the size of the study, no range of release prices was investigated.

- Second, to ensure that the Reserve would not be drawn down in response to a crude oil supply problem, the release price would also include a minimum margin between the price of fuel oil and WTI crude oil on the NYMEX. Given that typical winter margins are $\$ 0.10-0.15 /$ gallon, the trigger was assumed to be $\$ 0.30 /$ gallon. This margin would be exceeded only during a true shortage of fuel oil (either regional or worldwide).

- Third, since the benefits of the Reserve are dependent on its prompt use during the period that commercial stocks are unavailable, it was assumed that buyers would be prequalified and would be able to acquire distillate up to the amount stored in the Reserve as long as they were willing to pay the pre-specified minimum price and/or margin.

Practical procedures for accomplishing these objectives are discussed in Chapter V.

The effectiveness of the reserve obviously depends on how much oil is released. Therefore, for modeling purposes, it is necessary to make assumptions about drawdown termination. These were embodied in two separate cases:

- In the first, termed the "ceiling price" strategy, the drawdown was assumed to cease when prices stated to fall below the level at which use of the reserve was initiated (i.e., $\$ 0.80$ per gallon). That is, prices are not returned by the reserve back to the pre-emergency level. This case probably puts a lower bound on benefits that are calculated for the product reserve. 
- The other release policy, termed the "trigger price" strategy, is aimed at establishing a high-end bound on benefits. It assumes that each time a reserve is triggered by high prices $(\$ 0.80$ per gallon), the entire reserve is sold. In this case, prices would be taken lower than the inflated trigger level. ${ }^{12}$

Although these assumptions are illustrative, the Department believes they provide a reasonable basis for calculating the range of benefits of a Government-owned Distillate Reserve.

\section{Potential Consumer Benefits of a Distillate Reserve}

The use of a Government-owned Distillate Reserve in the Northeast would provide benefits to consumers in the Northeast and to the Nation. Some of the gains and losses, however, are transfers between different sectors of the economy. These gains and losses are real enough to the sectors receiving them, but from a larger perspective do not have much of an effect on the overall economy. For example, to some degree distillate price reduction benefits to consumers in the Northeast are a reduction in profits to U.S. suppliers outside the Northeast. For this reason the calculation of the Distillate Reserve's overall benefits must be largely based on an examination of how changes in distillate prices affect the regional and national economies.

Since the effect of price reductions on distillate demand is relatively small, the principal direct effect of price reduction is to transfer income from distillate suppliers to distillate consumers. Because most of the distillate supply comes from domestic sources this wealth transfer is neutral if viewed from the perspective of the whole United States unless different weights are placed on welfare benefits of consumers and producers or people in primarily-consuming regions versus people in primarilyproducing regions. Nevertheless, the consumer gains are of interest to policy makers, so consumer savings are reported separately.

Appendix $D$ describes the details of the model used to evaluate Reserve benefits, and Exhibits $D$ 15 through D-18 list in detail the benefits that would occur from using the Distillate Reserve in specific circumstances. The model predicts that in most years the Reserve would not be used. At the other extreme is the rare event such as December 1989 during which very cold weather arrives when inventories are very low. In a repetition of that particular case, both the ceiling price and trigger price release strategies yield the same results. The model results shown in Exhibit D-21 predict a drawdown of 6.7 million barrels of the Distillate Reserve, and a price suppression of $\$ 0.21$ per gallon. In that event consumers throughout the region, whose overall consumption would be approximately 2 million barrels of distillate oil per day would have their bills reduced by $\$ 500$ million over the course of the winter.

\section{Components of the Reserve's Benefits}

The study used a whole economy or macroeconomic approach to computing benefits. This approach was used previously to evaluate the benefits of the Strategic Petroleum Reserve crude oil inventory. In this approach, the benefit of the Reserve is considered to be the national benefit of maintaining economic activity that might otherwise be lost due to a price shock, and the money saved from reducing the cost of imports (terms of trade effect). In such a framework, the Government's "profit" selling the distillate at prices higher than its purchase price are treated as a negative cost.

12 Examination of model runs indicates that it is unlikely that prices would be lowered below the normal seasonal levels under this assumed strategy. 
In previous analyses of the effect of crude oil supply disruptions, economists concluded that an oil price shock of significant magnitude and duration can affect the economy in an adverse manner. An interagency group of Government economists concluded that a percentage increase in the price of crude oil can lead to a smaller percentage decrease in the level of national GNP with a ratio of $0.021 .^{13}$

While it may seem that a short price shock would have virtually no effect on the economy, studies of world oil price stocks have shown that stocks as short as one quarter in length do have substantial effects. However, most weather-related distillate price increases are likely to be much shorter in duration than the oil supply disruptions used to estimate the effect of oil price increases on U.S. GDP. For the purpose of this report, the study used the -0.021 GDP to crude oil price elasticity to estimate the potential GDP benefits from a Distillate Reserve, explicitly recognizing that academic work has not endorsed any specific relationship between product price changes and the GDP.

The proportion of distillate supplies to the Northeast provided by foreign refiners is a key component of the calculation of the terms-of-trade benefit of the Reserve. A review of normal distillate supply data for December and January of the 1986-96 period indicated that about 22 percent of distillate (excluding jet fuel) is imported. During winter cold spells the proportion of imports rises, particularly during December events. During the 1989-90 cold spell, distillate (excluding jet fuel) imports rose to 31 percent of total supplies.

Not all price increases associated with official imports of distillate would necessarily transfer out of the country. Some "imports" are supplied from the U.S. Virgin Islands, and other imports are provided by U.S. oil companies. In addition, most cold spells are smaller than the 1989-90 event, so the share of imports would be smaller than during the 1989-90 period. For the purpose of the analysis in this report the Department assumed that 25 percent of all consumer price savings in the Northeast due to a Distillate Reserve would be a terms-of-trade benefit. Again this estimate of the benefits is likely to be an upper bound.

Benefits were first calculated in 1996 dollars for a notional year near the present, then they were weighted with the appropriate probabilities to obtain an expected annual benefit. The result was then assumed to represent the expected benefit stream over a 20-year operational life of the reserve. A discount factor of 7 percent (real) was applied to calculate the present value of this time series of benefits. ${ }^{14}$

\section{Benefits of the Reserve in 1989--An Example}

While in most years the reserve would not be drawn, some years it would have a large value. Appendix $\mathrm{D}$ provides an example of calculations of the benefits that would be attributed to the reserve had it existed in the severe winter of 1989. The study found that, if a ceiling price release strategy had been pursued in 1989:

- The preservation of economic activity attributable to drawing down a reserve of 6.7 million barrels of distillate would be about $\$ 686$ million;

- The terms of trade benefit would be about $\$ 106$ million;

13 U.S. Department of Energy, Energy Security, A Report to the President of the United States, March 1987, p. C-9.

14 A 7 percent real discount rate is prescribed for use by the Government by the Office of Management and Budget. 
- The Government would make a profit of $\$ 46$ million from drawing and selling the distillate (equating to $\$ 0.167$ per gallon); and

- Consumer savings, including reductions in jet fuel, would total $\$ 425$ million.

The first and second items are normally added together and displayed as national economic benefits (even though they derive from lowering regional prices). Here they total $\$ 792$ million (all figures are in \$1996). In this study, the third item is treated as a return to the Government of some of its investment costs. That is, it is accounted for as a negative cost. As discussed earlier, the last item is normally viewed as a transfer between sectors of the domestic economy. It is reported separately because it is of importance to consumers and producers, but it is not considered to be additive to the national economic benefits above.

The Reserve is unlikely to be used to respond to cold spells occurring in March due to the ability of U.S. Gulf refiners to respond to incremental demand for distillate at that time. The most substantial cold spells with the largest price impacts are likely to occur in December, and the maximum size of the Reserve would be one able to deal with a repeat of the 1989 event. Under a ceiling price release strategy, this would require a reserve of 6.7 million barrels to achieve the goal of keeping distillate prices no higher than the ceiling price. Although a reserve of such size is likely to have substantial benefits, the study found that it is unlikely to have as large net benefits as a smaller size. ${ }^{15}$

\section{EXPECTED BENEFITS OF THE RESERVE}

The above example displays single-year results that would be expected in a severe winter emergency. In order to obtain an estimate for multi-year benefits and to correctly represent the statistical distribution of weather severity a number of additional calculations must be made. The most significant are the probability that an emergency would occur that requires the use of the reserve and the probability that stocks are low at that time. These two events are treated as being independent, leading to multiplication of their probabilities. With a one-in-ten chance of severe weather causing a price increase of the type modeled here, and a one in three chance of having low stocks at that time, one sees that there is only about 3 percent chance that the reserve would be used in each year. That is, in accumulating the expected benefits, the yearly benefits given a drawdown of the reserve are effectively multiplied by 0.03 .

\section{Findings}

This section addresses the quantitative findings of the study regarding the benefits of a regional petroleum product reserve. All benefits are displayed in 1996 constant dollars discounted at 7 percent. As noted earlier, it would take a number of years to permit and construct a reserve site in New England. This study assumes that such a reserve, regardless of its size, would not go into operation until the year 2005, after which it would be available for 20 years. To put the other concepts on a comparable time basis, their implementations were delayed until 2005 also. Other than these considerations, results were calculated for a generic reserve assuming that the level of impact of release of the oil would be independent of the reserve's location.

Exhibit IV-4 lists the benefit components for the three siting options under both drawdown strategies. For convenience, the two components of the national economic benefits are added together. Government profits from emergency sales are reported as negative costs in Chapter 5.

15 Although a smaller Reserve would have slightly lower absolute benefits, it would have a higher expected benefit/cost ratio since its cost would decline in direct proportion to size. 
Exhibit IV-4

Benefits Estimates for a $6.7 \mathrm{mmb}$ Reservea

(Millions of \$1996)

\begin{tabular}{|l|c|c|c|c|}
\hline \multirow{2}{*}{} & \multicolumn{2}{|c|}{6.7 mmb Reserve } & \multicolumn{2}{c|}{$2.0 \mathrm{mmb}$ Reserve } \\
\cline { 2 - 5 } & $\begin{array}{l}\text { Consumer } \\
\text { Savings }\end{array}$ & $\begin{array}{c}\text { National } \\
\text { Economic } \\
\text { Benefits }\end{array}$ & $\begin{array}{c}\text { Consumer } \\
\text { Savings }\end{array}$ & $\begin{array}{c}\text { National } \\
\text { Economic } \\
\text { Benefits }\end{array}$ \\
\hline $\begin{array}{l}\text { Regular } \\
\text { (Ceiling Price) } \\
\text { Drawdown }\end{array}$ & 28.5 & 39.7 & 24.5 & 34.0 \\
\hline $\begin{array}{l}\text { Full } \\
\text { Drawdown }\end{array}$ & 98.7 & 136.1 & 38.0 & 52.9 \\
\hline aFor a 20-year life time with annual benefits discounted at 7 percent per year. \\
\hline
\end{tabular}

The $6.7 \mathrm{mmb}$ case was initially thought to be the single most important case to study, because it would provide protection against the severest winter in 100 years. However, under the ceiling price drawdown strategy, which assumes only enough distillate is sold to keep prices at the already inflated trigger price level, on average, only one-fifth of the reserve was used per emergency. This led to consideration of the $2.0 \mathrm{mmb}$ reserve. Under the assumption that the Reserve is fully drawndown when price reaches a certain level, the benefits of a $6.7 \mathrm{mmb}$ reserve would rise sharply because on average five times more oil would be sold.

Exhibit IV-4 shows the extent to which the $6.7 \mathrm{mmb}$ RPPR is oversized if the more conservative drawdown strategy is employed. The incremental gain in benefits over the smaller reserve only amounts to about 14 percent even though the size of the reserve triples in going from 2 to $6.7 \mathrm{mmb}$. While the larger reserve would address the severe, but rare, events, in most cases a $2 \mathrm{mmb}$ reserve would be just as effective. With a more aggressive, and market intrusive, drawdown policy, the larger RPPR would have much more capability to bring market prices down, thereby raising its "benefit" as calculated in the study. Under this policy, the increase in benefits more closely parallels the expansion in size.

As noted above, consumer costs savings are separate from the macroeconomic benefits described above because they are viewed by economists as financial transfers within our economy from consumers to the oil industry. Changes in these benefits are similar to those for national economic benefits since both are proportional to the price impact that a reserve would have. It should be noted that "consumer savings" include savings not only in residential heating oil, but also in diesel fuel, kerosene and jet fuel sold in the Northeast because these products rise along with heating oil when a winter emergency occurs.

\section{OTHER CONSIDERATIONS}

\section{Collateral Price Impacts Outside of the Northeast}

This study and report are oriented to weather related events that increase the price of distillate fuel in the Northeast, and the calculation of the expected benefits from building a reserve to mitigate a price rise in the Northeast is limited to the impact on the Northeast. In reality the dynamics of the supply industry are such that the release of the Government reserves whether in New England, New York or 
on the Gulf Coast would reduce prices everywhere in PADDs I, II, and III, with attendant wealth transfers from suppliers to consumers. However, the impact of a Northeast price spike on prices in areas outside of the Northeast and the derivative impacts on the national economy of these price changes is beyond the estimating ability of the available data and models used by the Department for this study, and no quantitative estimate of the GDP or terms of trade benefits outside of the Northeast is included in this study.

\section{Practicality of Release Policy}

With the ceiling price release strategy, benefits are calculated assuming that wholesale prices of distillate are capped at the wholesale level. Within the model it was assumed that sufficient oil would be released to cap the price, but that when market conditions allowed prices to drop below the ceiling price, the regional reserve would close, and no more Government oil would be sold.

As a real life strategy, the ceiling price release is problematic, particularly under current legal authorities governing the release of the Strategic Petroleum Reserve. If prices were very high and the reserve was suddenly opened, demand for the Government distillate may be very intense if the Government was willing to sell at a price lower than the market price. In this case, all of the inventory may change hands in the early stages of the weather event. It would be better for the Government to continually advertise for sale distillate at a price that, adjusted for changes in crude oil costs, equates to a ceiling price determined by legislation or administration policy. Such a procedure would require some legislative adjustment to the Energy Policy and Conservation Act because it currently requires a Presidential declaration of emergency for any type of drawdown.

\section{Sensitivity to the GNP Elasticity Relationship}

In the estimate of national benefits the elasticity of the Gross National Product to the oil price change was adopted from prior work related to oil supply disruptions. For the purpose of this study there was consensus within the Department that the analytic approach of valuing the reserve by its expected ability to preserve gross domestic product during a price spike is appropriate, and also that there has been no recognized academic work done on the quantitative relationship of refined product price spikes to the Gross Domestic Product. In lieu of a directly applicable elasticity, the study team chose to use the elasticity of -0.021 developed from 1987 empirical work on the impact of crude oil disruptions on the national economy. This decision has two implications that flow directly from the assumption. First, distillate becomes directly substitutable for crude oil within the Strategic Petroleum Reserve without any implications for the value of the Reserve during a severe energy supply emergency. Second, recent academic work suggests that the relationship of crude oil price spikes to the GDP was much stronger than the -0.021 elasticity calculated in 1987 . Therefore, in any future analytic work that makes the assumption that crude oil and product elasticities are the same, the expected GDP benefits would be higher than the results reported in this study.

\section{Financial Effect on Residential Heating Oil Consumers of the Winter Cold Spell}

The group within the Northeast that would be affected in the most noticeable way by fuel oil price increases would be home heating oil consumers, particularly if they are low income fuel users. Although the increased cost of fuel oil would depend on the characteristics of the dwelling and the behavior of the household in response to the cold spell, the approximate effect of the cold spell on a typical household can be calculated using average data for the Northeast region.

The 1989 December cold spell lasted about five weeks, but direct effects of the cold spell on the fuel oil market, including the price effects, lasted about seven weeks. According to the Department's Residential Energy Consumption Survey (RECS), the average Northeast household heating with fuel 
oil used 740 gallons of fuel oil in $1993 .{ }^{16}$ With this level of annual consumption, consumption over the seven-week period of the cold spell event would be about 172 gallons.

Exhibit IV-5 shows the estimated effect of the December 1989 cold spell on typical heating oil consumers in the Northeast and the potential effect of a Distillate Reserve. This table indicates that a typical household bill for the seven-week period of the event would have increased by about $\$ 150$. This increase includes the effect of the higher prices due to petroleum market backwardation, as well as the effect of the cold spell itself.

With a ceiling price release strategy, the distillate reserve can offset only a small part of the cost increase affecting the typical household. In the example of the 1989 event, the Reserve could have reduced the $\$ 150$ cost increase to the average household by only $\$ 30$, or 20 percent. This result occurs because the Reserve would not have eliminated additional consumption during the cold snap, nor the higher price level during a low stock year, nor the price increase due to the difficulty of refilling storage tanks under emergency conditions, nor the price increase that occurs before the Reserve trigger conditions are met. However, if the Government used the full drawdown strategy instead of withholding supplies, the consumer savings would increase--perhaps as much as the proportional increases shown in Exhibit IV-4.

Although the typical household experienced a $\$ 150$ increase in heating oil costs during the December 1989 cold spell, some households experienced greater increases, even if they used the aver-e amount of heating oil. The actual cost increase for an individual household depended on the fuel $c$ : Jealer's delivery schedule, the amount of fuel oil provided during a delivery, and the particular pricing program subscribed to by each household and the household's ability or willingness to reduce heating requirements in response to higher prices.

According to a survey conducted by the Fuel Oil News, the typical household in the Northeast has a 275-gallon heating oil tank. ${ }^{17}$ In discussions with fuel oil dealers, the Department has determined that a household with a 275-gallon tank would normally receive about 200 gallons per delivery of heating oil. During the seven weeks of the December 1989 winter cold spell, the typical customer would have consumed 224 gallons of heating oil. This analysis indicates that virtually all consumers would have purchased oil during the period in which prices were reacting to the cold spell. Although the average retail price for the seven-week period was $\$ 1.44 /$ gallon, in one week the retail price reached $\$ 1.65 /$ gallon. If a household received a delivery in that week, they would have paid more for fuel consumed during the seven-week period than the average amount estimated for the typical household in Exhibit IV-5.

16 DOE/EIA-0321(93), Household Energy Consumption and Expenditures 1993, October 1995, P. 52.

17 Fuel Oil News, December 1996, P. 14. 
Exhibit IV-5

Effect of December 1989 Cold Spell on Typical Household Fuel Oil Bill

Ceiling Price Drawdown Strategy

(\$1996)

\begin{tabular}{|l|c|c|c|}
\hline $\begin{array}{l}\text { 7-week Time Period } \\
\text { in December/January }\end{array}$ & $\begin{array}{c}\text { Consumption } \\
\text { (gallons) }\end{array}$ & $\begin{array}{c}\text { Price } \\
\text { (dollars/gallon) }\end{array}$ & $\begin{array}{c}\text { Total Cost } \\
\text { (dollars) }\end{array}$ \\
\hline Normal (1987-96) & 172 & 1.00 & 172 \\
\hline $1989-90$ Price Level & 172 & 1.10 & 189 \\
\hline $1989-90$ Cold Spell & 224 & 1.44 & 322 \\
\hline $\begin{array}{l}\text { Increase above } \\
\text { Normal }\end{array}$ & 52 & 0.44 & 150 \\
\hline $\begin{array}{l}\text { Effect of Ceiling } \\
\text { Price Reserve } \\
\text { Release }\end{array}$ & 0 & -0.13 & -30 \\
\hline
\end{tabular}

RECS data indicate that about 12 percent of all households in the nation using fuel oil were below the poverty line in 1993, and about 21 percent were below 150 percent of the poverty line. Assuming that the national percentages are valid for the Northeast, these figures provide a range of affected households of $\$ 0.8-\$ 1.4$ million. $^{18}$ The total cost increase to these consumers associated with the fuel oil price increase from a December 1989 type event (assuming their household fuel use was average) would have been $\$ 119$ - $\$ 208$ million. Use of the Reserve could have reduced these expenditures by $\$ 24$ - $\$ 42$ million.

18 RECS provides an estimate of 7.4 million households using fuel oil for heating in the Northeast Census region. This estimate combined with the 740 gallons per household provides an estimate of total residential fuel oil consumption that is too high relative to DOE's State Energy Data System (SEDS) estimates and DOE estimates of regional petroleum supplied. Assuming the 740 gallons per household is correct for annual consumption, the number of households would have to be 6.65 million. The percentage of low income customers in the Northeast has been applied to this lower estimate of fuel oil customers to determine the absolute number affected. 

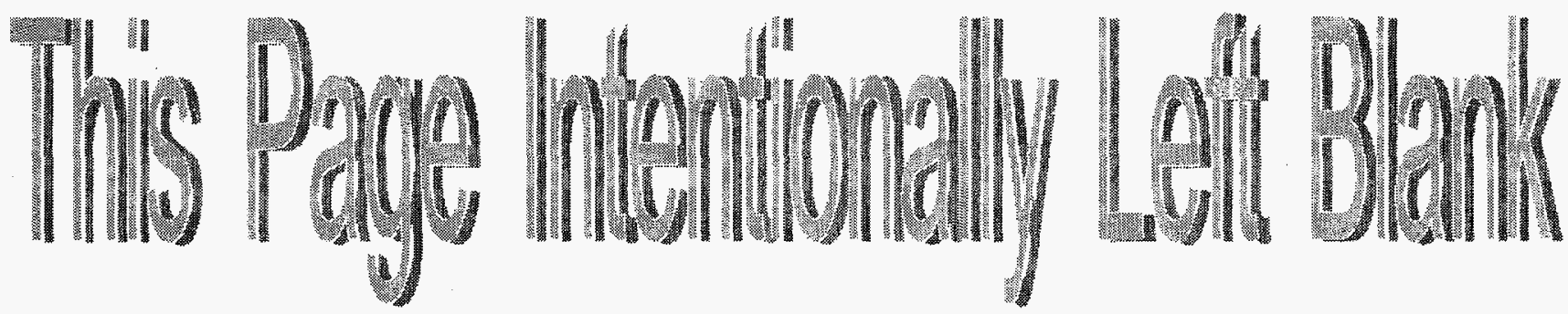
This chapter of the report presents an overview and analysis of two different sizes for the Reserve, five alternatives among those sizes, and the effect on costs of two different release strategies. For a $6.7 \mathrm{mmb}$ reserve, the alternatives are:

- Storage in a Government constructed reserve in New England;

- Storage in government-leased commercial facilities in the New York Harbor area;

- Storage in the Federal Government's existing crude oil storage facilities in the U.S. Gulf Coast; and

- A $6.7 \mathrm{mmb}$ hybrid-storing $2.0 \mathrm{mmb}$ of heating oil in leased capacity in New England while storing the bulk of the Reserve $(4.7 \mathrm{mmb})$ on the Gulf Coast in an SPR cavern.

Options for a $2 \mathrm{mmb}$ reserve are proposed under the same conditions except that a hybrid configuration is not considered.

The larger reserve was chosen to deal effectively with a worst case-a 1989 low stocks extreme cold weather event. The hybrid was picked to increase the responsiveness of the SPR-based concept, albeit at a higher cost. The smaller size, 2.0 million barrels, was chosen to explore the effectiveness of small reserve sizes that are close to the expected drawdown of 1.3 million barrels plus a safety margin of about 50 percent. The expectation is that these sizes will inform and bound the analysis.

The overview analyzes and summarizes the advantages and disadvantages related to each approach under each size. A discussion of the costs is reserved to the end of the chapter where the four approaches and two sizes are analyzed and compared.

\section{LARGE RESERVE SIZE: 6.7 MILLION BARRELS}

\section{Federal Government Owned Storage of $6.7 \mathrm{mmb}$ in New England}

As the data in the previous chapters have shown, a cold weather crisis would be expected to last four weeks or less. ${ }^{19}$ At the extreme, local heating oil distribution systems begin to exhibit stress due to the weather, road and river conditions, and the volume of demand. The best location for a reserve is in New England itself. Emergency heating oil stocks can be provided almost immediately when the combination of weather, market conditions, and demand results in local tightness in the market and a price surge.

The feasibility of long-term leasing of commercial storage space in New England was one of the first options examined by DOE. However, the conclusion was reached that there was not sufficient commercial space available in New England for a Government reserve of 6.7 million barrels. Smaller reserves, however, particularly the 2.0 million barrel approach, either as stand-alone or as part of the hybrid option, fit comfortably within the available capacity of New England. During a normal year (that is a year when prices and stocks are at a normal or anticipated seasonal level) the presence of DOE

19 Setting the time period of the crisis is arbitrary to some degree. If the ceiling price release strategy is used, then the crisis could be defined by the length of time prices are above the ceiling price level. Under the trigger price release strategy and perhaps in the view of many consumers, the length of the crisis is determined by the time it takes prices to return to normal seasonal levels. 
stocks would most likely have little impact on both the capacity available for commercial stocks and the actual levels of these stocks.

Exhibit V-1 shows the 1996-1997 data for commercial storage capacity in the New England states. Of the options considered, only the 6.7 million barrel option (requiring a shell storage capacity of about 7.5 million barrels) would strain New England storage capacity. It is apparent from Exhibit V-1 that even in a year of low stocks, the 6.7 million barrel option would not be easily available without affecting commercial stocks. Further details on New England storage capacities and levels of inventory may be found in Appendix B.

Exhibit V-1

New England 1996-1997 Heating Oil Storage Capacity and Utilization (Barrels)

\begin{tabular}{|c|c|c|c|c|c|}
\hline $\begin{array}{l}\text { FACILITY } \\
\text { LOCATION }\end{array}$ & $\begin{array}{l}\text { NUMBER } \\
\text { OF } \\
\text { TERMINALS }\end{array}$ & $\begin{array}{l}\text { SHELL } \\
\text { STORAGE } \\
\text { CAPACITY }\end{array}$ & $\begin{array}{l}\text { SHELL } \\
\text { FUEL OIL } \\
\text { CAPACITY }\end{array}$ & $\begin{array}{l}\text { MAXIMUM } \\
\text { SEASONAL } \\
\text { FUEL OIL } \\
\text { INVENTORY* }\end{array}$ & $\begin{array}{l}\text { AVAILABLE } \\
\text { CAPACITY** }\end{array}$ \\
\hline Connecticut & 34 & $14,915,124$ & $8,226,024$ & $4,600,000$ & $2,800,000$ \\
\hline Maine & 14 & $9,986,053$ & $2,058,500$ & $1,800,000$ & 52,600 \\
\hline Massachusetts & 21 & $16,250,165$ & $5,540,700$ & $4,800,000$ & 186,600 \\
\hline NHNT & 6 & $3,465,711$ & $2,260,700$ & $1,542,000$ & 492,600 \\
\hline Rhode Island & 9 & $5,762,136$ & $2,99,217$ & $1,670,000$ & 309,300 \\
\hline TOTAL & 84 & $50,379,189$ & $20,285,141$ & $14,412,000$ & $3,841,100$ \\
\hline \multicolumn{6}{|c|}{$\begin{array}{l}\text { *Equal to maximum amount of distillate inventory between } 1992-93 \text { and Nov. of } 1996-97 \text {, on a monthly } \\
\text { basis. } \\
{ }^{\star \star} \text { Assumes usable capacity is approximately } 90 \text { percent of shell capacity }\end{array}$} \\
\hline
\end{tabular}

For the 6.7 million barrel option based in New England, DOE would have to design and build new storage facilities. Based on analysis of New England's ports and their fuel oil markets, the optimum configuration for the Reserve would be to build three separate 2.5 million barrel storage facilities, one in the port of New Haven, Connecticut, one in the port of Boston, Massachusetts, and one in the port of Portland, Maine.

Each of these storage facilities would consist of five 500,000 barrel capacity fixed roof tanks. Rather than build a new marine terminal, the storage sites would be linked to existing port facilities for fuel oil via tankers or barge. In addition, each site would be equipped with a 16 truck loading station.

The major issues related to the 6.7 million barrel option are environmental and cost. The full costs and conceptual engineering designs for this option can be found in Appendix E. A summary and analysis of the costs can be found in the last section of this chapter.

\section{Advantages of Building a 6.7 Million Barrel Reserve in New England}

There are a number of possible advantages to government owned storage in New England:

- Since the heating oil problems are most acute in the New England area, by having the Reserve located in this area the Reserve would be in a position to respond rapidly to any heating oil crisis. 
- By situating the components of the Reserve where there will be access to road transportation and local barge transportation DOE avoids the problem of product tanker availability at the height of the heating oil season, as well as time and distance constraints.

- The presence of a Government Heating Oil Reserve in New England, which can be used in a crisis, would dampen radical price escalation due to anticipation of a shortage.

\section{Disadvantages of This Option}

There are, however, a number of disadvantages to this option which can be categorized as cost and environmental concerns.

- The cost of constructing three Government storage facilities in New England would be very high. Actual implementation, including all the required permitting, environmental requirements, and construction, would be subject to Government procurement procedures and construction requirements and would likely take approximately seven years before fill. This is discussed in more detail at the end of the chapter and in Chapter VI.

- In addition, this option raises substantial environmental concerns. Under the National Environmental Policy Act (NEPA), construction of new Government-owned storage capacity would require an Environmental Impact Statement (EIS) which would take at least 24 months, including initial coordination with the host state and public scoping.

- Impediments to permit acquisition vary significantly among the states according to differences in their respective coastal management programs. Connecticut's Coastal Management Act specifically disallows siting within the coastal boundary of new tank farms or other new fuel or chemical storage facilities which can reasonably be located inland. If a facility must be in the coastal boundary, it must abut existing facilities or be in an industrial urban area. On the other hand, in Massachusetts, if neither dredging or new construction is involved, permit acquisition is mainly a task of coordination and the state's role is primarily advisory. In fact, the state and local governments would likely be supportive of a proposal to reactivate a dormant facility for waterdependent activity.

- Another environmental concern centers around air emissions related to storage tanks. Storage tanks containing petroleum products are emission sources of volatile organic compounds (VOCs) and organic compounds categorized as hazardous air pollutants (HAPs). The three localities that are under consideration as potential storage sites are all classified as nonattainment regions under the ozone National Ambient Air Quality Standards (NAAQS), and in one case under the particulate NAAQS, as shown in Exhibit V-2.

\section{Exhibit V-2}

NAAQS Attainment Status for Proposed Heating Oil Storage Tanks Sites

\begin{tabular}{|l|l|}
\hline City, State & Nonattainment Status \\
\hline New Haven, Connecticut & $\begin{array}{l}\text { Serious Ozone Nonattainment Area, Moderate } \\
\text { PM10 Nonattainment Area }\end{array}$ \\
\hline Boston, Massachusetts & Serious Ozone Nonattainment Area \\
\hline Portland, Maine & Moderate Ozone Nonattainment Area \\
\hline
\end{tabular}


- The proposed storage sites will each consist of five vertical fixed roof tanks with a shell capacity of 500,000 barrels each. The total estimated annual emissions from the storage tanks are summarized below in Exhibit V-3 by area:

Exhibit V-3

Estimated Emissions

\begin{tabular}{|c|cc|}
\hline Location & Pounds/year & Tons/year \\
\hline New Haven & 2,955 & 1.48 \\
Boston & 2,758 & 1.38 \\
Portland & 2,432 & 1.22 \\
\hline
\end{tabular}

The emissions estimated above are conservative for typical operating conditions. A number of the national air permitting programs evaluate whether or not a project violates the emission threshold by the "potential to emit." Since the potential to emit would be much larger (an estimated 10.9, 10.7, and 8.7 tons per year respectively) they may be greater than the program thresholds, subjecting the project to the New Source Review program and the Title V Operating Permit program. Should this occur the project may be subject to emission offsets and air quality impact modeling as part of the permitting process.

- In addition, DOE is proposing to build petroleum storage facilities in a region where there has been consistent and considerable community opposition to energy projects that bring high environmental risks. The implicit costs of local opposition and a long drawn out permitting process may be too high.

- Since the product would be stored in aboveground tanks, stability problems require about one-third of the product to be turned over each year. This may be inconvenient or excessively expensive in New England's small petroleum market. (The question of product stability and turnover requirements is discussed in detail in Appendix I.)

\section{Federal Government Leased Storage of 6.7 MMB In New York Harbor Area}

There are a significant number of commercial petroleum storage facilities with available capacity for leasing in the New York/New Jersey area. Although not in the immediate New England region the New York Harbor location is sufficiently close to provide adequate distribution to all New England ports. Marine distribution via barge ranges from 12 hours to Connecticut to 30 hours to Maine.

Exhibit V-4 shows data on available commercial storage capacity that could be leased within the New York/New Jersey Harbor area. The data show that capacities and availabilities are far greater than in New England. 


\section{Exhibit V-4 \\ New York/New Jersey 1996-1997 Commercial Storage Capacity}

(Barrels)

\begin{tabular}{|c|c|c|c|c|}
\hline $\begin{array}{c}\text { FACILITY } \\
\text { LOCATION }\end{array}$ & $\begin{array}{c}\text { NUMBER OF } \\
\text { TERMINALS }\end{array}$ & $\begin{array}{c}\text { SHELL STORAGE } \\
\text { CAPACITY }\end{array}$ & $\begin{array}{c}\text { SHELL FUEL } \\
\text { OIL CAPACITY }\end{array}$ & $\begin{array}{c}\text { CAPACITY AVAILABLE } \\
\text { FOR LEASE }\end{array}$ \\
\hline New York & 2 & $7,363,000$ & $4,217,000$ & $2,350,000$ \\
\hline New Jersey & 7 & $34,144,000$ & $16,444,000$ & $3,750,000$ \\
\hline TOTAL & 9 & $41,507,000$ & $20,661,000$ & $6,100,000$ \\
\hline
\end{tabular}

For the 6.7 million barrel Reserve option, leasing capacity in the New York/New Jersey area would be geographically advantageous and would alleviate the pressure on capacity available to industry for normal stock build in New England. Under this option the Government would lease the full 6.7 million barrels of storage capacity in the New York/New Jersey area and pay the normal commercial rates for the use of the terminals' distribution facilities. The major issues related to this option include cost concerns (possibly transportation) and the impact stability issues would have on product turnover, and thus costs. A summary and analysis of the costs can be found in Exhibit V-5 at the end of the chapter.

\section{Advantages of Leasing 6.7 Million Barrels of Storage Space in the New York Area}

Compared with building 7.5 million barrels of shell capacity in New England, there are advantages to leasing 6.7 million barrels of capacity in the greater New York area.

- Use of existing facilities would have significantly lower cost than new Government constructed facilities as the owners would likely find long-term, relatively secure, storage agreements to be preferable to empty capacity.

- Leasing existing storage in the New York Harbor area would mean that transportation problems in accessing the fuel oil, while not eliminated, would be minimized.

- If existing facilities are available, leasing would permit faster achievement of the storage goals compared to construction of new facilities.

- Lease of existing facilities would also involve fewer environmental issues than new construction. Even lease of new facilities might proceed faster due to private sector incentives.

\section{Disadvantages of Leasing 6.7 Million Barrels of Storage Space in the New York Area}

There are also disadvantages relative to new construction of 7.5 million barrels of shell capacity in New England or use of a Gulf Coast salt dome.

- There is concern about the pressure that would be put on the barge market in the New York Harbor area, particularly at a time when a number of barges would be retired under the Oil Pollution Act of 1990 (OPA90).

- A large public stockholding in the New York Harbor area might put pressure on private storage capacity, thereby raising the price of storage. 
- Because no one site has the requisite capacity, product is stored in various non-contiguous facilities, thus requiring more management, contracting, co-ordination, and administrative efforts.

- Because the product would be stored in aboveground tanks, a clear cost and administrative disadvantage is the necessity of product turnover. (Product stability is discussed in detail in Appendix I.)

Compared with building 7.5 million in shell capacity in New England there appear to be few new environmental issues. Long-term leasing at commercial storage sites by the Federal Government would require an Environmental Assessment (EA) which would take at least 12 months. No circumstances have been identified that would preclude a "Finding of No Significant Impact."

\section{Federal Government Storage of 6.7 MMB in the Existing SPR in the U.S. Gulf Coast}

The SPR has four underground storage facilities in the U.S. Gulf Coast with a combined capacity of 680 million barrels and a current crude oil inventory of 563 million barrels. A portion of this capacity could be used for heating oil storage. The major concern about storage in the U.S. Gulf Coast is the distance from the Northeast. (The hybrid option deals specifically with this concern.) Analysis shows that supplies must begin to arrive in the Northeast within two weeks of the onset of the crisis to present a credible deterrent to ricing prices. Heating oil stored in the SPR in the U.S. Gulf Coast could be loaded on a tanker, reach New England ports, and be discharged in ten days, with a quick response by Government decision makers and absent bad weather at sea.

The 6.7 million barrel option assumes that the Federal Government will convert one of the 10 million barrel caverns at the SPR's Big Hill storage site from crude oil to heating oil storage. The full details of the design adaptations and the attendant costs can be found in Appendix $E$.

\section{Advantages of a 6.7 Million Barrel Reserve Stored in SPR Caverns}

There are obvious benefits to the use of one of the existing SPR storage facilities.

- Adaptation of existing facilities will mean much lower capital and operating costs as well as lower environmental risks and costs.

- With storage in salt caverns there is less of a problem with product degradation, and turnover requirements are projected at roughly every ten years.

- Because the facilities exist, implementation time is only one year, including adaptation time, which is considerably shorter than building a new site.

- There appear to be no incremental environmental requirements under this option. Dedicating an existing storage cavern at Big Hill for distillate storage for a Refined Product Reserve could probably be accommodated within existing NEPA documentation and permits.

\section{Disadvantages of a 6.7 Million Barrel Reserve Stored in SPR Caverns}

Most of the disadvantages relate to distribution issues. Distribution problems center around three factors: the SPR's response capability in moving distillate from the cavern to the docks; dock capability to deal with large volumes of product moving out quickly; and, most critically, tanker availability.

- It will be necessary to keep the local SPR distribution system ready to distribute heating oil rather than crude oil. A major aspect of response capability is the SPR's ability to move the heating oil 
out of the cavern to the docks over a crude oil system in a timely fashion. In general, crude oil disruptions usually do not require instantaneous responses because of the volume of long-haul crude on the water at any given time. This is not true of a heating oil crisis which will require a very fast response. The engineering design adaptations shown in Appendix $E$ estimate approximately two weeks to clean the lines before switching from crude oil to heating oil. Since product should begin arriving in the Northeast within two weeks, and at least ten days will be necessary for shipment, the only way for this option to be viable would be to maintain heating oil in the lines only switching back to crude oil when necessary. The study includes this requirement in its cost estimates.

- Although the average drawdown of a $6.7 \mathrm{mmb}$ reserve is estimated to be only $1.3 \mathrm{mmb}$, a severe emergency requiring the entire reserve might take 19-28 days to accomplish. At the Unocal terminal in Nederland, crude oil received from Big Hill is moved through the terminal to the surge tankage and dock through lines dedicated to crude. Some minor modifications would need to be made to connect the fuel oil system to the terminal's product storage and movement systems. Terminal personnel indicated that, with proper notification, they could possibly make available as much as 500,000 barrels in tankage to support out loading operations. Loading would be accomplished from the main dock, which can service more than one vessel through flexible hoses. While normal out loading rates are in the range of 5,000 barrels per hour, additional pumps are required to boost the rate to $10,000-15,000$ barrels per hour (costs are included in the study). Such pumping rates would allow the fill of approximately one 250,000 barrel vessel per day, assuming the availability of such vessels on a continuous basis.

- A perennial problem is the availability of product tankers at the height of the heating oil season and the constraints of the Jones Act regulations. The availability of sufficient right-sized vessels to assure the continuous movement of product from the Nederland area to New England would be economically precluded without a waiver of the Jones Act, which requires all coastwise movements to be made in U.S.-flag vessels. Without a waiver of the Jones Act, even with plentiful supplies of heating oil available in the U.S. Gulf, the limited number of Jones Act product tankers would cause their charter rates to be bid up, thus offsetting the mitigating effects additional supplies would have on a regional price spike. This was the case in December 1996, when even with a glut of supplies in the Gulf, it was uneconomical to charter vessels to move the product to New England. The availability of a sufficient number of qualified vessels at economical rates must be assured, either through case-by-case or blanket Jones Act waivers.

- Because of the limited time frame in which supplies from a Regional Reserve would be effective in precluding a price spike, and the seven to ten days physically required to steam from the U.S. Gulf to New England, the lead time to begin the flow of vessels must be minimized. Even with an expedited case-by-case Jones Act waiver procedure, such as the one agreed to by Customs, the Maritime Administration, and DOE for crude oil drawdown, up to three days would be consumed in securing a waiver for each particular movement. The uncertainty of waiver approval and the subsequent chartering of a foreign flag vessel, if approved, for each movement is an additional deterrent to the prospective purchaser. This obstacle may reduce the number of purchasers to a level below the necessary minimum to maintain a steady stream of supplies moving out of the Reserve. With a blanket Jones Act waiver announced concurrent with a decision to release the regional stock at Big Hill, prospective purchasers could begin fixing contingent charters with foreign flag vessels already en route to the Gulf area, so that they are ready to begin loading by the time the supplies are available at the terminal.

- An additional concern about transportation from the Gulf Coast, whether by Jones Act or foreign flag tankers, is the impact of OPA90 has had in increasing the number of restrictions on single hull tankers. These restrictions, which would in themselves exert upward pressure on tanker rates, 
combined with the fact that tankers would be needed at the peak of the seasonal demand swing, raise questions about the economic and physical viability of this option.

It should be emphasized that the viability of this option depends on the ability of the Government and its potential customers to move product from the SPR site in the U.S. Gulf to New England within two weeks. More importantly, the market has to believe that this is feasible for this option to offset the rise in prices in the Northeast.

It should be also pointed out that the mission of the SPR is to protect the nation against the exigencies of a crude oil cutoff. Should this occur at the same time as a heating oil crisis then the crude problem would take precedence and the heating oil would not be drawn down.

\section{Federal Government Leased Storage of $2.0 \mathrm{mmb}$ In New England and $4.7 \mathrm{mmb}$ in SPR Caverns}

Many of the problems associated with Gulf Coast storage could be alleviated with the creation of a hybrid Distillate Reserve, where two million barrels are stored in a Northeast location and the balance is stored in a Gulf Coast SPR cavern. While this would be feasible, the costs associated with dedicating a cavern to storage in the Gulf Coast would not change because the volume in storage is reduced. Therefore, any volume that is stored in New York leased space may simply be treated as an additive cost to the Gulf Storage option.

\section{SMALL RESERVE SIZE: 2.0 MILLION BARRELS}

A smaller reserve would reduce both front-end and total program costs and would fit better into available capacity than the $6.7 \mathrm{mmb}$ configuration. On the negative side, it might not be large enough to address a very cold month like December 1989. In addition, if storage was in the SPR caverns, not much would be saved on non-oil costs compared to a $6.7 \mathrm{mmb}$ reserve.

\section{OTHER CONCERNS ABOUT THE FEDERAL GOVERNMENT OPTIONS}

\section{Response Requirements and Sales Mechanisms for a Refined Product Reserve}

As the earlier chapters of this report have shown heating oil crises are of very short duration. Government action to mitigate against the surge in prices demands an immediate and rapid response. This will necessitate changes in the current procedures governing the SPR. These changes would be required irrespective of the location of the Reserve.

\section{Current SPR Sales Mechanisms}

DOE has, over time, developed a competitive sales process for the existing U.S. SPR crude oil inventory. The schedule for this process provides for the issuing of a Notice of Sale, i.e., solicitation to industry for offers to purchase SPR oil, receipt and evaluation of offers, receipt of payment and performance guarantees and awarding of contracts - all within about 16 days from a Presidential decision to drawdown the Reserve. Consistent with this schedule, the SPR is maintained in a state of readiness so that it is physically capable of starting the drawdown and delivery of its inventory to purchasers within 15 days of the drawdown decision.

Amendment 4 to the SPR Plan allows for two methods in the sale/distribution of SPR petroleum price competition and "directed" sales. The primary method is through a price competitive sale with contracts awarded to those financially responsible offerors offering the highest prices. Under the secondary option, the Secretary of Energy may direct the distribution of up to 10 percent of the volume sold competitively in a manner that he/she selects. In this case, the price of the oil would be 
administratively fixed based on the average price of the SPR oil sold at the contemporaneous competitive sale.

\section{Shortening the Administrative Delays in the Sales Process}

The existing SPR drawdown and competitive sales process and 15-day readiness posture have proven adequate for distributing crude oil from the Reserve under emergency situations for the Presidentially-mandated sales. While the sales process and the purchasers' arranging of transportation may consume up to three or four weeks before the crude oil will physically arrive at refineries for processing, there is likely to be sufficient amounts of other oil in-transit to refiners which will meet their needs until SPR oil is received.

For the purposes of an RPPR drawdown, however, where the need would be to immediately release product for distribution so as to prevent a dramatic rise in prices for that product, the current SPR drawdown and competitive sales schedule for crude oil would likely be too time-consuming to be effective. This would especially hold true for an RPPR located in the U.S. Gulf Coast where seven to ten days would be added to the schedule to allow for marine vessels to load, transport, and discharge their cargoes.

\section{An Alternative Sales Mechanism}

The alternatives for providing a more immediate RPPR response capability within the existing regulatory competitive sales framework include:

- An emergency sales approach. The SPR would develop Standard Sales Provisions designed specifically for use in a rapid response RPPR drawdown. Various refinements could be adopted which would reduce the sales time. As an example, assuming industry's ability to rapidly respond to a notice of sale of RPPR oil, the current 16-day sales process could be shortened by reducing the time allowed for offerors to prepare and submit their bids from 7 to 3 or fewer days.

- Expedited financial quarantees. An additional day or so could be saved if payment and performance guarantees were demanded after award but prior to any delivery. Currently, receipt of acceptable financial guarantees (normally letters of credit) is a condition for contract award, and offerors are allowed up to 5 business days after being notified that they are successful to arrange and submit their guarantees. Industry has demonstrated, however, that this can be accomplished in 1 or 2 days. With these and other possible enhancements, as well as maintaining an RPPR in a state of immediate readiness, a competitive sales process could be developed which would allow for a contract to be awarded within about 7 days of a drawdown decision. An oil release from the RPPR could then commence as soon as the commercial transportation system could accommodate the distribution.

- A contingent sales approach. In the late summer before the heating oil demand builds up, DOE would solicit competitive offers from product distributors/wholesalers to enter into contingent sales agreements. The offerors would bid a premium/discount against some form of benchmark price, and the successful offerors would execute agreements with the Government which pre-define the necessary RPPR sales terms and conditions for delivery and payment. These agreements, however, would not be effective until there was a decision to drawdown the RPPR. Once there was a drawdown decision, only a couple of days would then be needed for arranging financial guarantees and finalizing quantities and delivery schedules.

Any of these alternatives are potentially viable; however, should an RPPR be established, the options will need to be more thoroughly analyzed to determine which one would better function within 
the petroleum product market, as well as to assure the Government of the purchasers' ability to pay for the oil and to perform under the contract. Of the possibilities, the contingent sales concept would provide the quickest response time. However, it would be the most administratively burdensome because the agreements would need to be re-executed frequently.

\section{Implementing the Sale}

Even after clearing the sale and potential customers as described above, there remains the question of exactly how the oil might be sold. SPR oil sales are implemented by the Defense Fuel Supply Center (DFSC) issuing a "request for bids" (RFB), then evaluating the responses in conjunction with DOE. Such a procedure is similar to the "trigger price" release modeled in this study. DOE would decide that it is going to sell a given amount, then accept all bids up to that amount as long as the bids were in a given market range. Additional RFB's would be issued sequentially until the desired amount was sold. This has been the procedure for the revenue-raising sales made in 1996.

On the other hand, DOE could simply "post" a price that would be available to qualified purchasers. In practice, this price would have to be at or above the market when advertised to avoid runs on the DOE terminals. Assuming that the price was set correctly initially, as the market becomes tighter, DOE would become the incremental supplier at its posted price. This would tend to act as a ceiling price limiting the price run up. Of course, the posted price could be adjusted as the need rises.

The ceiling price concept would also require legislative specification. A margin over a given crude cost could be specified as the initiation price, with automatic authority granted to the DOE to make sales when the margin is reached. This would be controversial in Congress.

\section{Legal Concerns}

DOE has the authority under EPCA to establish an RPPR. However, an RPPR established under EPCA would be part of the SPR and subject to the constraints on drawdown provided in EPCA. Except for limited test drawdown authority granted to the Secretary, a Presidential finding is necessary before the SPR can be drawn down. Under EPCA Section 161(d), the President must find that a drawdown is "required by a severe energy supply interruption or by obligations of the United States under the international energy program." A severe supply interruption is defined as an emergency situation in which there is a significant reduction in supply that results in a severe enough price increase as to have a "major adverse impact on the national economy." In addition, under EPCA Section 161(h), up to 30 million barrels can be drawn down from the SPR if the President finds a circumstance "exists that constitutes, or is likely to become, a domestic or international energy supply shortage of significant scope or duration," and the drawdown will prevent or reduce the shortage's impact.

As mentioned above, under EPCA Section 161(g), the Secretary can authorize a sale of up to 5 million barrels of crude for purposes of continuing evaluation of the SPR Distribution Plan, but there is no mechanism for authorizing a larger sale without a Presidential finding. Consequently, to implement an RPPR and to facilitate a rapid response, particularly if a trigger mechanism is used, legislation may be necessary.

\section{Product Stability and Turnover}

Product stability and shelf life affect the costs of the options since the more frequent the turnover the higher the throughput and administrative costs. Concerns have arisen because of the presence of chemically reactive, and hence unstable, catalytic cracker produced stocks in much of the middle distillate fuel pool. 
The trend in the United States, and increasingly worldwide, toward greater refining complexity to meet the growing demand for light products reduces the proportion of straight-run distillate components. With the advent in the United States of low-sulfur on-road diesel, the quantities of cracked stocks blended to No. 2 home heating oil have increased; cracked stocks from the catalytic cracker, coker, and asphalt plant distillates contribute to fuel oil instability The trend is such that much of No. 2 heating oil is now considered unstable for even short-term storage and shipping. Pipeline companies have reported batches of No. 2 heating oil discoloring in the days that it takes to transit the lines. Shelf life expectancies as short as 3 months have been quoted. Concern in industry is sufficient that a joint industry project is currently being organized to examine heating oil stability issues.

The general consensus is that any fuel produced for long-term storage should not include cracked stocks since olefins react to form sediments. In addition, today's U.S. heating oil contains appreciable sulfur (around 0.25 percent) and nitrogen. These factors, together with present industry operating experience essentially eliminate "standard" No. 2 heating oil from contention as a candidate for longterm storage.

U.S. industry experience is substantiated by the Danish experience. The Danes have successfully stored distillates both above- and belowground for long periods, in some cases as long as 20 years. However, changes in the national product specifications necessitated the complete turnover of the inventory. The original products were all straight run, containing no cracked material. Due to changes in specifications and the increasing complexity of European refining the replacement products all contained cracked stocks. The Danes have found that the replacement stocks do not have the same stability and have to be rotated every one to three years.

The most relevant experience is that of the Germans, who store crude oil, product blend stocks, finished gasoline, and finished distillates/gas oils in salt caverns. The German storage organization, EBV, has reported successful storage of distillates up to 8-and-a-half years and believes that 10-year storage is feasible. However, in order to maximize the life of the gas oil in the caverns, EBV has very strict specifications for the fuel that all tenders must satisfy. These specifications are far stricter than the new European diesel specification, especially in regards to olefins and cracked stock.

A more detailed discussion of these concerns can be found in Appendix I. Nevertheless, it is apparent that if long-term storage is required, heating oil (as it presently exists) is not appropriate. However, should either low-sulfur diesel or a special highly refined diesel be stored, purchase costs would be higher than for heating oil. Offsetting this are the lower costs of less frequent turnover. At drawdown it is not clear whether or not the Department could recoup its costs should it store super refined diesel. If turnover is required it is also not clear what the market reaction would be to highly refined diesel: whether it would be discounted as regular diesel or whether it would be viewed as blend stock. All these factors have to be considered as uncertainties in calculating the costs of the proposed program.

\section{COST ANALYSIS AND COMPARISON}

The detailed costs and engineering designs for the New England and the U.S. Gulf Coast options are contained in Appendix $E$. This part of the chapter offers an overview and compares the costs of the options and release strategies in Exhibit V-5 (shown at the end of the chapter). Costs are further discussed in Chapter VI.

As Appendix $E$ shows, options vary considerably in NEPA requirements, construction requirements, and the time line to implementation. The option with the longest time line is that of a new-build in New England. If the NEPA work began in 1998 the sites would only be ready for fill in 
2005. In Chapter VI, in order to compare the costs and benefits of all four options, all were assumed to begin operations in $2005 .^{20}$

For both the New England and the New York options, low sulfur diesel fuel is stored with product replacement every third year. Heating oil was not considered because of product stability questions; therefore, the concepts costed out here accommodate most of the concerns about product turnover expressed earlier in the report. For the Gulf Coast option, super refined diesel is stored.

Consistent with the Energy Information Administration's 1996-97 projections, real oil prices are assumed to grow by 1.4 percent per year. This affects both the purchase cost of distillate fill in the year 2005, Government "profits" from emergency sales, and the salvage value of the oil when the program terminates after 20 years. ${ }^{21}$

Two strategies for acquiring fill are explored:

- In the first, the required amount of fill is assumed to be purchased on the open market. To the extent that the distillate serves the same purpose as crude oil in the event of a worldwide oil emergency, this concept would expand the capability of the SPR slightly. That "benefit" is not included in this study. The fill is assumed to be salvaged at the price of low sulfur diesel fuel at the end of the program.

- In the second option, crude oil equal in volume to the required distillate fill (6.7 or $2.0 \mathrm{mmb}$ ) is traded for an equal value of distillate. The amount obtained varies slightly depending on whether super-refined diesel or low-sulfur diesel is needed, but the trade supplies roughly 80 percent of the fill. The remainder is assumed to be purchased. At program termination, another trade to restore the SPR to its original size is performed, and the remaining distillate is salvaged. ${ }^{22}$

While purchasing distillate fill for the reserve is a major front-end cost, over the life of the program, its discounted salvage value is about one-third of its costs.

Government sales of the reserve under emergency conditions would net the Government a small profit over the purchase cost of the fill. Since these would offset the cost of the subsequent fill plus some operating costs, they are treated as a negative cost, rather than a benefit. For completeness, the sensitivity to release strategy is included in the Exhibit. Costs are not sensitive to this variable.

20 Setting the start date of all the options to 2005 has the advantage of setting the alternatives to the same benchmark. The disadvantage is that some options, such as leasing could begin providing protection much sooner than 2005. In the final measure, benefits and costs are discounted at an annual rate of 7 percent. Therefore, leasing and SPR-cavern storage cases where the annual expected benefits exceed costs would tend to look more positive if the options were assumed to be implemented earlier than the year 2005 .

21 The 20-year life cycle assumed for net present value calculations requires that the value of the program's assets at the end of the period be considered as a revenue flow realized at that time. It does not imply that the Government would eliminate the program or the underlying policy at the end of 20 years. Because of this, although Appendix $E$ includes closure costs they are not included in the cost estimates.

22 A small penalty is assessed to compensate for the very remote possibility that a crude oil emergency happens after a heating oil problem, but before the product reserve can be refilled. The penalty, which is based on the assumption that SPR oil in an emergency would be worth twice its market value before the emergency, amounts to about $\$ 0.5$ million (discounted) over the life of the product reserve. 


\section{Observations}

Exhibit V-5 shows that costs vary widely depending, in order, on: size, design/siting strategy, and the method of obtaining the fill for the reserve. The cost per program of providing this service can be obtained by dividing total program costs by the size of the reserve. Depending on whether distillate is obtained by purchase or crude oil trade:

- The life cycle cost of a $6.7 \mathrm{mmb}$ Government-constructed reserve in New England is $\$ 50-\$ 59$ per barrel stored.

- For $6.7 \mathrm{mmb}$ of leased storage, the life cycle cost is $\$ 19$ to $\$ 28$ per barrel of distillate.

- Gulf Coast SPR cavern storage of $6.7 \mathrm{mmb}$ would cost $\$ 4$ to $\$ 14$ per barrel of distillate.

The life cycle costs per barrel for a $2 \mathrm{mmb}$ reserve in leased storage in New York or New Jersey, or in an SPR cavern are about the same as the above averages. Under the costing assumptions employed in this study, however, the per-barrel costs for New England construction of only $2 \mathrm{mmb}$ would fall to 32 dollars to 41 dollars per barrel. This is because building a smaller reserve could avoid high-cost areas such as Boston.

Compared to the reference case using the regular drawdown policy and purchased fill, exchanging crude oil for product or adopting a very aggressive drawdown approach tend to lower costs by fixed amounts regardless of where the RPPR would be located. For that reason, since construction costs are low in the SPR cavern storage option, choosing to trade crude for product fill and adopting an aggressive drawdown strategy could lead to relatively low net financial outlays.

The logistical analysis performed in the study suggests that release of product from an RPPR based entirely in the U.S. Gulf, however, would take 7-10 days to reach consumers in the Northeast. Thus, the low SPR storage costs may not lead to creation of an RPPR that is as effective as modeled in this study. The hybrid $6.7 \mathrm{mmb}$ RPPR fill for this option is purchased outright, its net life cycle cost ranges between $\$ 120$ and $\$ 122$ million, depending on drawdown policy; if crude oil is traded for product, the range of net life cycle cost is $\$ 57$ to $\$ 59$ million (\$1996). On a per barrel of distillate stored basis, this would amount to 9 dollars to 18 dollars. It should be noted that the hybrid concept, while more expensive in absolute terms is one-half to $2 / 3^{\text {rds }}$ the per-barrel cost of a $2 \mathrm{mmb}$ reserve in leased storage in New York/New Jersey. 


\begin{tabular}{|c|c|c|c|c|}
\hline \multicolumn{5}{|c|}{$\begin{array}{c}\text { Exhibit V-5 } \\
\text { Regional Product Reserve Cost Components } \\
\text { (Discounted \$1996) }\end{array}$} \\
\hline & \multicolumn{2}{|c|}{ New England Construction } & \multicolumn{2}{|c|}{ Lease in NY/NJ } \\
\hline $6.7 \mathrm{mmb}$ Reserve & Purchase Fill & Exchange Crude & Purchase Fill & Exchange Crude \\
\hline $\begin{array}{l}\text { Capital Costs } \\
\text { (Including EIS) }\end{array}$ & 257 & 257 & - & - \\
\hline $\begin{array}{l}\text { Annual and } \\
\text { Operating Costs }\end{array}$ & 69 & 69 & 117 & 117 \\
\hline Cost of Fill & 113 & 20 & 113 & 20 \\
\hline Salvage of Fill & (39) & (7) & (39) & (7) \\
\hline \multicolumn{5}{|c|}{ Expected Government Sales Profits } \\
\hline Ceiling Strategy & (6) & (6) & (6) & (6) \\
\hline Trigger Strategy & (8) & (8) & (8) & (8) \\
\hline \multicolumn{5}{|l|}{ Total Net Costs } \\
\hline Ceiling Strategy & 395 & 334 & 186 & 124 \\
\hline \multirow[t]{2}{*}{ Trigger Strategy } & 393 & 332 & 184 & 122 \\
\hline & \multicolumn{2}{|c|}{ Gulf Cavern Storage } & \multicolumn{2}{|c|}{ Hybrid--NY/NJ Lease and SPR } \\
\hline $6.7 \mathrm{mmb}$ Reserve & Purchase Fill & Exchange Crude & Purchase Fill & Exchange Crude \\
\hline $\begin{array}{l}\text { Capital Costs } \\
\text { (Including EIS) }\end{array}$ & 3 & 3 & 2 & 2 \\
\hline $\begin{array}{l}\text { Annual and } \\
\text { Operating Costs }\end{array}$ & 16 & $16^{\circ}$ & 47 & 47 \\
\hline Cost of Fill & 119 & 23 & 117 & 22 \\
\hline Salvage of Fill & (39) & (8) & (39) & (7) \\
\hline \multicolumn{5}{|c|}{ Expected Government Sales Profits } \\
\hline Ceiling Strategy & (5) & (5) & (5) & (5) \\
\hline Trigger Strategy & (8) & (8) & (8) & (8) \\
\hline \multicolumn{5}{|l|}{ Total Net Costs } \\
\hline Ceiling Strategy & 93 & 28 & 122 & 59 \\
\hline Trigger Strategy & 91 & 27 & 120 & 57 \\
\hline
\end{tabular}




\begin{tabular}{|c|c|c|c|c|}
\hline \multicolumn{5}{|c|}{ Exhibit V-5 (Continued) } \\
\hline & \multicolumn{2}{|c|}{ New England Construction } & \multicolumn{2}{|c|}{ Lease in NY/NJ } \\
\hline $2.0 \mathrm{mmb}$ Reserve & Purchase Fill & Exchange Crude & Purchase Fill & Exchange Crude \\
\hline $\begin{array}{l}\text { Capital Costs } \\
\text { (Including EIS) }\end{array}$ & 41 & 41 & - & - \\
\hline $\begin{array}{l}\text { Annual and } \\
\text { Operating Costs }\end{array}$ & 23 & 23 & 36 & 36 \\
\hline Cost of Fill & 34 & 6 & 34 & 6 \\
\hline Salvage of Fill & $(11)$ & (2) & (11) & (2) \\
\hline \multicolumn{5}{|c|}{ Expected Government Sales Profits } \\
\hline Ceiling Strategy & (5) . & (5) & (5) & (5) \\
\hline Trigger Strategy & (7) & (7) & (7) & (7) \\
\hline \multicolumn{5}{|l|}{ Total Net Costs } \\
\hline Ceiling Strategy & 82 & 64 & 53 & 35 \\
\hline Trigger Strategy & 80 & 61 & 51 & 33 \\
\hline & \multicolumn{2}{|c|}{ Gulf SPR Cavern Storage } & & \\
\hline $2.0 \mathrm{mmb}$ Reserve & Purchase Fill & Exchange Crude & & \\
\hline $\begin{array}{l}\text { Capital Costs } \\
\text { (Including EIS) }\end{array}$ & 2 & 2 & & \\
\hline $\begin{array}{l}\text { Annual and } \\
\text { Operating Costs }\end{array}$ & 6 & 6 & & \\
\hline Cost of Fill & 35 & 7 & & \\
\hline Salvage of Fill & (11) & (2) & & \\
\hline \multicolumn{5}{|c|}{ Expected Government Sales Protits } \\
\hline Ceiling Strategy & (5) & (5) & & \\
\hline Trigger Strategy & (7) & (7) & & \\
\hline \multicolumn{5}{|l|}{ Total Net Costs } \\
\hline Ceiling Strategy & 27 & 8 & & \\
\hline Trigger Strategy & 24 & 5 & & \\
\hline
\end{tabular}



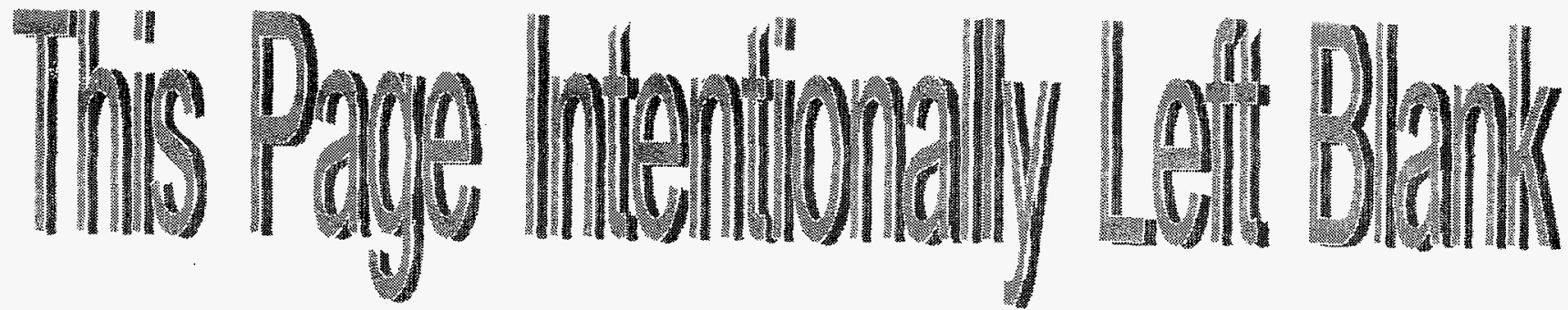
This chapter displays the benefit/cost ratios for the various regional product reserve options considered in this study. The benefits are taken from Chapter IV and the costs are taken from Chapter $\checkmark$ and Appendix $E$.

\section{Methodology}

The approach used in this chapter is the standard economic analysis of Government programs or projects recommended by the Office of Management and Budget (OMB) in Circular A-94: Guidelines and Discount Rates for Benefit-Cost Analysis of Federal Programs. Tables show the present discounted value of both the costs and the benefits of options, the benefit/cost ratio, and the net present value of benefits minus costs.

Benefits are defined as the sum of the gross domestic product and terms of trade benefits. Government profits from sale of the reserve's distillate in an emergency is treated as a negative cost. ${ }^{23}$ Values for consumer savings (normally treated as transfers within the U.S. economy) are shown in Chapter IV.

In addition:

- The constant-dollar discount rate used for both the costs and the benefits was 7 percent, as required by $\mathrm{OMB}$.

- Costs and benefits are expressed in 1996 dollars.

- Once filled, the Reserves are assumed to be operational for 20 years.

- After 20 years, the Reserve has no remaining salvage value, other than the value of the distillate fill.

- As Appendix E shows, all three Reserve sites have very different development time lines, with the New England Reserve having the longest implementation time. Therefore, in order to place the benefits and costs in comparable years, all Reserves are assumed to become operational in 2005, the year in which the New England Reserve could become operational.

- Low sulfur diesel is assumed to be stored at both the New England site and the New York site. Turnover of one-third of the product is assumed to be necessary every year. The product is expected to be exchanged on the market with no loss or gain to the Federal Government except for the transaction costs. A discussion of product stability and turnover requirements can be found in Appendix I.

- Super refined diesel is assumed to be stored in the SPR caverns in the Gulf Coast with turnover required every ten years. Sale of the product on the market is expected to be discounted to the price of low sulfur diesel at a loss (cost) to the Federal Government. Cost of the product turnover also includes transaction costs.

${ }^{23}$ In derivation of government profits in Appendix D, that expected profit was treated as a positive benefit. 
- The price of crude oil from the EIA's Annual Energy Outlook 1997 (AEO97) was used to calculate the costs of the various distillate products. The AEO97 reference case projection of distillate prices grows at 1.4 percent per year through 2015 , and the assumption was made that the price of the distillates would grow at 1.4 percent through 2025.

- In 1996 dollars the price of heating oil was assumed to be $\$ 23.45$ in 2005 , the price of low-sulfur diesel to be $\$ 24.07$, and the price of super refined diesel to be $\$ 25.80$. Additive prices were assumed to be $\$ 0.025$ per gallon.

- The computations in this chapter were based on a more up-to-date estimate of the 1996 GDP than was used in Appendix D. The Appendix used $\$ 7,393$ billion while $\$ 7,581$ billion is used in this chapter, which increases the GDP benefit by the ratio of the two.

- After accounting for declining residential heating oil use, growth in real GDP is assumed to increase the economic benefit of having the reserve by 0.42 percent per year.

- The initial cost for the product was reduced in the 'Crude Oil for Product' Option by trading existing SPR crude oil for the equivalent value in product. The cost saving of the oil exchange was further reduced to reflect the small but non-negligible probability that the SPR benefit of that oil will be lost whenever a crude oil shortage occurs right after a cold wave in which the RPPR oil is sold.

\section{Discussion of Results}

The tables below address first the $6.7 \mathrm{mmb}$ reserve where a ceiling price drawdown strategy is assumed employed, then a $2 \mathrm{mmb}$ reserve that uses the same drawdown strategy. To bound the benefits on the high end, and therefore the benefit/cost relationships, a trigger price, or full, drawdown policy is applied to the two sizes of reserve. Because it might take 7-10 days to deliver the crude to the Northeast, benefits are not computed for the option wherein all product is stored in SPR caverns. The hybrid concept, which would base $2 \mathrm{mmb}$ of a $6.7 \mathrm{mmb}$ reserve in leased storage in the New York/New Jersey area would ensure that the larger reserve is both readily available and shares some of the cost advantages of Gulf Coast-based storage.

\section{Ceiling Price Drawdown Policy}

Exhibit Vl-1 shows the results for a $6.7 \mathrm{mmb}$ reserve under four siting concepts. Trading crude oil for distillate fill, as described in Chapter $V$, would reduce life cycle costs by about $\$ 60$ million for each of the options. The hybrid option would incur about the same costs to modify SPR caverns for 4.7 $\mathrm{mmb}$ as would the full 6.7 reserve, and add the cost of storing $2 \mathrm{mmb}$ in relatively expensive leased storage tanks. As a result, its costs are over twice as high as storing all the oil in the SPR. It follows that the hybrid concept's costs would outweigh its benefits by about $\$ 18.8$ million over the 20-year life of the reserve.

Under the drawdown strategy assumed for the ceiling price drawdown case, on average, very little of the reserve is used in emergencies. Release is not assumed until prices have already risen significantly, then oil releases continue only as long as prices would otherwise remain at the inflated "ceiling" price. On average in each emergency, only about $1.3 \mathrm{mmb}$ is employed. It follows that a 2 $\mathrm{mmb}$ reserve could accomplish almost as much as a larger reserve, sacrificing very little in benefits, while costing substantially less. 
Exhibit VI-1

Benefits and Costs of a $6.7 \mathrm{mmb}$ Reserve

Ceiling Price Drawdown Strategy

\begin{tabular}{|l|c|c|c|c|}
\hline Fill Strategy/Siting & Benefits & Costs & Benefit/Cost Ratio & Net Present Value \\
\hline Purchase Distillate Fill & \multicolumn{5}{|l|}{} \\
\hline New England Construction & 39.7 & 395.2 & 0.10 & $(355.5)$ \\
\hline NY/NJ Lease & 39.7 & 185.6 & 0.21 & $(145.9)$ \\
\hline SPR Gulf Storage & $\mathrm{NC}^{\mathrm{a}}$ & 92.8 & $\mathrm{NC}^{\mathrm{a}}$ & $\mathrm{NC}^{\mathrm{a}}$ \\
\hline Hybrid NY/NJ; SPR & 39.7 & 122.0 & 0.33 & $(82.3)$ \\
\hline Trade Crude Oil for Product & & & & $(294.1)$ \\
\hline New England Construction & 39.7 & 333.8 & 0.12 & $(84.4)$ \\
\hline NY/NJ Lease & 39.7 & 124.1 & 0.32 & $\mathrm{NC}^{\mathrm{a}}$ \\
\hline SPR Gulf Storage & $\mathrm{NC}$ & 28.5 & $\mathrm{NC}$ & $(18.8)$ \\
\hline Hybrid NY/NJ; SPR & 39.7 & 58.5 & 0.68 & \\
\hline aNot Computed. & & & & \\
\hline
\end{tabular}

Exhibit VI-2 shows the results of this variation in size. Constructing Government-owned sites in New England is still not competitive from a benefit/cost point of view, but leasing in the New York Harbor area is essentially viable if costs are reduced by trading crude oil for product fill. ${ }^{24}$

24 Recall that the strategy of purchasing fill outright results in a larger amount of oil being available to address worldwide crude oil shortages also, and that this was not taken into account in the benefits calculations. Therefore, benefits for this approach are slightly understated. 
Exhibit VI-2

Benefits and Costs of a $2.0 \mathrm{mmb}$ Reserve

Ceiling Price Drawdown Strategy

\begin{tabular}{|l|c|c|c|c|}
\hline Fill Strategy/Siting & Benefits & Costs & Benefit/Cost Ratio & Net Present Value \\
\hline Purchase Distillate Fill & & & & \\
\hline New England Construction & 34.0 & 82.1 & 0.41 & $(48.1)$ \\
\hline NY/NJ Lease & 34.0 & 53.1 & 0.64 & $(19.1)$ \\
\hline SPR Gulf Storage & $\mathrm{NC}^{\mathrm{a}}$ & 26.8 & $\mathrm{NC}^{\mathrm{a}}$ & $\mathrm{NC}^{\mathrm{a}}$ \\
\hline Trade Crude Oil for Product & & & & \\
\hline New England Construction & 34.0 & 63.8 & 0.53 & $(29.8)$ \\
\hline NY/NJ Lease & 34.0 & 34.8 & 0.98 & $(0.8)$ \\
\hline SPR Gulf Storage & $\mathrm{NC}$ & 7.6 & $\mathrm{NC}^{\mathrm{a}}$ & $\mathrm{NC}^{\mathrm{a}}$ \\
\hline aNot computed. & & & \\
\hline
\end{tabular}

\section{Trigger Price Drawdown Policy}

Because prices are assumed to be considerably inflated before a drawdown decision is made, it would require a relatively large sale of oil to bring them back down to normal. The trigger price drawdown policy would take that direction. Most of all, its consideration here shows how, incurring no additional costs, operational policy makes the reserve more or less effective. In this case, full use of the reserve in each emergency is assumed. While it might seem that this is an overeaction, in no case was the amount of oil released sufficient to drag prices below normal levels.

The most apparent effect, shown in Exhibit VI-3, is to raise the benefit/cost ratio of the $6.7 \mathrm{mmb}$ reserve considerably. The hybrid Gulf Coast SPR/Northeast leasing storage option becomes positive even if the oil fill is purchased outright. Given a crude for product trade for distillate fill, only the New England construction option remains negative due to its high costs. 
Exhibit V1-3

Benefits and Costs of a $6.7 \mathrm{mmb}$ Reserve

Trigger Price Drawdown Strategy

\begin{tabular}{|l|c|c|c|c|}
\hline Fill Strategy/Siting & Benefits & Costs & Benefit/Cost Ratio & Net Present Value \\
\hline Purchase Distillate Fill & \multicolumn{5}{|l|}{} \\
\hline New England Construction & 136.1 & 393.2 & 0.35 & $(257.2)$ \\
\hline NY/NJ Lease & 136.1 & 183.6 & 0.74 & $(47.5)$ \\
\hline SPR Gulf Storage & NC $^{\mathrm{a}}$ & 90.8 & $\mathrm{NC}^{\mathrm{a}}$ & $\mathrm{NC}^{\mathrm{a}}$ \\
\hline Hybrid NY/NJ; SPR & 136.1 & 120.0 & 1.13 & 16.1 \\
\hline Trade Crude Oil for Product & & & & \\
\hline New England Construction & 136.1 & 331.9 & 0.41 & $(195.8)$ \\
\hline NY/NJ Lease & 136.1 & 122.2 & 1.11 & 13.9 \\
\hline SPR Gulf Storage & NC & 26.5 & NC & NC \\
\hline Hybrid NY/NJ; SPR & 136.1 & 56.6 & 2.41 & 79.5 \\
\hline aNot computed. & & & & \\
\hline
\end{tabular}

Exhibit VI-4 shows results for the same drawdown strategy for the $2 \mathrm{mmb}$ reserve. Benefits would not expand as much as for the larger reserve, nevertheless the negative net present value for even the remaining negative option, New England construction, becomes quite low considering that they are accumulated over a 20 -year period.

Exhibit VI-4

Benefits and Costs of a 2 mmb Reserve

Trigger Price Drawdown Strategy

\begin{tabular}{|l|c|c|c|c|}
\hline Fill Strategy/Siting & Benefits & Costs & BenefitCost Ratio & Net Present Value \\
\hline Purchase Distillate Fill \\
\hline New England Construction & 52.9 & 79.8 & 0.66 & $(26.9)$ \\
\hline NY/NJ Lease & 52.9 & 50.8 & 1.04 & 2.1 \\
\hline SPR Gulf Storage & $\mathrm{NC}^{\mathrm{a}}$ & 24.5 & $\mathrm{NC}$ & $\mathrm{NC}^{\mathrm{a}}$ \\
\hline Trade Crude Oil for Product & & & & \\
\hline New England Construction & 52.9 & 61.5 & 0.86 & $(8.6)$ \\
\hline NY/NJ Lease & 52.9 & 32.5 & 1.63 & 20.4 \\
\hline SPR Gulf Storage & $\mathrm{NC}$ & 5.3 & $\mathrm{NC}^{\mathrm{a}}$ & $\mathrm{NC}^{\mathrm{a}}$ \\
\hline aNot Computed. & & & \\
\hline
\end{tabular}




\section{Summary}

The results above should be viewed not in the absolute sense, but should be interpreted as a range of costs and benefits given a particular strategy. In general, the New England construction option seems net negative for strategies considered, but there are approaches that make all the other options positive. However, deciding to construct a large reserve, then adopting an expensive fill strategy and an unresponsive employment policy would produce a reserve whose costs would greatly outweigh its benefits. 
This chapter examines policy options for Government action to address distillate price increases in the Northeast that could be alternatives to the creation of a Government-owned Distillate Reserve and catalogues major issues that accompany each option. Five possible options are examined: a privatelyowned Distillate Reserve; a Federally-built, state-run reserve; low income heating oil assistance program; a "summer fill" fuel oil program; and fixed-price or levelized-price fuel oil contracts.

\section{Privately-Owned Distillate Reserve}

One option to increase the volume of distillate fuel oil stored in the Northeast is a regulatory program requiring companies that provide fuel oil to the region to maintain a specific level of stocks each winter to ensure that adequate supplies will be available to meet increased demand due to unusually severe weather, and, thus, mitigating against price surges. EPCA already provides the statutory authority to establish a similar regulatory program as part of the SPR, called the Industrial Petroleum Reserve (IPR). This section examines a program within EPCA, discusses the limitations of the existing authority, and describes the advantages and disadvantages of such a program. While it is possible that new legislative authority might be passed that would authorize a regulatory program outside of the Strategic Petroleum Reserve, the issues raised below would be common to most variations of the regulatory approach.

\section{The Industrial Petroleum Reserve Program}

Section 156 of EPCA authorizes the Secretary to establish an IPR as part of the SPR. ${ }^{25}$ This discretionary authority can be used to require refiners and importers of petroleum products to store up to three percent of the previous year's throughput or imports, consistent with an economically sound and competitive petroleum industry. The Secretary is authorized to exempt firms that are inequitably affected or would otherwise incur special hardships. This discretionary authority in EPCA to create an IPR has never been implemented.

Past analyses and studies of IPR options in the United States have looked primarily at three possible approaches to establishing an IPR. Under the first approach, importers and refiners would store the mandatory inventories in their own facilities. Under the second alternative, importers and refiners would be required to store their inventories in centralized, government-owned facilities. Under the third approach, importers and refiners would be permitted to store the inventories in centralized privately owned facilities.

The U.S. is a signatory to the International Energy Agreement which requires each participating country to hold a minimum level of petroleum stocks. Most IEA countries, other than the United States, impose some form of compulsory storage obligations on the oil companies doing business within their borders to meet the IEA requirement. An overview of the experience of other IEA countries may be found in Appendix F. Many countries have state oil companies which may utilize public "strategic" stocks in the day-to-day commercial market.

2542 U.S.C. §6236,; see also Appendix H. 
The principal advantages of the IPR, in theory, are that there would be little or no outlay of public funds, and that private oil companies should be better suited to manage product stocks in a costeffective manner to ensure greater product supply stability. Since these companies store and distribute these products on a regular basis, increasing their level of stocks by some relatively small amount should not lead to either enormous costs or much incremental administration. In contrast, a government-owned and managed Reserve would require the creation of an incremental administrative and storage function unless it were added to the existing SPR program in the U.S. Gulf.

In addition, if the Department already has statutory authority to carry out this program, the overall process of creating it could be somewhat less difficult than the development of other programs. Unfortunately, it appears the Department does not exactly have the authority required to implement a regulatory program focused only on the Northeast.

\section{Disadvantages of This Option}

Disadvantages can be categorized as Government administrative and legal problems, costs to the industry and equity issues, and the constitutional issue of "takings."

EPCA provides the authority for the Department to require refiners and importers to store three percent of their production or imports. Since the minimum annual level of stocks already held in the Northeast constitutes over three percent of consumption as defined by EPCA, it is not clear whether the Department could require a higher level of stockholding. The Department might wish to stipulate that the three percent be incremental to some minimum operating level, but there is considerable dispute over what constitutes this minimum level. However, while section 156 provides for the Secretary to require each importer of petroleum products and each refiner to maintain inventories, it does not provide for limiting the requirement to importers and refiners traditionally serving the Northeast market.

A second concern is the administrative complexities of administering an IPR, such as determining which crudes and products should be stored and assuring that all refiners and importers meet their obligations. If a firm were required to store three percent of its refinery throughput or imports, it might dedicate part of its existing inventory rather than increasing stocks. This would defeat the objectives of the regulatory program. Adjudicating requests for hardship relief could also prove to be cumbersome.

Requiring mandatory stock levels raises cost and equity issues for the industry. Creating a regional IPR would impose mandatory stock levels only on those parts of the industry that provide product to the Northeast. This would impact not only entities physically present in the Northeast but many of the refiners in the Gulf Coast that send product to the Northeast. The Department would also be concerned that this type of regulation would cause some current suppliers to leave the market entirely.

Although the cost of this requirement should not be overwhelming, other basic issues here are, 1) who would absorb the cost of carrying the incremental inventories, and 2) what would this do to the competitive standing of this part of the industry? Depending on what the mandated stock levels were, it is unclear as to whether the affected entity could fully pass through the incremental cost of increased inventories to consumers. In addition, the increased cost of carrying this incremental inventory may put heating oil at a competitive disadvantage with competing fuels, such as natural gas.

A further complication, which increases the administrative burden to the Government, is that the universe of suppliers is not constant. The higher costs of doing business in the Northeast, particularly 
if costs cannot be fully recouped, may change market composition. A major issue under this option would be to assure that the burden is shared equitably without forcing some companies to curtail their activities in this region.

The final issue is the continuing concern over whether requiring refiners and importers to set aside a portion of their inventories might be construed by the courts as an unconstitutional "taking" of property without just compensation. The concern has not decreased since it was first expressed in the original SPR Plan. If requiring private parties to contribute oil stocks to the IPR is a "taking," there will be a substantial question as to the measure of the property interest taken. Thus, even if successfully defended in court, it is possible that implementation of an IPR could be significantly delayed by litigation.

\section{Federally-Built, State-Controlled Regional Petroleum Product Reserve}

Some Members of Congress have expressed interest in a state-controlled alternative to a Federal Government-owned and managed Distillate Reserve. Under this alternative the SPR would construct and fill new storage facilities in the Northeast, but then turn over control to the Governors of the Northeastern states to authorize the use of distillate stocks in an emergency.

\section{Advantages of This Option}

State officials proposing this option have suggested that the Governors are "closer to the people" and could better determine when drawdown of the Reserve is appropriate than the President.

\section{Disadvantages of This Option}

Leaving the decision of drawdown to the discretion of state Governors could have a number of adverse consequences, generally due to the uncertainty this would create with respect to the likely use of the Reserve. If the petroleum industry is unsure about the Reserve's frequency of use, it will try to insulate itself from potential losses. One way this might be manifested is in lower private inventories a counter productive outcome. But if companies held even lower stocks, state-level intervention might become sufficiently frequent that the companies themselves would come to depend on it. Another way would be to hold additional inventories to obviate the need to use the Reserve, but this would raise average costs and retail prices.

Another problem relates to the difficulty of obtaining agreement between a large number of Governors concerning the appropriate conditions for drawdown of the Reserve. Although it would be possible to allocate authority for drawdown of portions of the Reserve to individual Governors, drawdown of the Reserve would be unlikely to have the desired effect on prices. The benefit of having a single drawdown authority is that the national welfare is considered, and most of the benefits will be accrued by the country as a whole. Being close to the situation is only a great benefit if an availability problem occurs, but the history of the Northeast suggests that the problem is unlikely to be one of availability but simply high prices.

As discussed, except for limited test authority vested with the Secretary, section 161 of EPCA authorizes drawdown of the SPR only upon a Presidential finding. The statute has no provision expressly authorizing the President to delegate the decision to declare a severe energy supply interruption. Thus, it is an issue as to whether the President may delegate this decision authority to the governor of a State or within the Executive Branch of the Federal government. Even if it is determined that the drawdown decision can be delegated, the drawdown would be subject to the constraints provided in section 161 of EPCA, which are generally beyond the scope of State governors. 
An alternative approach which would accomplish the same objectives without raising Constitutional issues would be to amend EPCA to permit the States to borrow fuel oil from the Reserve in proportion to the fuel oil consumption of each State. After the end of the heating season, the States would return fuel oil to the Reserve. The lending of Federal resources in an emergency is a well-established principle and would avoid the issues involved in a delegation of the authority to declare a severe energy supply disruption. Governors could choose whether or not to drawdown their State's portion of the fuel oil in light of their emergency needs, permitting the supplies to reach fuel oil users in a more timely fashion than a drawdown under current authorities. However, as with all new legislation, this approach would raise new issues, among which would be allowing all 50 State governors equal access to the Reserve.

\section{Low-Income Home Energy Assistance}

Since the Northeast distillate supply problem appears to be an economic problem, the most appropriate program to deal with one facet of it may be a temporary heating bill subsidy program for the poor. Such a program already exists, and it could be expanded if necessary to deal with problems related to high fuel oil costs in the Northeast.

The Low-Income Home Energy Assistance Program (LIHEAP)is a block grant program that underwrites programs providing energy assistance to needy households. ${ }^{26}$ LIHEAP appropriations of $\$ 1$ billion for FY1997 were included in the 1997 omnibus appropriations, as were $\$ 120$ million of unobligated FY1996 funds. An additional $\$ 300$ million in weather emergency funds were also authorized by P.L. 104-134. All states, territories, and Indian tribes and tribal organizations may apply for a block grant to underwrite their programs to assist low-income households within their jurisdiction. Congress has established a formula for distributing the funds based on each jurisdiction's share of home energy expenditures by low-income households nationwide.

The LIHEAP program covers four types of assistance: heating, cooling, crisis intervention, and weatherization. By far the largest component of funding is for heating assistance, followed by that of crisis intervention which usually occurs during the heating season in the Northern States.

Assistance can take several forms. Payments in either cash or vouchers may be made directly to the effected households, or, more commonly, payment may be made directly to the home energy suppliers (i.e., fuel oil dealers or the local utility). LIHEAP assistance is not intended to pay or offset all energy costs but rather provide supplemental assistance.

Data from the U.S. Department of Health and Human Services (HHS) for Fiscal Year 1994 (winter 1993-94) $)^{27}$ show that the Northeast received $\$ 450$ million in the winter of 1993-94. About 30 percent of these funds, or $\$ 140$ million, was provided to residences heating with fuel oil. Approximately 600,000 households heating with fuel received these funds, compared with the 800,000 households below the poverty line or the 1.4 million households who were below 150 percent of the poverty line.

In January 1997, the severity of the weather in the Northwest and high heating fuel prices throughout the United States prompted the President to release $\$ 210$ million in emergency funds.

26 Originally set up under the Low-Income Home Energy Assistance Act of 1981 (P.L. 97-35) and reauthorized several times.

27 U.S. Department of Health and Human Services, Administration for Children and Families, Low Income Home Energy Assistance Program: Report to Congress for Fiscal Year 1994, March 1996. 
While the Midwest received a disproportionate share due to the extreme weather experienced there, States in the Northeast received $\$ 60$ million. This justification for the release included reference to the "...one-time spike in fuel costs."

\section{Advantages of This Option}

If the principal concern about the high heating bills associated with severe cold spells is their effect on the poor, then LIHEAP may have the correct focus to deal with the problem. Rather than expend large amounts of money to assist all fuel oil consumers, LIHEAP could be used to target the funds on those who really suffer financial hardship. Given that the LIHEAP program already exists, it could be utilized without a substantial increase in administrative costs.

The data on the LIHEAP program expenditures in 1993-94 suggest that LIHEAP may already be addressing a large portion of the true financial hardship associated with the high financial costs related to fuel oil expenditures during severe winter cold spells. Even during the extremely severe winter cold spell of December 1989, implementation of a Distillate Reserve would only have reduced the heating bills of those below 150 percent of the poverty line by $\$ 120-\$ 240$ million. It appears they were already receiving $\$ 140$ million in a year that did not have bills that were as high.

\section{Disadvantages of This Option}

LIHEAP is not oriented toward providing funds in response to higher heating bills on a real-time basis. Assistance is provided based on expenditures in the prior year. As a result, the problems associated with severe weather in one month would be addressed with supplemental emergency funding.

LIHEAP is a demand oriented program, as opposed to all other options considered in this report that are supplemental sources of supply. As such, it is a means tested program in which the beneficiaries are defined, and there will inevitably be equity issues involving those who either do not qualify or fail to receive benefits for administrative reasons.

\section{Summer Fill Fuel Oil Program}

Congress has expressed interest in a policy of encouraging consumers to purchase heating oil during the summer as a means of building up regional stocks at the tertiary level and thus alleviating winter heating oil shortages. Under this program the Federal government would create a program to provide incentives for this activity.

According to industry representatives, during the post-war period "summer fill" programs were relatively common. Retailers of distillate fuel oil would fill their tanks in the summer, with payment to the wholesalers due only when the fuel was actually used. A similar program existed between the retailers and consumers. Homeowners' tanks were filled during the summer, but bills were paid only when the fuel oil was used. The program provided incremental storage for the refiners and, at the same time, provided a buffer to both the retailers and the consumers against the onset of winter. Essentially, the program was a price subsidy program from the refiners at a time when prices were very low and predictable.

28 "President Clinton Releases Emergency Home Energy Funds," Press release from The White House, January 31, 1997. 
There have been substantial changes in the market and in the use of heating oil since the first oil price shock in 1973. Price controls have vanished, and prices are somewhat higher and far more volatile. With rapidly escalating prices in the 1970 s, it became much more expensive for refiners to carry the holding costs of heating oil for three to four months, and summer fill programs began to disappear. In addition, increased price competition also worked against the summer fill program.

Consumers, in turn, have reacted to the higher prices by buying more efficient furnaces and improving home weatherization. This gain in efficiency, combined with increasing liability concems about underground tanks, has led to smaller, above-ground tanks. As a result of these changes, the average size of a household tank is now $\mathbf{2 7 5}$ gallons.

There are in existence summer contracts whereby the consumer receives a discount on the price paid for heating oil by fixing his order in early summer. These contracts do not necessarily involve actual physical delivery. There is some anecdotal evidence that there are retailers purchasing and receiving their heating oil in the early summer. However, this appears to be a price control mechanism rather than concern about physical availability of product.

\section{Advantages of This Option}

Exhibit VII-1 calculates the cost savings of June fill compared to October fill for various size tanks. The size of the average fill was obtained from the Northeast distributors. The costs are based on average wholesale June and October prices, with the appropriate retail markup, for the 11-year period 1986-96. The consumer discount rate used is 10 percent. The resulting estimated savings are very small. In years when the June-to-October price spread is larger, the savings will be larger, but in other years the summer fill program could have net costs for households. The larger problem is that the savings shown in Exhibit VII-1 are calculated using a static analysis; i.e., it assumes that changes in the seasonal demand pattern for fuel oil would not affect the pattern of seasonal prices. Unless the number of households taking advantage of the summer fill program was small, the current patterns are unlikely to hold up.

Exhibit VII-1

Average Household Cost Savings of June Fuel Oil Tank Fill

\begin{tabular}{|l|r|r|r|}
\hline & \multicolumn{3}{|c|}{ Tank Size (gal.) } \\
\cline { 2 - 4 } & \multicolumn{1}{|c|}{275} & \multicolumn{1}{c|}{550} & \multicolumn{1}{c|}{.000 } \\
\hline Average Fill (gal.) & 200 & 400 & 700 \\
Average June Price (\$/gal.) & $\$ 0.99$ & $\$ 0.99$ & $\$ 0.99$ \\
Average October Price (\$/gal) & $\$ 1.04$ & $\$ 1.04$ & $\$ 1.04$ \\
Cost to Fill in June & $\$ 198.00$ & $\$ 396.00$ & $\$ 693.00$ \\
Cost to Fill in October & $\$ 208.60$ & $\$ 417.20$ & $\$ 730.10$ \\
Price Savings & $\$ 10.60$ & $\$ 21.20$ & $\$ 37.10$ \\
Cost of Money for June-October & $\$ 6.60$ & $\$ 13.20$ & $\$ 23.10$ \\
\hline Net Cost Savings of June Fill & $\$ 4.00$ & $\$ 8.00$ & $\$ 14.00$ \\
\hline
\end{tabular}

In a dynamic market a shift in demand from the fall to early summer would have an impact on the absolute price of distillate and the prices of other products, particularly gasoline. Prices of distillate are typically lower in June than in October precisely because demand for distillate in June is lower than refinery output. If June demand increases, June prices would also increase. 
In the Northeast 6.5 million households use fuel oil. Assuming that 0.65 million households already participate in summer fill,that the average tank size is 275 gallons, and that the average fill is 200 gallons, then the demand shift for distillate from October to June would be 1.2 billion gallons if all the remaining households were to shift. ${ }^{29}$

Exhibit VII-2 is an illustration of what might happen to seasonal demand patterns if there were a major shift to early summer fill. The likely result would be a rise in the June price of heating oil and of gasoline.

\section{Disadvantages of This Option}

The principal disadvantage of this option is that it does not address the price run-up problem due to severe winter cold spells. The cause of this problem is not low stock levels in consumers fuel oil tanks, per se. The problem is low primary stocks in the Northeast at the end of October. Purchasing additional fuel oil in June to store in consumers' tanks will not ensure that primary stock levels at the end of October are sufficient to prevent price increases due to severe cold spells during the Decemberto-February period. If the oil industry knows that consumer tanks are full, it may reduce primary stocks accordingly to offset this change.

The oil industry currently has every incentive to provide consumers with fuel oil at the lowest possible cost. The industry is very competitive, and most consumers can choose among several fuel oil dealers for their supplies. If greater use of summer fill programs could reduce consumer bills, the industry would implement them. Mandating fill schedules that are not consistent with the industry's voluntary practices for supplying fuel oil consumers is likely to increase the annual cost of fuel oil to these consumers.

29 Some of the automatic fill programs include fill in the late spring/early summer. This appears to be related to the individual distributors inventory patterns rather than a general pattern. 


\section{Exhibit VII-2}

Illustrative Effects of a Summer Fill Program on Northeast Residential Distillate Consumption

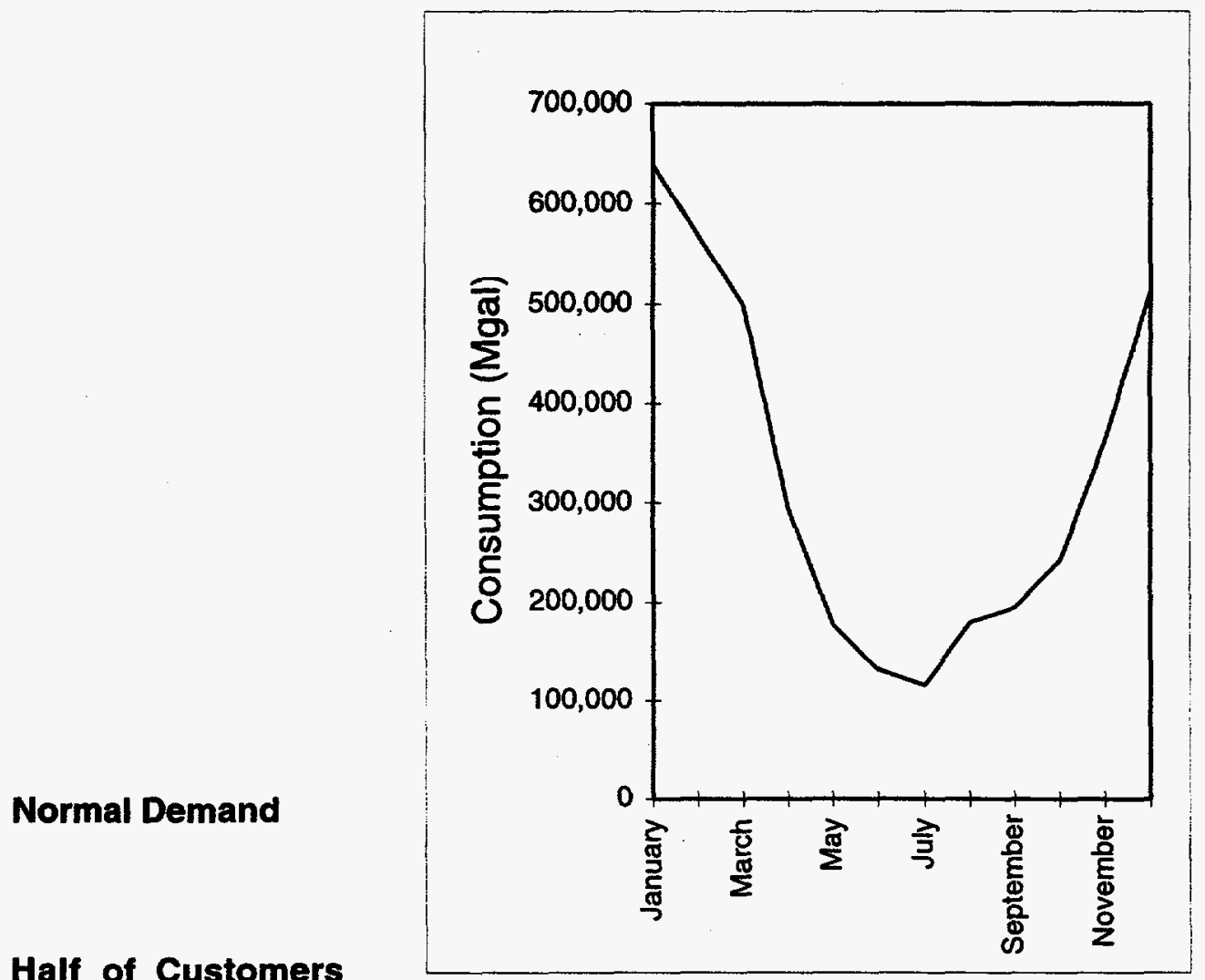

Half of Customers

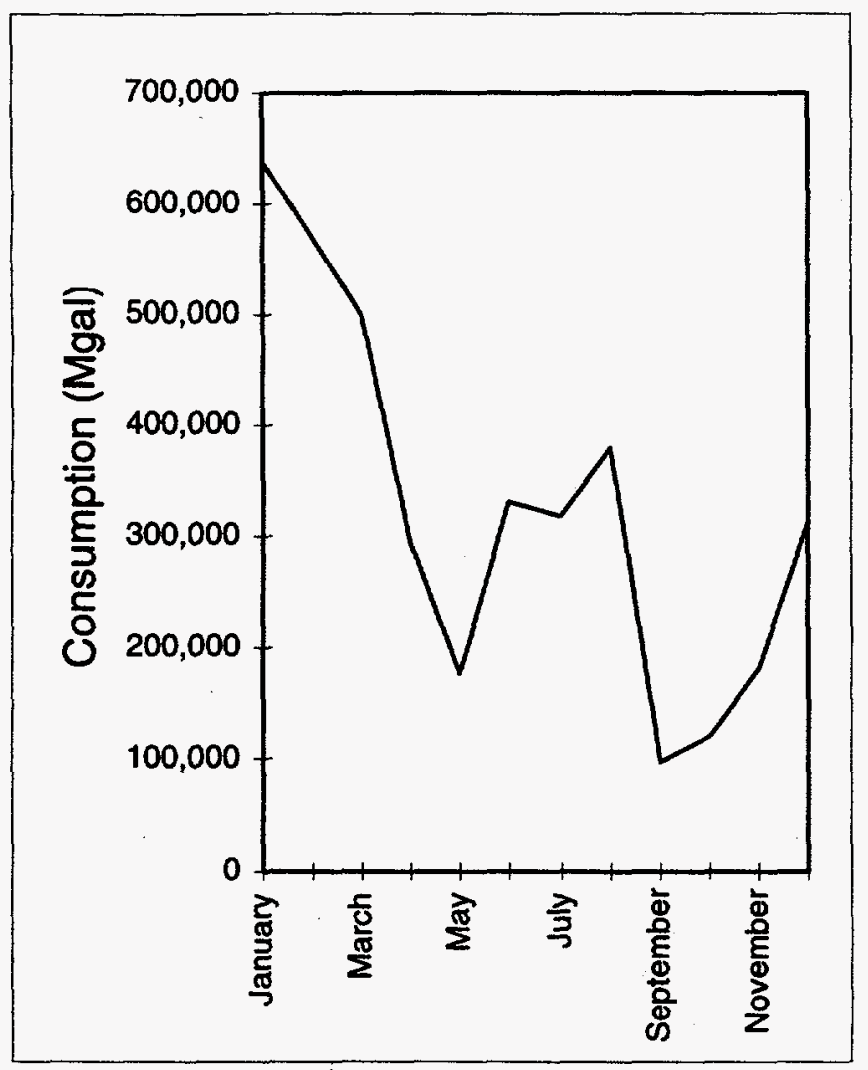

All Customers

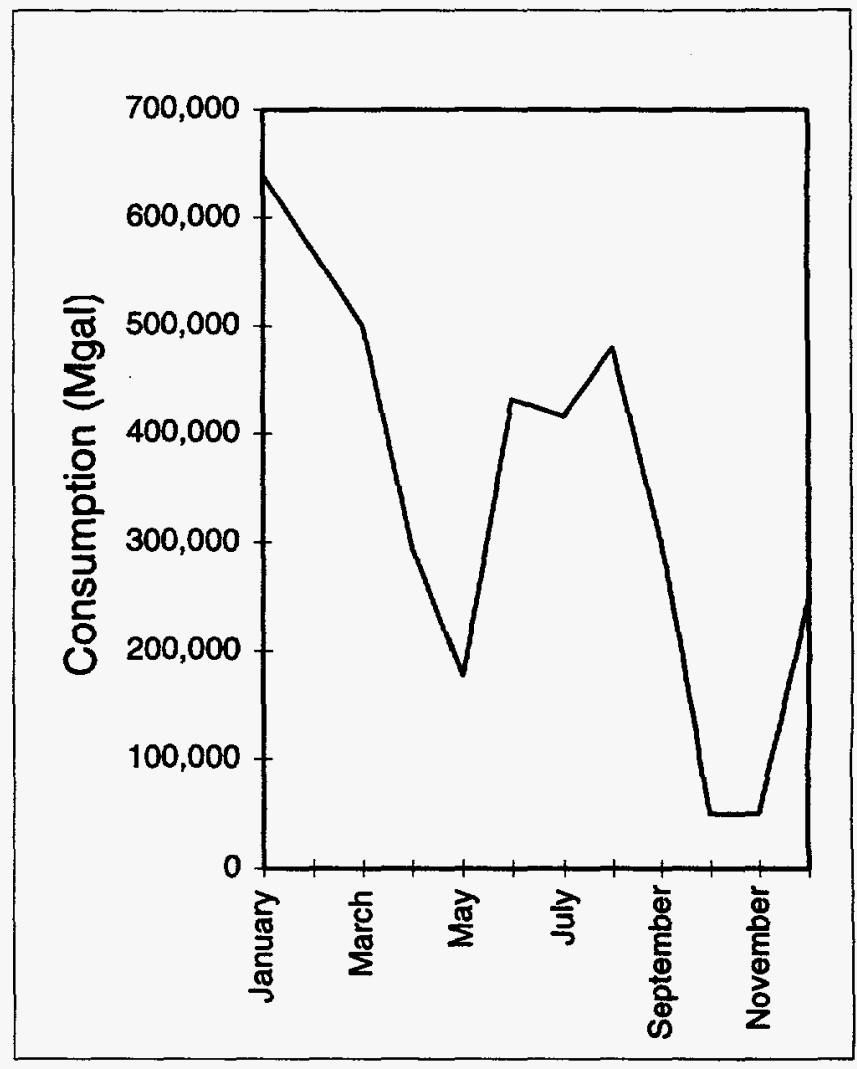




\section{Fixed-Price or Levelized-Price Heating Oil Contracts}

Fixed price or levelized price heating oil supply contracts are another approach that potentially could eliminate the significantly higher fuel oil bill due to a severe winter cold spell. These contracts eliminate the possibility that a consumer will receive an unusually-high fuel oil bill during or after a severe winter cold spell. Although these contracts work in different ways, essentially they average the cost of fuel oil over a year and in this manner delay the impact of an increase in fuel oil consumption, in prices, or in both. A Federal program could either require that fuel oil distributors offer such programs or that consumers accept them.

There is little data available on the prevalence of fixed or levelized price fuel oil contracts currently in effect in the Northeast. Nevertheless, conversations with fuel oil distributors in the region, while anecdotal, do indicate certain trends.

The use of fixed or levelized price contracts appears to be increasing in the Northeast. The most prevalent characteristics of these contracts appear to be as follows:

- A constant amount is paid every month throughout the year based on the dealer's estimate of the customer's likely cost for a year's fuel oil;

- A "pre-buy" contract is signed whereby the customer contracts in the summer for a specific amount at a specific price during the coming heating season. The customer calls the dealer for fill and any deviations in the volume are settled the following summer;

A price cap for the following heating season is specified, which allows both dealer and customer to hedge the price over the coming season.

There are numerous other variations, but the contract characteristics listed above appear to be the main forms. Depending on the distributor, the percentage of customers on a fixed or levelized price schedule appears to range from 15 percent to 50 percent. The trade press indicates that approximately 35 percent of the retail dealers in New England offer some form of fixed or levelized price contract.

The other form of contract growing in popularity is the automatic fill program. This is where the dealer maintains a profile on the individual customer and decides on delivery. Again, depending on the individual dealer, the percentage of customers on automatic plans range from 40 to 90 percent. Some dealers offer discounts to customers on automatic fill and some fill in the summer, but there does not appear to be any particular pattern. Much of this depends on the individual dealer, his circumstances, and how competitive the market is in which he operates.

\section{Advantages of This Option}

The use of a fixed or levelized price contract does provide protection from potential financial surprises due to higher-than-normal consumption, prices, or both. For customers with limited ability to finance unexpected expenses, such a program can be of great value. There is no "free lunch," however, associated with these contracts. Normally, fuel oil dealers levelize consumer payments by requiring the consumer to begin payments in the summer before the fuel oil is actually delivered. For a consumer with a limited budget such a plan solves the price spike problem by forcing him to save for these events by paying the dealer in advance.

Even plans that allow consumers and dealers to hedge do not actually reduce the total cost of fuel oil over time. By fixing prices ahead of time, the consumer avoids price volatility, but sometimes this 
is done by paying more for heating oil and sometimes less than he would have paid at the monthly price.

\section{Disadvantages of This Option}

There are clearly no disadvantages of having this option available to consumers, as long as they are not required to accept it. If they were required to accept it, some consumers would be forced to pay for their fuel oil before they need it. Clearly some consumers would rather delay paying their bills as long as possible. 